\title{
The Development of Reversible Bending Fatigue Tester and Its Application to High Burn-up Spent Nuclear Fuel Integrity Study under Normal Transportation Vibration
}

August 2014

Prepared by

Jy-An John Wang and Hong Wang

Materials Science and Technology Division

Program Manager

Bruce Bevard

Oak Ridge National Laboratory

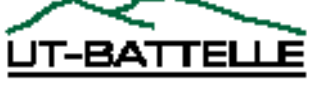




\section{DOCUMENT AVAILABILITY}

Reports produced after January 1, 1996, are generally available free via the U.S. Department of Energy (DOE) Information Bridge.

Web site http://uww.osti.gov/bridge

Reports produced before January 1, 1996, may be purchased by members of the public from the following source.

National Technical Information Service

5285 Port Royal Road

Springfield, VA 22161

Telephone 703-605-6000 (1-800-553-6847)

TDD 703-487-4639

Fax 703-605-6900

E-mail info@ntis.fedworld.gov

Web site http://www.ntis.gov/support/ordernowabout.htm

Reports are available to DOE employees, DOE contractors, Energy

Technology Data Exchange (ETDE) representatives, and International Nuclear Information System (INIS) representatives from the following source.

Office of Scientific and Technical Information

P.O. Box 62

Oak Ridge, TN 37831

Telephone 865-576-8401

Fax 865-576-5728

E-mail reports@adonis.osti.gov

Web site http://www.osti.gov/contact.html

This report was prepared as an account of work sponsored by an agency of the United States Government. Neither the United States government nor any agency thereof, nor any of their employees, makes any warranty, express or implied, or assumes any legal liability or responsibility for the accuracy, completeness, or usefulness of any information, apparatus, product, or process disclosed, or represents that its use would not infringe privately owned rights. Reference herein to any specific commercial product, process, or service by trade name, trademark, manufacturer, or otherwise, does not necessarily constitute or imply its endorsement, recommendation, or favoring by the United States Government or any agency thereof. The views and opinions of authors expressed herein do not necessarily state or reflect those of the United States Government or any agency thereof. 
ORNL/TM-2013/573

NUREG/CR-XXXXX

Materials Science and Technology Division

The Development of Reversible Bending Fatigue Tester and Its Application to High Burn-up Spent Nuclear Fuel Integrity Study under Normal Transportation Vibration

Jy-An John Wang and Hong Wang

Materials Science and Technology Division

Oak Ridge National Laboratory

\section{Program Manager \\ Bruce Bevard}

Date Published: August 2014

Prepared by

OAK RIDGE NATIONAL LABORATORY

P.O. Box 2008

Oak Ridge, Tennessee 37831-6285

managed by

UT-BATTELLE, LLC

for the

U.S. DEPARTMENT OF ENERGY

under contract DE-AC05-00OR22725 


\section{Executive Summary}

For high burn-up spent nuclear fuel (SNF), it is expected that the spent fuel cladding will have a high population of microcracks and hydrides, including macro-hydrides and micro-hydrides. This will reduce the stress intensity required to advance the crack growth. The linking of these microcracks during vibration loading also reduces the fatigue threshold/incubation period significantly, accelerating fatigue failure. In addition to the damages in cladding, the microstructure of comprising fuel pellets and interfaces of fuel rod have changed dramatically after the high burn-up process. These modifications have a direct impact on the structural integrity and vibration response of SNF rods in transportation.

As a result of that, the vibration has been included as one of mandatory testing conditions for the structural evaluation of package that is used in transporting spent nuclear fuel by US NRC (Nuclear Regulation Commission) in 10 CFR §71.71. Currently, no testing system is available to test the spent nuclear fuel and evaluate the performance of fuel rod during the spent fuel transportation. It is the aim of this research project to develop a system that can appropriately test the response of high burn-up SNF rod in a simulated loading condition.

The SNF rods are lying horizontally in a designed transportation and supported by the spacers within fuel rod assembly. These rods are subjected to oscillatory bending due to inertia effect. This oscillatory bending is the major vibrational load of SNF rods as mentioned in 10 CFR $\S 71.71$ and its effect on integrity of the SNF rods needs to be captured by the designed testing system. Beside their composite structure of fuel pellets and cladding, the SNF rods are typically ended with various burn-induced damages (pores and micro cracks), oxide and hydride layers, residual stresses, altered interfaces, and trapped fissure products. More important, they are still highly radioactive after a long-term service in nuclear reactor. These complications have never been seen before within a well-characterized specimen of convention cyclic bending testing and are needed to be considered appropriately for the said system to truly simulate the performance of SNF rods.

Vibration integrity of high burn-up spent nuclear fuel in transportation remains to be a critical component of US nuclear waste management system. The structural evaluation of package for spent fuel transportation eventually will need to see if the content or spent fuel is in a subcritical condition. However, a system for testing and characterizing such spent fuel is still lacking mainly due to the complication involved with dealing radioactive specimens in a hot cell environment. Apparently, the current state-of-the-art in spent fuel research and development is quite far away from the delivery of reliable mechanical property data for the assessment of spent fuels in the transport package evaluation.

Under the sponsorship of US NRC, ORNL has taken the challenge in developing a robust testing system for spent fuel in hot cell. Extensive literature survey showed that a variety of bending fatigue testing methods have been developed including cantilever beam bending, three-point/ 
four-point bending, pure bending, as well as their variants to take account of environmental factors, particularly temperature. The bending fatigue testing has been evolved into the nonrotating and rotating in more than a half century, based on if the rotation is introduced to carry out the reverse bending. On the other hand, the vibration of SNF rod usually features the deflection instead of rotation in a transportation process, and the dominant frequencies involved with these dynamical events are generally less than $100 \mathrm{~Hz}$. Therefore, the non-rotating reverse bending that can be accomplished by a universal material testing machine or its equivalents has been focused in this report.

Currently, cyclic bending fatigue test is being used in testing and characterizing various engineering materials and their components including concrete, composites, ceramics, metal alloys, metallic glasses, and so forth. This includes unipolar mode without reversible and bipolar mode with full reversible. Mechanical support/ contact techniques to enable the designed beam bending boundary condition have been advanced significantly. However, most of the bending fatigue tests are application-based.

Following conclusions can be drawn:

- Among the bending fatigue testing methods reviewed, four-point bending fatigue has been proven to be a matured experimental technology in testing a type of materials and components that have a limited deformation before failure. This has been demonstrated for asphalt mix beam and self-align test rig.

- The above-mentioned techniques are mainly used in fatigue tests without bending reversible.

- A variety of supports were developed in bending fatigue testing including rotary joints, slide connection, and flexures. They either deviate from a true frixed boundary condition or have contact damages involved.

- Four-point/ three-point bending and cantilever bending all suffer from an inherent drawback related to the shear in the range of beam that has a non-uniform bending moment. This has a significant impact on the materials that are sensitive to the shear.

- Pure bending fatigue has been used for high strain fatigue in testing metallic alloys and composites. The implementation of pure bending concept is mostly application-based with partial success.

- Environmental chambers and/or high temperature furnaces are currently incorporated into some critical bending fatigue tests. Setup of specimen is mostly accomplished manually without the capability of accommodating the testing materials that are radioactive.

A bending fatigue system has been proposed and developed to test high burn-up SNF rods. The pure bending is adopted as a bending mode of testing system. Use of pure bending method in which a uniform bending moment is exerted on the gage length of specimen apparently eliminates the effect of shear. The latter can eventually lead to a failure mode that is not relevant to the fatigue failure we are concerned with. Main features are summarized as follows: 
- Rigid sleeves are introduced to reinforce the specimen and at the same time to enable the conversion of external force couples into the bending moments.

- Bending moments are applied through two horizontal rigid arms of a U-frame structure. The arms are equipped with two co-axial holes that accommodate the rod to be tested.

- Roller bearings or equivalent bearing sets in the arms of U-frame allow the release of any axial load related to the loading of specimen and at the same time transfers the bending moments from the rigid arms to the specimen.

- The initial setup of a specimen in testing can be accomplished by a simple insertion of the specimen into the holes. It is advantageous of this implementation for a hot-cell environment because most of the operations available can be adapted for the current testing system.

- U-frame has a less number of comprising components, which would result in a test system with enhanced reliability and controllability.

- Versatile designs in the loading member and joints or corners of U-frame provide wide options for different experimental studies.

This report provides the detailed description on the latest development of a cyclic integrated reversible-bending fatigue tester (CIRFT) dedicated to vibration integrity investigation of spent fuel rod under normal transportation vibration. Particularly, design and analysis, engineering processes including fabrication, calibration and modifications, and instrumentation and measurement were described. The CIRFT is manly composed of a U-frame testing setup and a real-time curvature measurement method. 1) The U-frame setup of CIRFT consists of two rigid arms, third members, and linkages to universal testing machine. 2) The curvature of bending rod is obtained through a three-point deflection measurement method. Three LVDTs are utilized and clamped into the side connecting plates of U-frame to capture the deformation of rod.

Unique features of the system include: 1 ) the setup enables the installation of rod by simple insertion using linear bearings incorporated with rigid sleeves. 2) The reverse cyclic bending test can be carried out effectively and efficiently by push and pull at the loading point of the setup (depending on test machine, current version of U-frame can go up to 2 to $5 \mathrm{~Hz}$ on MTS 810). Any test machine with linear motion function can be used to drive the setup. 3) The embedded and preloaded linear roller bearings eliminate the backlash existing in the conventional reverse bending. 4) Minimized number of linkages to universal machine is used. Namely, there are only two linkages needed at the two loading points of a U-frame setup, whilst a conventional four/three point bending demand four linkages. 5) The curvature measurement is immune to the effects arising from compliant layers and rigid body motion of machine. The LVDT technique is proven to be robust in hot-cell environment and is free from the restraints related to non-contact measurements. 6) Test protocol for cyclic reversible bending test is developed and provided.

The tests using surrogate rods mainly composed of SS cladding/tube revealed several important phenomena that may throw light on the response of spent fuel rod. 1) Static cyclic load (10N/s under force control) in compressive mode (with respect to that at the loading point of U-frame) 
produced increased irreversible curvature and also increased flexural rigidity under loading of the surrogate rod. 2) Dynamic cyclic load in compressive mode resulted in increased flexural rigidity of the surrogate rod prior to the fracture of cladding. 3) Pellets and epoxy bonding exhibited various effects on the response of surrogate rods during the loading process as validated from static tests. 4) Dynamic cyclic load (2Hz) in reversible mode demonstrated a substantial cyclic softening before the fracture of the surrogate rod. The degree of decrease in flexural rigidity was consistent in both measurement and on-line monitoring. The developed CIRFT system is thus verified and demonstrated to be ready for further pursuit in hot-cell test.

The continuous upgrade resulted in the third generation (3G) U-frame testing setup.

- Rigid arms are split along the LBB axis at rod sample ends. For each arm, this results in a large arm body and an end piece.

- Mating halves of bushings were modified into two V-shaped surfaces on which linear roller bearings (LRB) are embedded.

- The rod specimen is installed into the test fixture through opening and closing slide endpieces.

The 3G apparently has addressed major issues of setup identified in the previous stage and been proven to be eligible to be further pursued in a horizontal set-up to be implemented into Bose Linear motors universal tester system.

On the other hand, the purchase of universal testing machine or Bose dual LM2 TB was completed and the testing system was delivered to ORNL in August 2012. Installation confirmation of the system and on-site training were given by Bose field engineer and regional manager on 8/1-8/2/2012. Calibration of Bose testing system has been performed by ORNL as the integration of ORNL setup into the Bose TestBench occurred after the installation. Major challenge with this process arose from two aspects: 1) the load control involves two load cells, and 2) U-frame setup itself is a non-standard specimen. ORNL has been able to implement the load control through Cycle Indirect along with pinning the U-frame setup. Additional modifications to setup and interfaces have been made subsequently based on the observations during the testing.

Two meetings (November 2012 and January 2013) were held with hot-cell group to discuss the potential issues with both epoxy mounting of rigid sleeve and U-frame setup. Many suggestions were provided to make the procedure friendlier to the manipulator in hot cell. Addressing of these suggestions resulted in another cycle of modifications of both vise mold and setup. The initial meeting I\&C group occurred in November 2012 with regard to the Bose cable modification and design of central connector panel to integrate the cables and wires. The first round of cable modification and central panel fabrication was completed in February 2013. The testing with the modified cables exhibited substantial noises and the testing system was not shown to be stable. It is believed the cross talk is responsible to the noise, and a central panel with a better grounding and shielding is highly recommended. The central panel has been re- 
designed and fabricated in March 2013. In the subsequent period, the ORNL has made substantial effort to debug the noises with the load cell channel, and to resolve the noises and nonlinearity with RDP LVDTs related to the integration of RDP LVDTs to Bose system.

At the same time, ORNL has completed the verification tests of Bose test system, including cycle tests under reversible bending in load control, bending tests under monotonic load, and cycle tests under reversible bending in load control on MTS machine to verify the results of Bose machine. These results are shown to be consistent under equivalent loading conditions, especially for the cycle tests.

Rad hardened LVDTs and radiation grade load cells were incorporated into the Bose system. The integrated Bose system was finalized and delivered to the hot cell in August 2013. The CIRFT system was officially operated in hot-cell since September 2013 after the completion of all the required calibration and benchmark of the CIRFT system in the hot-cell environments. The details of the static bending and dynamic bending fatigue test results are also provided in the report. 


\section{Table of Contents}

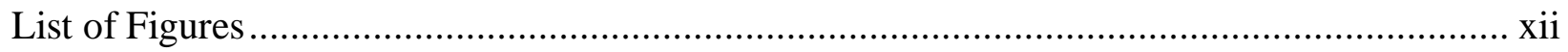

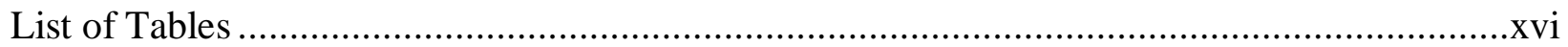

ACKNOWLEDGEMENT ................................................................................................ xvii

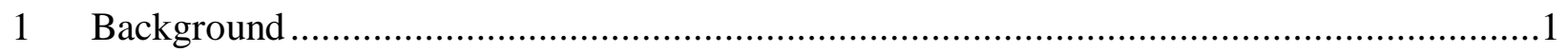

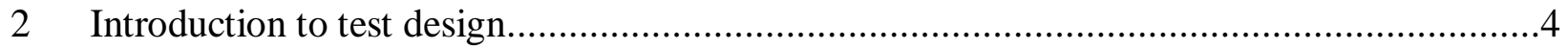

$3 \quad$ Test method and test system development ……….......................................................6

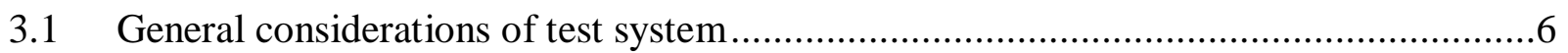

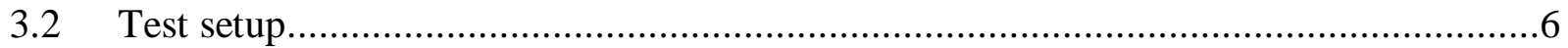

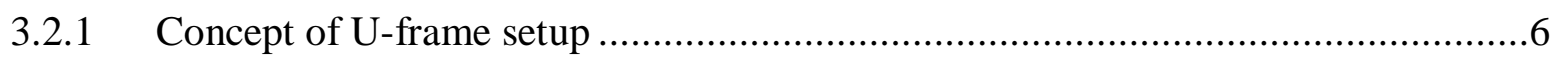

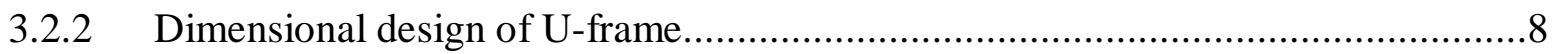

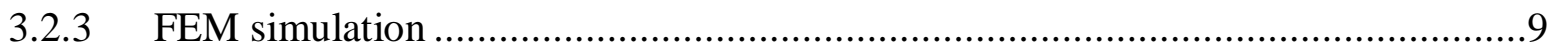

3.2.4 Design study on the effects of setup weight, driving mode, and setup layout ........12

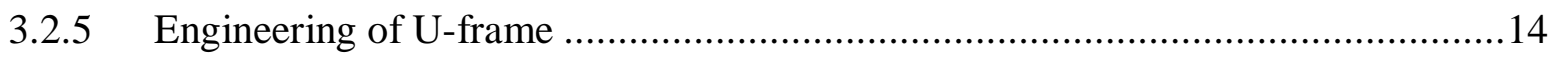

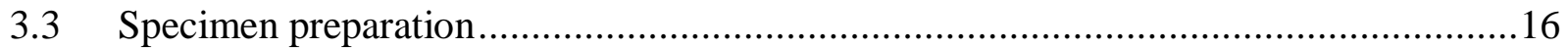

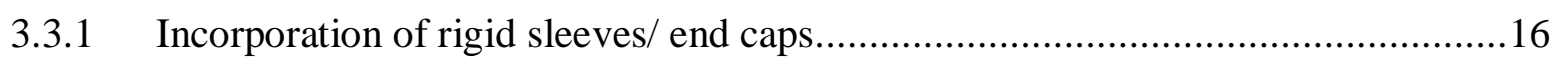

3.3.2 Mounting end caps to specimen using epoxy .....................................................17

3.4 Measurement of mechanical deformation of SNF rods .............................................18

3.4.1 Selection of robust sensors for hot cell testing ....................................................18

3.4.2 Three-point rod displacement measurement using LVDTs ....................................19

3.5 Testing machine and integration of ORNL testing setup..............................................21

3.5.1 Selection of Bose dual linear motors testing bench...............................................21

3.5.2 Design of U-frame integration......................................................................24

3.5.3 Implementation of U-frame integration ..............................................................24

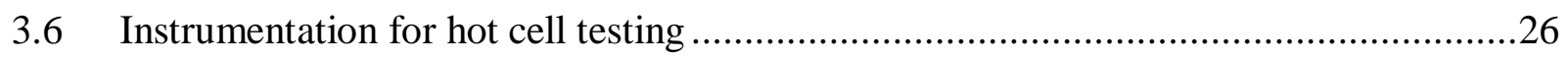

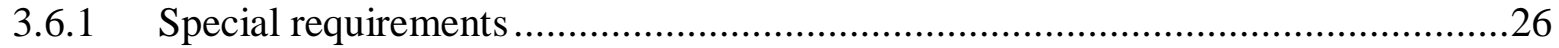

3.6.2 Central panel and cable modification.................................................................26

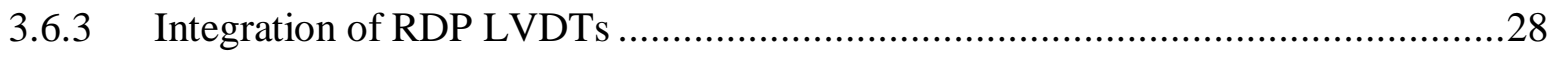

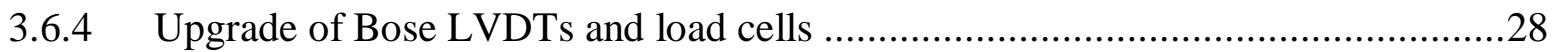

4 Demonstration of test equipment using surrogate rods ......................................................30

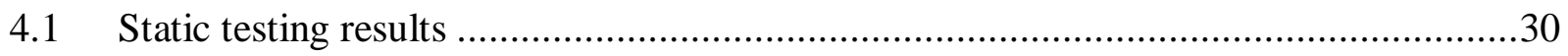




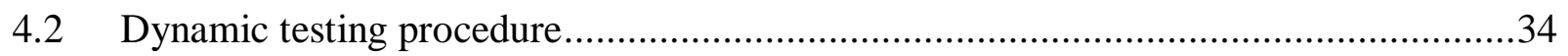

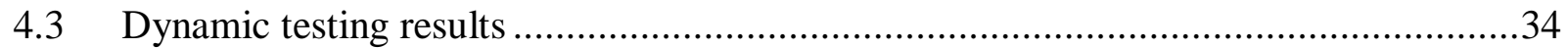

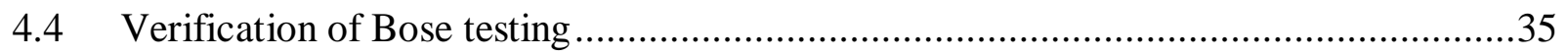

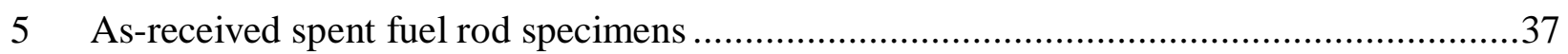

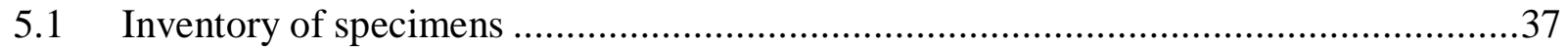

6 In-cell installation, calibration and benchmarking of testing system..............................40

6.1 Adaptation and installation of testing system....................................................40

6.2 Verification tests using SSAP surrogate rods..................................................41

6.3 In-cell preparation of specimens .................................................................42

6.4 Benchmarking of test system.......................................................................43

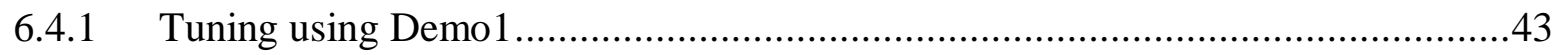

6.4.2 Static on Demo1/ 606B2 (+ dynamic) ....................................................44

6.4.3 Static on Demo2/ 606B3B..........................................................................46

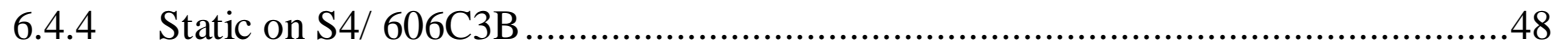

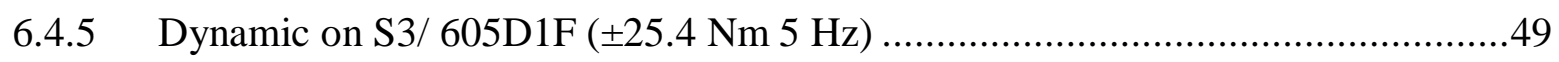

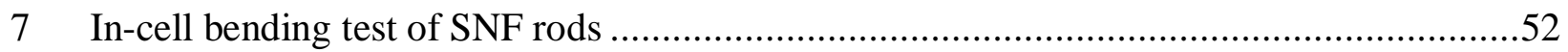

7.1 Test procedure and data processing .............................................................52

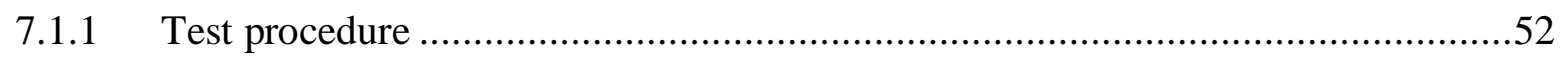

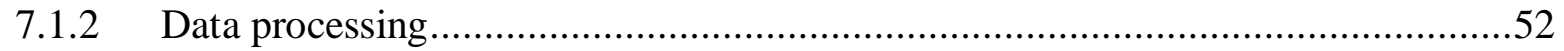

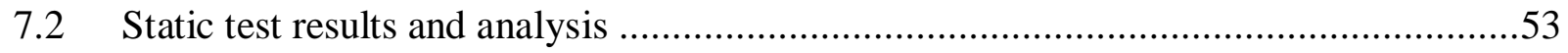

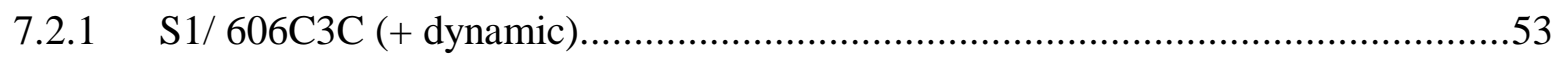

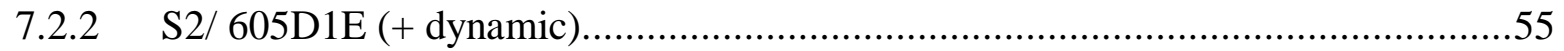

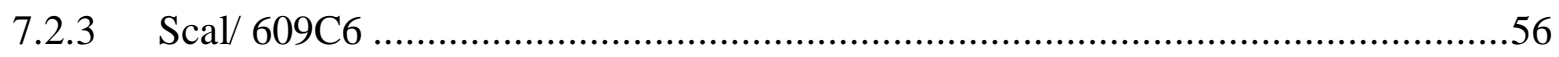

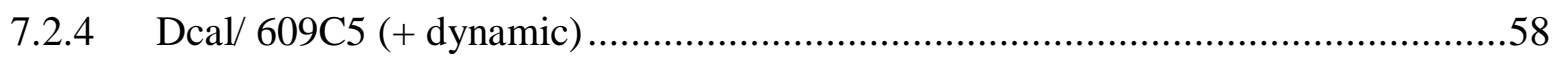

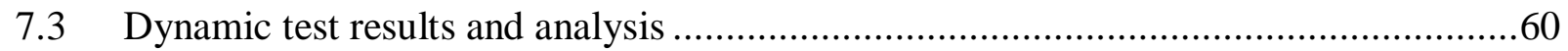

7.3.1 DL1/ 607C4B ( \pm 15.24 Nm 5 Hz) ............................................................61

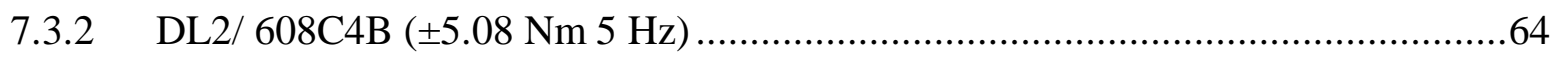

7.3.3 DL3/ 605C10A $( \pm 10.60$ Nm 5 Hz) ........................................................65

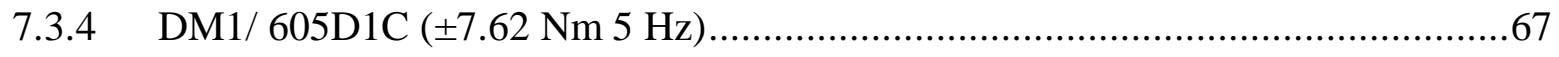

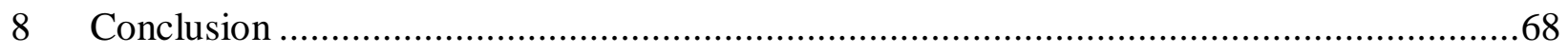

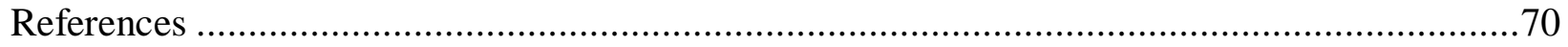




\section{List of Figures}

Figure 1 Cross-sectional illustration of typical pressurized water reactor fuel assembly. The spacer grids can impart vibration loads to spent fuel rods during transportation........................3 Figure 2 U-frame-assisted bending fatigue testing setup for reversal bending when rigid arms are (a) closing, (b) neutral, and (c) opening. The rod is offset from the vertical linking member.......8 Figure 3 Three-dimensional solid modeling of U-frame test setup; the rod is co-planar with the vertical linking members.

Figure 4 Dynamic response of U-frame setup obtained by steady-state analysis; F0 is load amplitude 40, 60, $80 \mathrm{lb}$ or 178, 267, and $356 \mathrm{~N}$. The displacement is measured at the loading point of the U-frame setup in inches.

Figure 5 Dynamic response comparisons in terms of (a) displacement and (b) stress between horizontal design and vertical design with counterweights. The results are based on the symmetric loading $178 \mathrm{~N}$ (40 lb) and $356 \mathrm{~N}$ (80 lb) at $10 \mathrm{~Hz}$.

Figure 6 (a) U-frame setup equipped with linear roller bearings (LRBs) that are preloaded by bolting the end blocks. The enlarged view in (b) shows the rod inserted. The rigid sleeves have an octagonal shape and are mounted to the rod with cast epoxy as shown in (c)......................16

Figure 7 Vise mold for assembling octagonal rigid sleeves into a rod....................................18 Figure 8 Demonstration of the three-point measurement method using three LVDTs. The Uframe setup is equipped with LBBs and integrated on a MTS 810 servo-hydraulic testing machine.

Figure 9 Time series for (a) load, (b) LVDT1, 2, and 3, (c) converted moment, and (d) calculated curvature. A surrogate rod composed of SS tube only was used. Octagonal rigid sleeves were integrated to the SS tube (ID $9.525 \mathrm{~mm}$, OD $11.07 \mathrm{~mm}$, and length $152.4 \mathrm{~mm}$ ) by use of epoxy. The tests were conducted on the MTS servo-hydraulic machine 810 using $101.6 \mathrm{~mm}$ U-frame

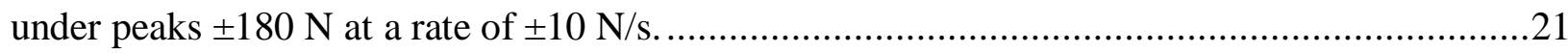

Figure 10 Performance curves of Bose ElectroForce 3510 .............................................23

Figure 11 ORNL's recommendation for two linear motors in a horizontal plane......................25 Figure 12 ORNL U-frame setup integrated into Bose dual LM2 test bench. (a) Frontal view. (b)

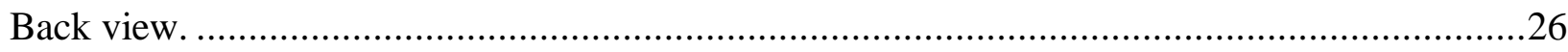

Figure 13 Concept of central panel for bending fatigue testing system..................................27

Figure 14 Central panel mounted to the Bose breadboard. ...............................................28

Figure 15 Three static bending tests were completed with maximum relative displacement 20

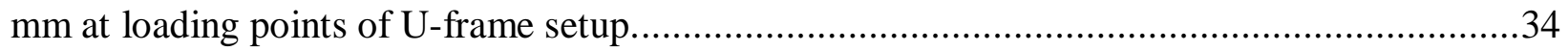

Figure 16 Moment as a function of cycles or cycles to failure. No failure was observed for SSAP13, SSAP21, and SSAP26. The SSAP26 was continued at $10 \mathrm{~Hz}$ after $4 \times 10^{6}$ cycles at 5 Hz. SSAP25 was irradiated 2 weeks under a sandwich configuration between 6- and 7-fuel rod layers. SSAP27 irradiated 4 weeks.

Figure 17 Moment as a function of cycles or cycles to failure. SSAP30, SSAP33 and SSAP36 had 440C hardened rigid sleeves. 
Figure 18 View of CIRFT installed at ORNL hot cell.

Figure 19 Variations of (a) curvature range, (b) applied moment range, (c) flexural rigidity as a function of number of cycles for SSAPdemo1, SS cladding with 10 alumina pellets, under $\pm 25.40 \mathrm{Nm} 5 \mathrm{~Hz} ; \mathrm{N}_{\mathrm{f}}=9.5 \times 10^{4}$ cycles.

Figure 20 Curve of moment versus curvature for SSAPdemo2 with maximum relative displacement $24 \mathrm{~mm}$; rate was set at $0.1 \mathrm{~mm} / \mathrm{sec}$ at loading points of U-frame.

Figure 21 (a) Rod (Demo1, 606B2) was inserted. (b) One pin was turned away and end-cap loaded with epoxy inserted into the lower chamber.

Figure 22 (a) Curve of moment versus curvature with maximum relative displacement 20mm, and (b) moment versus curvature in the subsequent repeated static tests with relative displacement 20 or $24 \mathrm{~mm}$ for Demo1 (606B2). The rate at loading points of U-frame was set at 0.1 and $0.2 \mathrm{~mm} / \mathrm{s}$ in loading and unloading, respectively.

Figure 23 Variations of (a) curvature range, (b) applied moment range, (c) flexural rigidity as a function of number of cycles for Demo1 (606B2); $\mathrm{N}_{\mathrm{f}}=3.96 \times 10^{3}$ cycles under $\pm 30.48 \mathrm{Nm} 5 \mathrm{~Hz}$.

The specimen had been subjected to repeated static loading before the cycle test. .46 Figure 24 Mating fracture surfaces of Demo1 (606B2); reference marker indicates the frontal maximum stress line (facing the operator). $\mathrm{N}_{\mathrm{f}}=3.96 \times 10^{3}$ cycles under $\pm 30.48 \mathrm{Nm} 5 \mathrm{~Hz}$. The specimen had been subjected to repeated static loading cycles before the dynamic cycle test.....46 Figure 25 Moment-curvature curve for Demo2 (606B3B) with rate $0.1 \mathrm{~mm} / \mathrm{sec}$ at the loading points of U-frame; the rod was broken, peak moment $=83 \mathrm{~N}^{*} \mathrm{~m}$.

Figure 26 (a) and (b) Mating fracture surfaces, (c) frontal (compressive) and (d) back side (tensile) of Demo2 (606B3B). The rate was $0.1 \mathrm{~mm} / \mathrm{sec}$ at the loading points of U-frame; the rod was broken, peak moment $=83 \mathrm{Nm}$. .48

Figure 27 (a) and (b) Mating fracture surfaces, (c) frontal (compressive) and (d) back (tensile) side of S4 (606C3B). The rate was $0.1 \mathrm{~mm} / \mathrm{sec}$ at the loading points of U-frame; the rod was broken, peak moment $=85 \mathrm{Nm}$.

Figure 28 Variations of (a) curvature range, (b) applied moment range, (c) flexural rigidity as a function of number of cycles for S3 (605D1F); $\mathrm{N}_{\mathrm{f}}=2.5 \times 10^{4}$ cycles under $\pm 25.4 \mathrm{Nm} 5 \mathrm{~Hz}$. ......50 Figure 29 (a) and (b) Mating fracture surfaces, (c) frontal and (d) back sides of S3 (605D1F). $\mathrm{N}_{\mathrm{f}}$ $=2.5 \times 10^{4}$ cycles under $\pm 25.40 \mathrm{Nm} 5 \mathrm{~Hz}$.

Figure 30 (a) Curve of moment versus curvature, and (b) equivalent strain- stress curve for S1 (606C3C); based on static loading cycle in which maximum relative displacement was $24 \mathrm{~mm}$ and rate at loading points of U-frame set at 0.1 and $0.2 \mathrm{~mm} / \mathrm{s}$ in loading and unloading, respectively.

Figure 31 (a) and (c) Mating fracture surfaces, (c) and (d) lateral sides near the neutral axis of bending rod for S1 (606C3C), which was subjected to 4 repeated static cycles to $24 \mathrm{~mm}$ maximum relative displacement followed by dynamic cyclic loading \pm 25.40 to $30.48 \mathrm{Nm} 5 \mathrm{~Hz}$; $1.4 \times 10^{4}$ failure cycles, 0.9 gram fuel particles collected. .54

Figure 32 (a) Curve of moment versus curvature, and (b) equivalent strain- stress curve for S2 (605D1E); based on static loading cycle in which maximum relative displacement was $24 \mathrm{~mm}$ 
and rate at loading points of U-frame set at 0.1 and $0.2 \mathrm{~mm} / \mathrm{s}$ in loading and unloading, respectively. .55

Figure 33 (a) and (b) Mating fracture surfaces, (c) frontal and (d) back sides for S2 (605D1E), which was subjected to 3 repeated static cycles to $24 \mathrm{~mm}$ maximum relative displacement followed by dynamic cyclic loading $\pm 30.48 \mathrm{Nm} 5 \mathrm{~Hz} ; 7.2 \times 10^{3}$ failure cycles, 0.6 gram fuel particles collected.

Figure 34 (a) Curve of moment versus curvature, and (b) equivalent strain- stress curve for Scal (609C6); based on static loading cycle in which maximum relative displacement was $24 \mathrm{~mm}$ and rate at loading points of U-frame set at 0.1 and $0.2 \mathrm{~mm} / \mathrm{s}$ in loading and unloading, respectively.

Figure 35 (a) and (b) Mating fracture surfaces, (c) and (d) laterals sides near the neutral axis of bending rod for Scal (609C6), which was subjected to repeated static loading to $24 \mathrm{~mm}$ maximum relative displacement and failed at $93.5 \mathrm{~N}^{*} \mathrm{~m}$ in the 4 th cycle, 1.3 gram fuel particles collected.

Figure 36 (a) Curve of moment versus curvature, and (b) equivalent strain- stress curve for Dcal (609C5); based on static loading cycle in which maximum relative displacement was $24 \mathrm{~mm}$ and rate at loading points of U-frame set at 0.1 and $0.2 \mathrm{~mm} / \mathrm{s}$ in loading and unloading, respectively.

Figure 37 (a) and (b) Mating fracture surfaces, (c) frontal and (d) back side for Dcal (609C5), which was subjected to 3 repeated static loading to $24 \mathrm{~mm}$ maximum relative displacement followed by dynamic loading: $\pm 30.48 \mathrm{Nm} 5 \mathrm{~Hz}$; $9.6 \times 10^{3}$ failure cycles, 0.2 gram fuel particles collected.

Figure 38 Variations of (a) curvature range, (b) applied moment range, (c) flexural rigidity as a function of number of cycles for DL1 (607C4B); $\mathrm{N}_{\mathrm{f}}=1.1 \times 10^{5}$ cycles under $\pm 15.24 \mathrm{Nm} 5 \mathrm{~Hz}$. Fuel particles collected $<1.0$ gram.

Figure 39 (a) Moment-curvature relation, and (b) moment-flexural rigidity relation at various numbers of cycles for DL1 (607C4B); $\mathrm{N}_{\mathrm{f}}=1.1 \times 10^{5}$ cycles under $\pm 15.24 \mathrm{Nm} 5 \mathrm{~Hz}$. Fuel particles collected $<1.0$ gram.

Figure 40 (a) and (b) Mating fracture surfaces, (c) frontal and (d) back sides for DL1 (607C4B), $\mathrm{N}_{\mathrm{f}}=1.1 \times 10^{5}$ cycles under $\pm 15.24 \mathrm{Nm} 5 \mathrm{~Hz}$. Fuel particles collected $<1.0$ gram. 63 Figure 41 Variations of (a) curvature range, (b) applied moment range, (c) flexural rigidity as a function of number of cycles for DL2 (608C4B); $6.4 \times 10^{4}$ cycles finished under $\pm 5.08 \mathrm{Nm} 5 \mathrm{~Hz}$, without failure.

Figure 42 Variations of (a) curvature range, (b) applied moment range, (c) flexural rigidity as a function of number of cycles for DL2 (608C4B) based on measurements with maximum relative displacement $0.4 \mathrm{~mm} ; 6.4 \times 10^{6}$ cycles finished under $\pm 5.08 \mathrm{Nm} 5 \mathrm{~Hz}$, without failure. .65 Figure 43 Variations of (a) curvature range, (b) applied moment range, (c) flexural rigidity as a function of number of cycles for DL3 $(60510 \mathrm{~A}) ; \mathrm{N}_{\mathrm{f}}=1.0 \times 10^{6}$ cycles under $\pm 10.60 \mathrm{Nm} 5 \mathrm{~Hz}$...66 
Figure 44 Variations of (a) curvature range, (b) applied moment range, (c) flexural rigidity as a function of number of cycles for DL3 (60510A) based on measurements with maximum relative displacement at 0.4 and $0.8 \mathrm{~mm} ; \mathrm{N}_{\mathrm{f}}=1.0 \times 10^{6}$ cycles under $\pm 10.60 \mathrm{Nm} 5 \mathrm{~Hz} . \ldots \ldots \ldots \ldots \ldots \ldots \ldots \ldots . . . . .67$ 


\section{List of Tables}

Table 1 Mechanical properties of U-frame component materials used in FEM .......................10

Table 2 Maximum stress in fuel rod specimen and compliant layer (MPa) obtained by FEM.....10

Table 3 Summary of FEM results for U-frame setup in static and dynamic loading conditions ..11

Table 4 Specifications of linear motor testing system ...................................................23

Table 5 Summary of verification tests using surrogate rods* ...........................................31

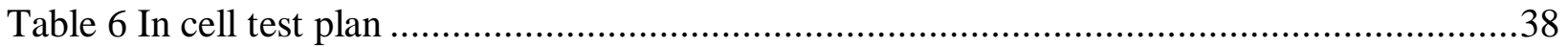

Table 7 Tuning parameters obtained by using Demo1 …...............................................43 


\section{ACKNOWLEDGEMENT}

The research was sponsored by the Office of Nuclear Regulatory Research, U.S. Nuclear Regulatory Commission under DOE contract DE-AC05-00OR22725 with UT-Battelle, LLC. The authors would like to thank NRC Program Manager Michelle Flanagan for providing guidance and support; and NRC officers Gordon Bjorkman, Bob Einziger, and Patrick Raynaud for providing valuable comments during the program development.

The authors gratefully acknowledge ORNL Program Managers Bruce Bevard and Rob Howard for their guidance; Ting Tan and Hao Jiang for providing FEM simulation support; Chuck Baldwin, Yong Yan, Brian Woody, and Scot Thurman for providing hot-cell operation support; Thomas Cox, Brian Sparks, and Randy Parten for providing drawing and machining support. 


\section{Background}

For high burn-up spent nuclear fuel (SNF), it is expected that the spent fuel cladding will have a high population of microcracks and hydrides, including macro-hydrides and micro-hydrides. This will reduce the stress intensity required to advance the crack growth. The linking of these microcracks during vibration loading also reduces the fatigue threshold/incubation period significantly, accelerating fatigue failure. In addition to the damages in cladding, the microstructure of comprising fuel pellets and interfaces of fuel rod have changed dramatically after the high burn-up process. These modifications have a direct impact on the structural integrity and vibration response of SNF rods in transportation.

As a result of that, the vibration has been included as one of mandatory testing conditions for the structural evaluation of package that is used in transporting spent nuclear fuel by US NRC (Nuclear Regulation Commission) in 10 CFR §71.71. Currently, no testing system is available to test the spent nuclear fuel and evaluate the performance of fuel rod during the spent fuel transportation. It is the aim of this research project to develop a system that can appropriately test the response of high burn-up SNF rod in a simulated loading condition. Before a disposition pathway, either recycling or geologic disposal, is chosen and implemented, the storage periods for SNF will likely be longer than originally intended. Therefore, the ability of the important-tosafety structures, systems, and components (SSCs) to continue to meet safety functions over extended times must be determined. In addition, whether SSCs can also meet applicable safety functions when the spent nuclear fuel is transported to its final location must also be determined. To facilitate all options for disposition and to maintain retrievability and normal back-end fuel cycle operations, the likelihood of the spent nuclear fuel remaining undamaged after storage and transportation needs to be evaluated.

Transportation packages for spent fuel must meet safety requirements under normal and accident conditions, as specified by federal regulations. For normal conditions of transport, it is required that the licensee assure that there will be no loss or dispersal of spent fuel, no significant increase in external surface radiation levels, and no substantial reduction in the effectiveness of the spent fuel package. This includes vibration loads incident to transport. ${ }^{1}$

The fuel assemblies are usually loaded in a transportation cask or in a dual-purpose canister with a transportation overpack. The transportation cask is then loaded onto a truck or railcar. In the proposed scenario, the transportation of fuel assemblies occurs in a horizontal position. The interaction between the vehicle and the ground creates vibration, which in turn is transmitted into the transportation cask internal structure (baskets) and fuel assembly spacer grids. A cross section of a typical pressurized fuel assembly is given in Figure 1. The displacement imposed on the spacer grids will be ultimately transformed into mechanical loading on fuel rods. Such mechanical loading is characteristic of oscillatory bending attributed to the slenderness of individual fuel rods and constraints provided by spacer grids. The oscillation may or may not take place symmetrically around the neutral axis of rod's section, depending on the initial 
equilibrium position of rod. The spectrum of the load or imposed displacement on rods generally contains frequency components around or less than $100 \mathrm{~Hz}$, depending on the vehicles used. ${ }^{2}$

Spent fuel rod vibration during normal transport is important because of the sustained loads involved and this is particularly important for high-burnup fuel ( $>45 \mathrm{GWd} / \mathrm{MTU})$. As the burnup of the fuel increases, a number of changes occur that may affect the performance of the fuel and cladding in storage and transportation. These changes include increased cladding corrosion layer thickness, increased cladding hydrogen content, increased cladding creep strains, increased fission gas release, and formation of a high burnup structure (HBS) at the surface of the fuel pellets. With respect to cladding hydrogen content, the solubility of hydrogen in zirconium increases with higher temperatures. When the concentration of hydrogen exceeds the solubility limit, zirconium hydrides form. Depending on the size, distribution, and orientation, these hydrides can embrittle the cladding and reduce ductility. Furthermore, the presence of hydrides may facilitate cracking if the hydrides are aligned radially, perpendicular to the hoop (tangential) tensile stress field. Although cladding hydrides are typically observed to be oriented in the circumferential direction, they can reorient to the radial direction, depending on the stress level of the cladding when it is cooled, which can occur following the drying process during the transfer of the fuel from the pool to a transportation cask or dual-purpose canister. Hydrides have also been shown to diffuse to colder regions of the cladding under a relatively small temperature gradient. The reorientation and diffusion of hydrides can result in cladding cracking. Even if a through-wall crack is not formed, the extent of cracking needs to be evaluated to determine if clad will fail due to stresses caused by normal handling or transportation. ${ }^{3}$ The current maximum rod-averaged burnup is limited by the US Nuclear Regulatory Commission to $62 \mathrm{GWd} / \mathrm{MTU}$ because of these changes and the lack of data at higher burnups. The transportation of highburnup commercial spent fuel is being handled on a case-by-case basis using the relevant criteria. ${ }^{1}$

Therefore, the evaluation of spent fuel rod integrity under vibration loading is an important part of the safety assessments needed for the extended storage and transportation of high-burnup spent fuel. 


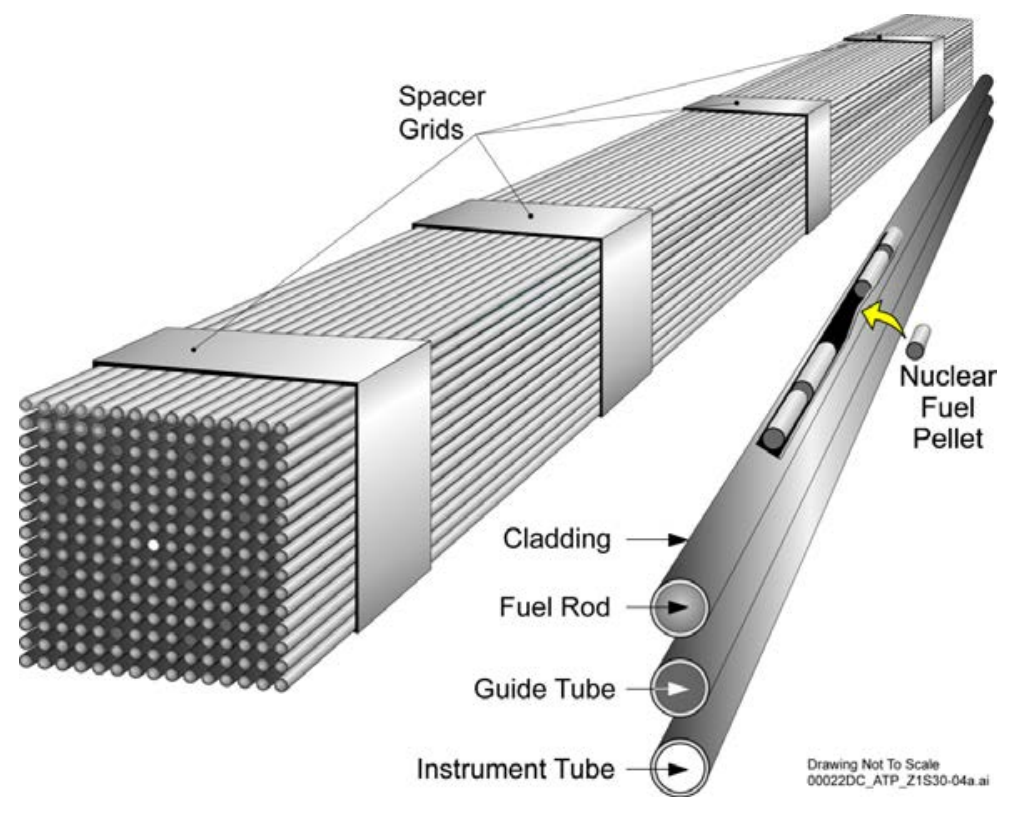

Figure 1 Cross-sectional illustration of typical pressurized water reactor fuel assembly. The spacer grids can impart vibration loads to spent fuel rods during transportation. 


\section{Introduction to test design}

Testing SNF rods is well known not to be trivial. First, SNF rods are highly radioactive. SNF has to be contained in a hot-cell, and can be accessed only remotely by manipulators. The test setup, specimen loading, and test operations must be simple. Second, a fuel rod has a heterogeneous composite structure originally composed of fuel pellets and cladding, and subsequently modified by high burnup process as mentioned above. Various failure modes could be triggered in transportation, including bending, splitting, etc. The bending-induced failure can be captured only by an effective testing approach. Last, rod vibration in transportation is not well characterized.

Although the mechanical properties of high- burnup cladding were studied by subjecting the materials to longitudinal (axial) tensile tests, ring-stretch tests, ring-compression tests, and biaxial tube burst tests, no method has been developed to investigate the mechanical properties and behavior of both the cladding and the fuel in it, in addition to dynamic reversible bending loading. Moreover, these existing test methods are designed for standardized specimen geometries that are different from specimen requirement for bending or cyclic bending of spent fuel rods, in which the individual rod is needed to be tested in as-received condition.

Bending fatigue testing has been around for some time. ${ }^{4,5,6,7}$ On the basis of the beam's boundary condition, the testing can be classified as cantilever beam flexure, ${ }^{8}$ three-point bending and four-point bending, ${ }^{9,10,11,12}$ and pure bending. ${ }^{13}$ Bending fatigue tests also include variants that have been developed in response to environmental factors, particularly temperature. ${ }^{14}$

Pure bend test methods are preferred for materials whose failure is sensitive to shear. ${ }^{15,16,17} \mathrm{~A}$ pure bending fatigue machine for reverse bending was first developed by Forrest and Penfold. ${ }^{18}$ It was modified and used by UK turbine-makers in testing high strain fatigue related to thermal transients on low alloy steels. ${ }^{19,20}$ The beam specimen was held by two cross-shafts. The crossshafts were free to rotate, and one of them was also free to move to release axial loading on the specimen. The rotation of cross-shafts was introduced through two crank-arms and links that were driven by an electric motor via gearboxes. The fatigue machine generally works in a low frequency (less than $1 \mathrm{~Hz}$ ) that is of interest to creep fatigue. The system lacked the strain control in the specified control mode.

Another reported pure bending approach is derived from the four-point bending principle. Similar to the flexure-based device, ${ }^{11}$ the implementation places the specimen under test in an inner span and reinforces the specimen-retaining part (end parts of outer span) with rigid sleeves. It is the rigid sleeves that convert the external force couples into bending moments applied to the specimen. ${ }^{13}$ Compliant layers are utilized as transits between the rigid sleeves and the specimen to control potential contact damage. Supports are provided by a position system equipped with rollers, and loading points are constructed by use of pivots on slide connections attached to a swing beam. The configuration of the setup ensures the release of axial stresses and is able to 
handle the large deformation fatigue in ductile materials. However, cyclic bending can only be conducted in non-reversal or unidirectional mode.

The main observations on the current status of bending fatigue testing and related issues can be summarized as follows: 1) Four-point bending fatigue has been proven to be a mature experimental technique in testing materials and components that have limited deformation before failure. The technique is mostly used in fatigue tests without reversible bending. 2) Four-point /three-point bending and cantilever bending all suffer from the inherent drawback related to transverse shear. This has a significant impact on materials that are sensitive to shear. 3) Various supports have been developed in bending fatigue testing, including flexures, ${ }^{11}$ rotary joints, ${ }^{12}$ slide connections, ${ }^{13}$ and motorized clamps. ${ }^{21}$ They are neither demonstrated nor enabled in reverse mode. 4) Pure bending fatigue has been used for high strain and low cycle fatigue in testing metallic alloys and composites. The implementation of the pure bending concept is usually application-based with partial success. 5) Environmental chambers and/or high temperature furnaces are currently incorporated into some critical bending fatigue tests. The setup of specimens and tests is all accomplished manually.

It becomes clear that, even though a variety of testing methods have been developed, these methods cannot be used in testing and characterizing the SNF rods. A new test system is required. The system must capture the failure mode of SNF rods in bending and be implemented in a hot-cell environment. 


\section{Test method and test system development}

\subsection{General considerations of test system}

Among the test methods examined, pure bending has been identified as a leading candidate for

bending fatigue testing of SNF rods. ${ }^{22}$ Pure bending eliminates the shearing-induced failure to which the SNF would be subjected should three- or four-point bending be used. Several important features of the new system with emphasis on pure bending have been identified as the initial condition for subsequent development. First, a universal materials testing machine or equivalent system is used as a driving mechanism in the targeted frequency range 1-100 $\mathrm{Hz}$. Second, rigid sleeves serve as a device to convert external force couples into bending moments. Third, the specimen supporting or holding mechanism allows the bending rod to move freely in axial direction but not in transverse direction so that inverse bending can be applied. The boundary condition involved with the latter is apparently different from the pivot or simply supported and was called frixed. ${ }^{11}$

\subsection{Test setup}

\subsubsection{Concept of U-frame setup}

Testing setup plans were investigated, including horizontal and vertical test setups. ${ }^{22}$ In the horizontal testing setup, the rod is set up horizontally and loading is introduced vertically with the loading points offset from the supporting points for an effective loading arm. Sliding connections are mostly used in the loading points. In contrast, the support mechanism has various forms in order to fulfill the requirements of a frixed boundary condition, including pivoting U-holders with a rotary-joint and cross-shafts. The bending moment applied to the rod specimen is quite straightforward and defined directly by the force and the loading arm. The vertical testing setup is quite different from the horizontal setup; in the vertical setup, the rod specimen is held vertically and bending is performed through vertical loading with the assistance of a reoriented U-frame whose opening faces aside. The U-frame is constructed with two rigid arms and a third member or linking member. The rod specimen is coupled by inserting it into the co-linear holes within the two rigid arms. The rod can be arranged to be offset (Figure 2) or coplanar to the third member (as will be discussed below). In addition, the corners or joints of the U-frame can be rigid or pivoting. The bending moment applied to the rod depends on the arrangement of the rod and the mechanism used in the corners.

A comparison between the two testing setups highlighted many advantages of the vertical setup featuring the U-frame. Particularly, the setup uses only two linkages to the driving. The installation of a rod specimen can be accomplished by simply dropping the rod into the holes once the U-frame is set up. The drop-in feature is shown to be an extremely important benefit for SNF testing because it can simplify the operation of manipulators in a hot-cell environment. The U-frame setup was thus selected in this project to test and investigate the bending fatigue and vibrational integrity of the SNF rods. ${ }^{23,24}$ 
The variations in the joint mechanism adaptable to the U-frame corners and the arrangement of the rod specimen relative to the linking member, as mentioned above, provide many options for the design. ${ }^{24}$ The investigation indicated that pivoting corners can fit into both the offset and coplanar designs, while rigid corners are feasible only in the offset design. In the case of rigid corners, the linking member acts as a flexure to enable the rotation of the two rigid arms while being axially loaded. Controlled by the displacement, the moment applied to the rod depends on the flexural rigidity of the rod and on the flexure as well. Thus, the rigidity of the flexure needs to be calibrated first in order to define the moment. The reliability of the rigid corners and the durability of the flexure are major concerns in cycles of long duration.

In the case of pivoting corners, the moment applied is defined by the external force and the loading arm with respect to the pivot. The linking member serves as an axial loading rod without flexing, and the system has none of the reliability issues found with rigid corners. One minor concern with pivoting corners relates to U-frame setup because the U-frame itself functions as a structure only if a rod is inserted, and the two rigid arms need to be set to a predetermined position beforehand. Overall, pivoting corners are shown to be much better than rigid corners. The selection of pivoting corners means that both offset and co-planar designs of specimen holes can be accommodated. Design screening depends on whichever is more effective and efficient in converting force couples into bending moments or flexural stresses.

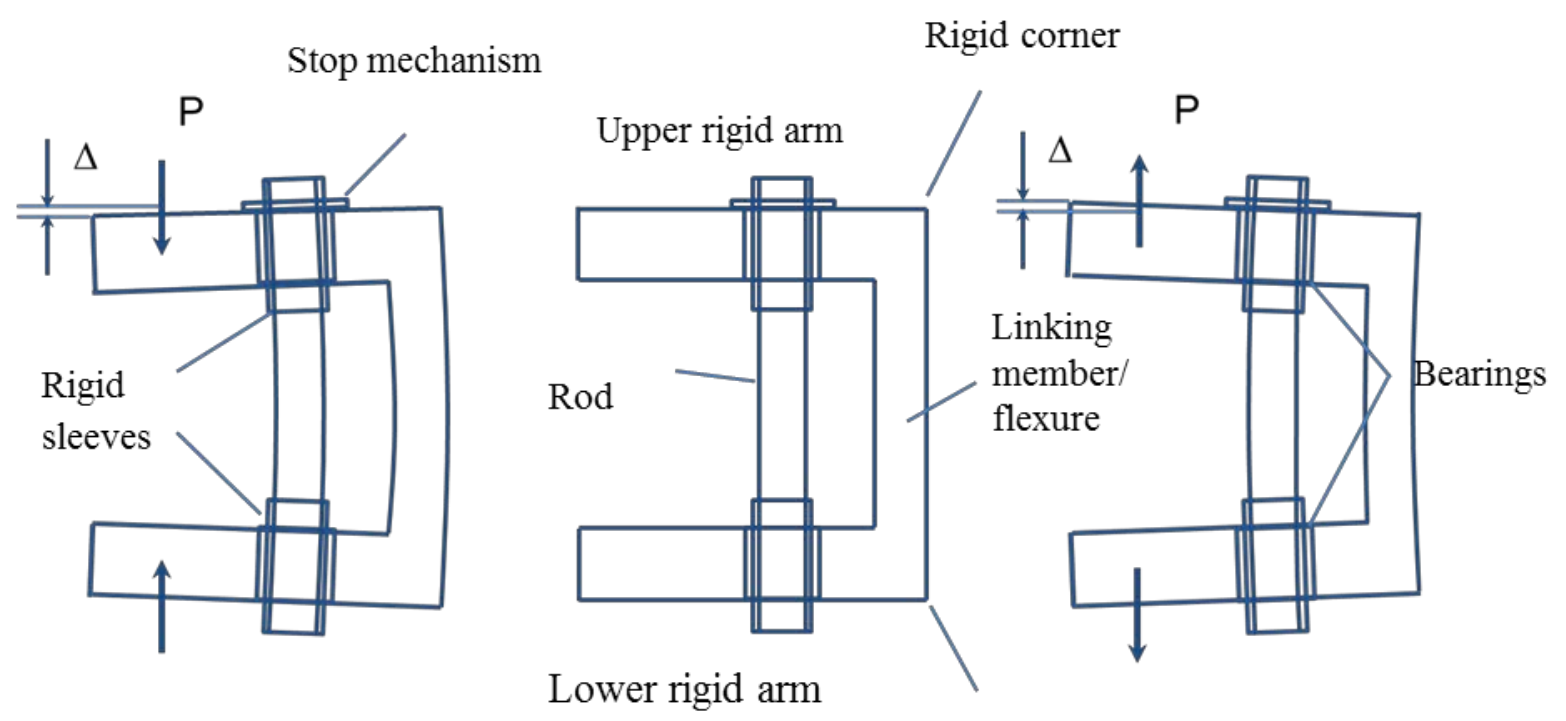

Rigid corner
(a) Rigid arms
(b) Rigid arms in
(c) Rigid arms
being closed
neutral position
being opened 
Figure 2 U-frame-assisted bending fatigue testing setup for reversal bending when rigid arms are (a) closing, (b) neutral, and (c) opening. The rod is offset from the vertical linking member.

\subsubsection{Dimensional design of $U$-frame}

The size of the U-frame design depends on the rod specimen to be tested. For the H.B. Robinson-2 SNF rods that are the focus of this study, the cladding is made of Zircaloy-4 (Zry-4). The inside and outside diameters (ID and OD) of the cladding are 9.46 and $10.70 \mathrm{~mm}$, respectively. The fuel pellets, made of $\mathrm{UO}_{2}$, are each $\phi 9.30 \times 15.2 \mathrm{~mm}$. A regular fuel rod measures $3.860 \mathrm{~m}$ long. Because it was not feasible to test an entire SNF rod in a hot cell, a section of $152.40 \mathrm{~mm}$ length was selected for this project, although a $228.60 \mathrm{~mm}$ length was also considered as an alternative.

Two sizes of rigid arms were studied: $50.80 \times 50.80 \times 266.70 \mathrm{~mm}$ for the offset design and 50.80 $\times 50.80 \times 203.20 \mathrm{~mm}$ for the co-planar design. ${ }^{23}$ Both sizes of rigid arms have a beam section of $50.80 \times 50.80 \mathrm{~mm}$, which can offer the rigidity and secondary loading arms required for converting the external force couples into bending moments. A gage length of $50.80 \mathrm{~mm}$ is available when the rod is inserted in the test configuration. In both the offset and co-planar designs, the rod is located $152.40 \mathrm{~mm}$ away from the loading point. In the former, the linking member is designed as an H-shaped structure and is offset $236.22 \mathrm{~mm}$ from the rod specimen. A solid model of the U-frame in a co-planar configuration is shown in Figure 3.

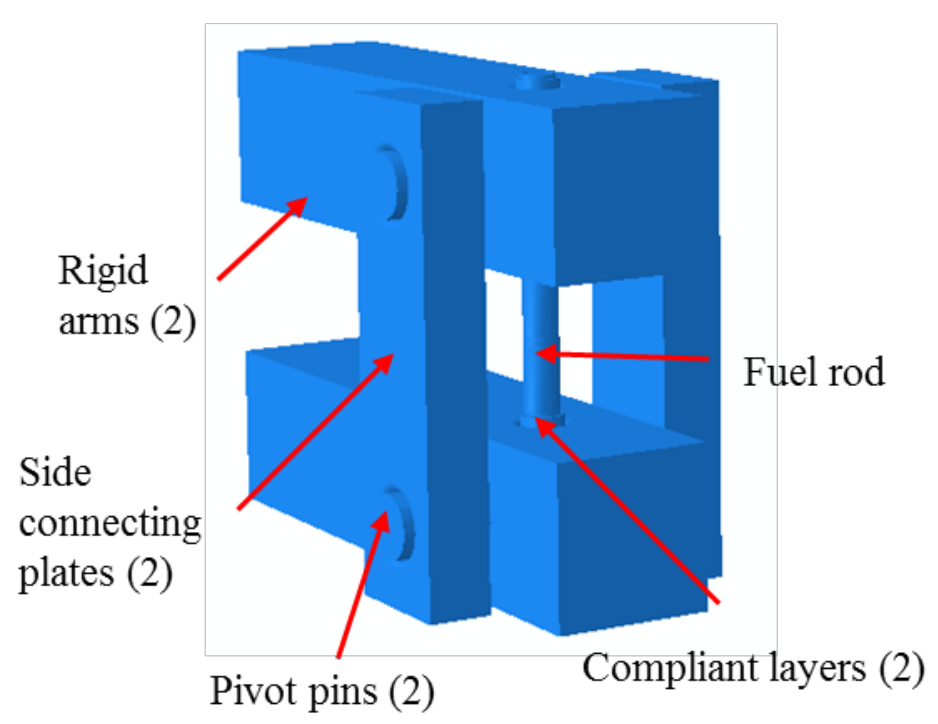

Figure 3 Three-dimensional solid modeling of U-frame test setup; the rod is co-planar with the vertical linking members. 


\subsubsection{FEM simulation}

\subsubsection{Static analysis}

A finite element method (FEM) model was developed to capture the major features of the Uframe, including the two rigid arms, the linking member, and the rod specimen/compliant layer. ${ }^{23}$ The durability of the bending system suggests that the U-frame components should be capable of surviving radiation and fatigue. For this reason, stainless steel (SS) 304 was considered as a primary material for these components. An investigation was also conducted to identify engineering plastics for the compliant layers, and polycarbonate was screened out on the basis of several sources. ${ }^{25,26,27}$ The mechanical properties of the cladding and pellets (Zry-4 and $\mathrm{UO}_{2}$ ) were based on a PNNL report ${ }^{28}$ and BARC research. ${ }^{29}$ The main mechanical properties are summarized in Table $1 .^{24}$

The U-frame was supported by two pins fixed in six degrees of freedom (DOF). The ends of the fuel rod were restrained with a light-duty compression spring of $0.175 \mathrm{~N} / \mathrm{mm}$. All of the forces were applied through equivalent tractions on the end faces of the rigid arms. Two stress-level solutions were pursued: one was elastic, in which the force at the loading end of the rigid arm was $178 \mathrm{~N}$, and the other was yielding, which corresponded to $1780 \mathrm{~N}$ force at the loading end.

The stress distribution within the fuel rod and compliant layer shows that, disregarding the rod arrangements in the offset and co-planar designs, the von Mises stress contours are symmetric to the longitudinal axis of the rod, with the maxima near the outer surface and the minima on the axis. Overall, the stress contours are quite uniform in the gage section of the fuel rod. Additionally, no stress concentration exists in the cladding near holding areas. A detail study showed that the maximum stresses actually developed on the surface of the fuel pellet, obviously due to the higher Young's modulus of the pellet.

The results are given in Table 2 for these two designs, in which the fuel rod and compliant layers are all within the elastic range under $178 \mathrm{~N}$. A significant increase in the fuel rod stress was observed when the design was switched from the offset to the co-planar rod configuration. Therefore, placing the fuel rod in the same plane as the linking members of the U-frame is more efficient in converting the external forces into the bending moment than is offsetting the rod. The co-planar arrangement of the rod has been thus adopted in the configuration of U-frame setup in this project.

It is our interest to investigate the case in which both the fuel rod and the compliant layer yield. Such a situation defines the maximum load level the U-frame will need to supply and, further, the required capacity of the testing machine. The load-bearing capacity of the U-frame with the co-planar configuration of the rod has been determined to be around $1780 \mathrm{~N}$. At the same time, the maximum displacement at each loading point increased from $1.83 \mathrm{~mm}$ to $17.86 \mathrm{~mm}$ when the load increased from $178 \mathrm{~N}$ to $1780 \mathrm{~N}$. As a result, the relative movement at two loading ends can 
be as high as $35.56 \mathrm{~mm}$. This would be the minimum stroke required of the actuator in a universal testing machine.

Table 1 Mechanical properties of U-frame component materials used in FEM

\begin{tabular}{|c|c|c|c|c|}
\hline Materials & Density $\left(\mathrm{kg} / \mathrm{m}^{3}\right)$ & $\begin{array}{c}\text { Young's } \\
\text { modulus }(\mathrm{GPa})\end{array}$ & Poisson's ratio & $\begin{array}{c}\text { Yield strength } \\
(\mathrm{MPa})\end{array}$ \\
\hline Stainless steel & 8,030 & 193 & 0.30 & 290 \\
\hline Polycarbonate & 1,210 & 7 & 0.35 & 69 \\
\hline $\mathrm{UO}_{2}$ & 10,970 & 201 & 0.32 & 2,146 \\
\hline $\mathrm{Zry}-4$ & 6,560 & 91 & 0.33 & 906 \\
\hline $\mathrm{Al}_{2} \mathrm{O}_{3}$ & 3,920 & 372 & 0.22 & 2,500 \\
\hline
\end{tabular}

Table 2 Maximum stress in fuel rod specimen and compliant layer (MPa) obtained by FEM

\begin{tabular}{|c|c|c|c|c|}
\hline $\begin{array}{c}\text { Rod } \\
\text { Arrangement }\end{array}$ & Solution & Pellet & Cladding & Compliant \\
\hline Offset & Static, $178 \mathrm{~N}$ & 20.437 & 10.963 & 12.763 \\
\hline Co-planar & Static, $178 \mathrm{~N}$ & 219.606 & 117.215 & 26.091 \\
\cline { 2 - 5 } & Static, 356 N & 439.212 & 234.430 & 52.181 \\
\cline { 2 - 5 } & Dynamic, $10 \mathrm{~Hz}$, & 123.421 & 66.192 & 11.722 \\
& $356 \mathrm{~N}$ & & & \\
\hline
\end{tabular}

a) Based on the elastic result at $178 \mathrm{~N}$

\subsubsection{Dynamic analysis}

The static model was modified to include additional material properties for dynamic analysis; namely, density and damping ratio. ${ }^{23}$ While the density was depending on the materials selected for individual components, the damping ratio was set to 0.05 for the system. A steady-state solution was investigated, in which input had load amplitudes of 178, 267, and $356 \mathrm{~N}$ and a frequency range of 10-100 Hz. The displacement response of the U-frame obtained by steadystate solution is presented in Figure 4. As expected, the displacement decreased significantly with increasing frequency under defined load amplitude. With the input of $178 \mathrm{~N}$, switching from static to $10 \mathrm{~Hz}$ dynamic loading resulted in a pronounced displacement drop at the loading 
ends of the rigid arms, from $1.829 \mathrm{~mm}$ to $0.455 \mathrm{~mm}$. The dynamic responses of the $\mathrm{U}$-frame at two typical frequencies $(10$ and $20 \mathrm{~Hz}$ ) are summarized in Table 3 along with the static results.

Under the dynamic loading, the maximum stress again occurred near the surface of the fuel rod, and all the components stayed within the elastic condition. The maximum Mises stresses for 356 $\mathrm{N}$ at $10 \mathrm{~Hz}$ were 123.421, 66.192, and 11.722 MPa for pellet, cladding, and compliant layers. These values are relatively low, only 22-28\% of those in the static case (Table 2). Such levels of stresses occurred in the fuel rod as a substantial amount of input energy was spent in driving the components of the U-frame instead of the rod specimen.

The FEM model assumed a perfectly plastic model for all fuel rod components. The use of a perfectly plastic model could lead to an underestimate of the ultimate load on the U-frame, because extensive strain hardening is typically observed with fresh fuel cladding material such as Zry-4. The strain-stress curve of the spent fuel cladding and the main controlling factors were also studied, ${ }^{28}$ but the effect of strain hardening on the bending performance of a spent fuel rod is unknown.

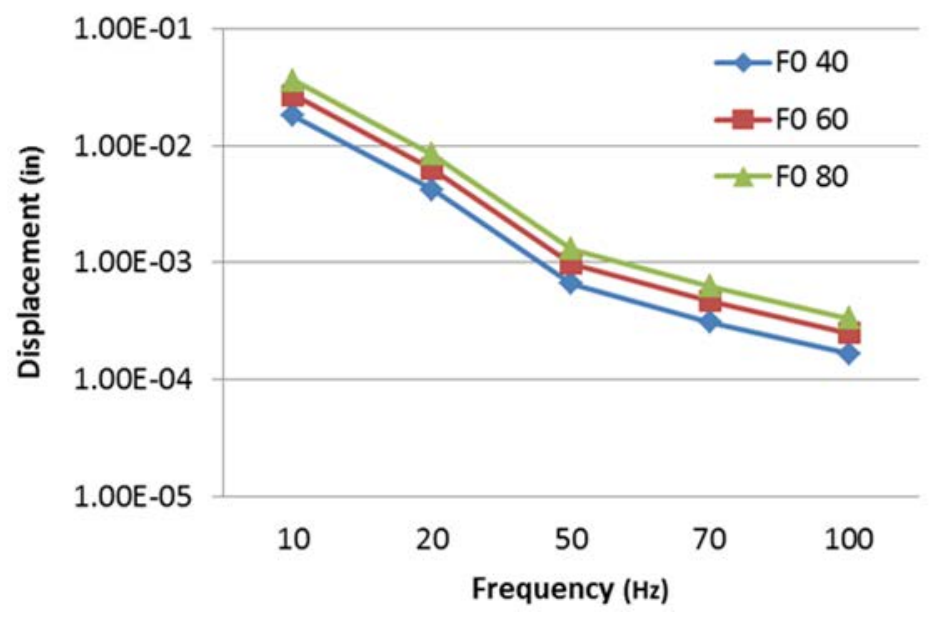

Figure 4 Dynamic response of U-frame setup obtained by steady-state analysis; F0 is load amplitude 40, 60, $80 \mathrm{lb}$ or 178, 267, and $356 \mathrm{~N}$. The displacement is measured at the loading point of the U-frame setup in inches.

Table 3 Summary of FEM results for U-frame setup in static and dynamic loading conditions

\begin{tabular}{|c|c|c|c|}
\hline Test condition & Frequency (Hz) & Force amplitude (N) & $\begin{array}{c}\text { Relative displacement } \\
\text { amplitude }^{\mathrm{a}}(\mathrm{mm})\end{array}$ \\
\hline
\end{tabular}




\begin{tabular}{|c|c|c|c|}
\hline Static & & 178 & 3.66 \\
\hline Static $^{\mathrm{b}}$ & & 1,780 & 35.56 \\
\hline Dynamic & 10 & 178 & 0.91 \\
\hline & 10 & 356 & 1.82 \\
\hline Dynamic $^{\mathrm{c}}$ & 10 & 1,780 & 9.10 \\
\hline & 20 & 356 & 0.42 \\
\hline Dynamic $^{c}$ & 20 & 1,780 & 2.12 \\
\hline
\end{tabular}

a) Relative displacement of the U-frame is twice that of the single arm.

b) Load at which fuel rod and compliant layer yield.

c) Based on the elastic result at $356 \mathrm{~N}$.

\subsubsection{Design study on the effects of setup weight, driving mode, and setup layout}

The weight effect on the deformation of rod has been demonstrated to be substantial with the current vertical layout of U-frame. The FEM study was conducted subsequently by adding counterweights to each rigid arm, in which load amplitude $178 \mathrm{~N}$ with $10 \mathrm{~Hz}$ was applied at the lower end of U-frame setup to simulate testing on MTS servo-hydraulic machine. ${ }^{30}$ The response of the U-frame was improved compared to that without counterweights. But the asymmetric deformation persisted in which the maximum stress quite offset from the middle of rod. Such offset of maximum stress location can be mitigated by using a lower driving frequency such as $0.1 \mathrm{~Hz}$. Thus, the observed asymmetrical deformation of rod is mainly attributed to the frequency response of system. As a result of the concern raised above, a FEM simulation has been carried out by applying $178 \mathrm{~N} \mathrm{10Hz} \mathrm{loads} \mathrm{at} \mathrm{both} \mathrm{loading} \mathrm{points} \mathrm{of} \mathrm{U-frame.}{ }^{30}$ The deformation of rod turned out to be quite symmetrical with both the maximum defection and stress occurred at the middle of rod.

A more advanced investigation into the horizontal layout of U-frame was conducted on various lengths of loading arm 101.6mm (4 in.) and $15.4 \mathrm{~mm}$ (6 in.). The counterweight is removed automatically in the horizontal layout because of no weight issue involved. The results showed the maximum loading-point displacements and maximum stresses of rod based on the horizontal layout were both an order of magnitude higher than those in the vertical layout of U-frame with counterweights as shown in Figure 5. Thus counterweights had a negative impact on system dynamic responses due to extra mass added to the system. At the same time, the effect of loading arm size on the responses of the U-frame can be seen; namely, the loading point displacement and maximum stress were all enhanced to a certain extent when a $101.6 \mathrm{~mm}$ loading arm length was used. 


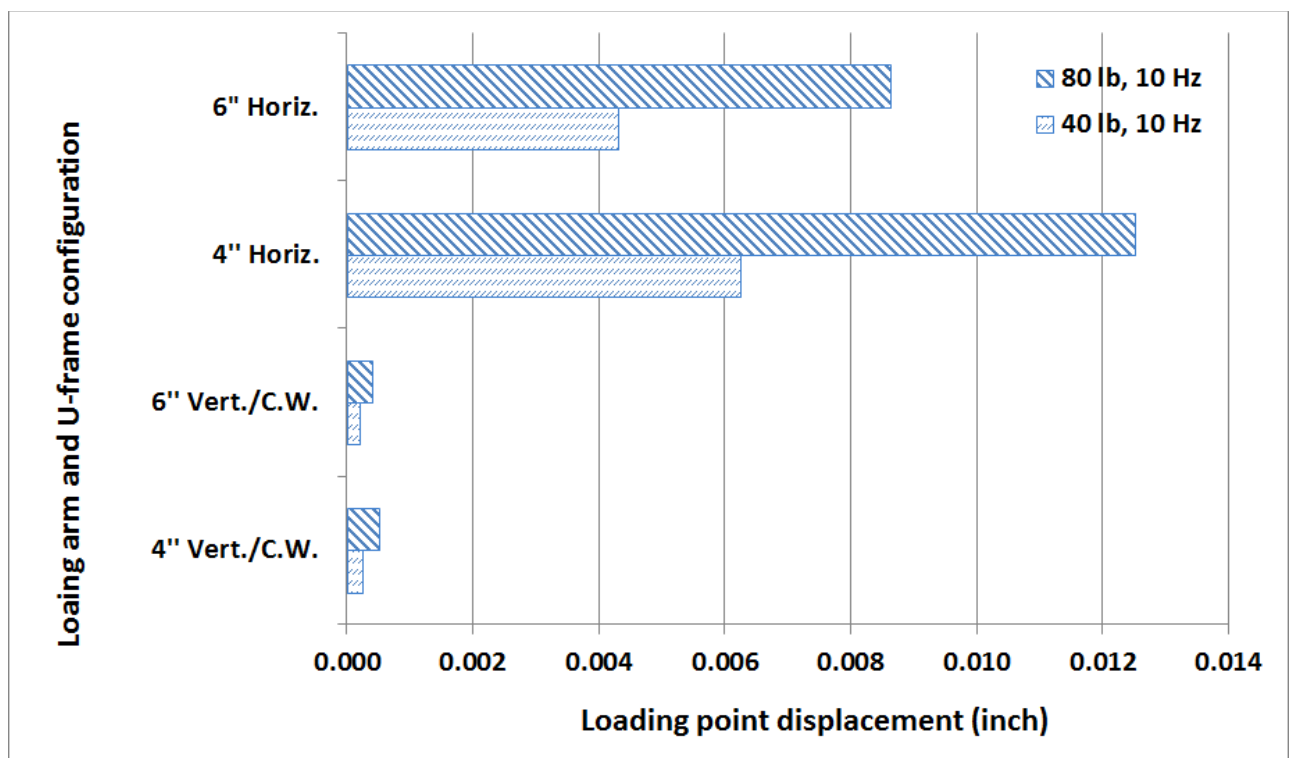

(a)

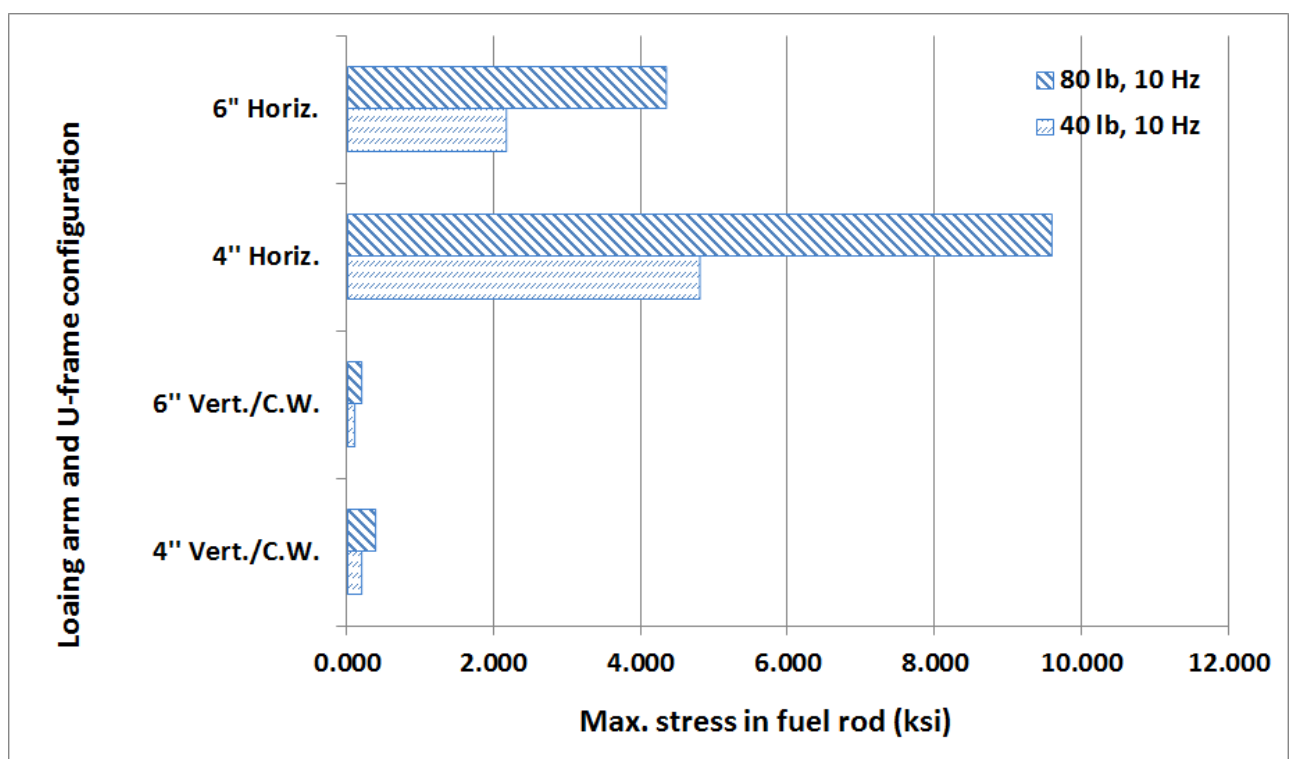

(b)

Figure 5 Dynamic response comparisons in terms of (a) displacement and (b) stress between horizontal design and vertical design with counterweights. The results are based on the symmetric loading $178 \mathrm{~N}(40 \mathrm{lb})$ and $356 \mathrm{~N}(80 \mathrm{lb})$ at $10 \mathrm{~Hz}$. 


\subsubsection{Engineering of U-frame}

\subsubsection{Performance target}

The FEM study discussed above revealed that the yielding load of the U-frame was $1780 \mathrm{~N}$ with a displacement range of $\pm 35.56 \mathrm{~mm}$ at the loading ends of the rigid arms. This characteristic load can serve as the performance target of the U-frame under design. Although the study was based on the assumptions including perfect plasticity, it is reasonable to use such a result as the starting point for engineering process.

Testing and calibration of the setup dedicated to spent nuclear fuel largely relies on use of surrogate rods. High density alumina and stainless steel (SS 304) have been selected as the pellet and cladding materials, respectively, because their mechanical properties are in the same ranges of $\mathrm{UO}_{2}$ and Zry-4 (Table 1). The alumina was also used by Papaioannou et al. to simulate fuel pellets in the fuel release tests due to impact-induced damage to the cladding. ${ }^{31}$ The geometric size of the surrogate rods was taken as that of a spent fuel rod to meet the similarity required for testing. A surrogate rod was prepared in the initial stage of the project with the cladding ID 9.449 $\mathrm{mm}$, OD $11.074 \mathrm{~mm}$, and length $152.400 \mathrm{~mm}$, and filled with a single rod $\phi 9.449 \times 152.4 \mathrm{~mm}$. The Teflon tubes, instead of polycarbonates, were prepared as compliant layers with ID 11.07 $\mathrm{mm}$, OD $16 \mathrm{~mm}$, and length $55.88 \mathrm{~mm}$. The Teflon tubes were considered to be able to provide a low friction on the contact with SS cladding while, at the same time, maintaining similar mechanical performance.

\subsubsection{Main components of $U$-frame setup}

\subsection{Rigid arms}

Engineering of the U-frame setup involves implementation of the designs of main components including rigid arms, side connecting plates, and linkage to the universal testing machine. ${ }^{23,24}$ The engineering process of $U$-frame is described in this section using vertical layout, but it is also apply to that in horizontal layout except the link to testing machine. The rigid arms function as loading arms and simultaneously as rod coupling devices. Each rigid arm features a vertical specimen hole to accommodate the rod. It can be seen that the coupling of rod to the rigid arms through Teflon layers, in fact, doesn't enable the drop-in to be realized for the specimen installation. A press-fit process is generally required to have the compliant layer properly contacted with the specimen hole, which is not feasible in hot cell. Linear bearings have been investigated subsequently. Use of linear bearing allows the axial motion of the rod under bending, but also needs two rigid sleeves pre-mounted to the two holding areas of the rod as will be described in the following. Between the rod and the rigid sleeve, a compliance layer is used to transfer loading from the rigid arms to the rod and to protect the rod from the potential contact damage. Testing showed that direct integration of a linear ball bearing (LBB) into the rigid arm could create substantial backlash in reverse bending. 
In a more advanced design, the rigid arms were split along the LBB axis. Such splitting resulted in a large arm body and a small end-block for a given rigid arm. Linear roller bearings (LRBs, THK FT2515-45L) were embedded in the two V-shaped surfaces modified from the mating halves of cylindrical surface. Thus, the rod specimen is installed into the test fixture by opening and closing the end-blocks in the upper and lower rigid arms. LRBs are preloaded through bolting and are secured with compression springs and associated retainers as demonstrated in Figure 6. It is worthwhile noticing that the LRBs have a higher dynamic loading capacity than LBBs and can provide a much more reliable performance in service. Although Teflon can be a plausible approach for compliance layer, cast epoxy has been adopted because the in-situ casting of epoxy is considered to be more feasible in hot cell than the press-fit or shrink-fit required in assembling a Teflon tube to the rod as will be discussed below.

Counterweights $(62 \times 38 \times 54 \mathrm{~mm})$ were introduced to eliminate the effect of self-weight on rod deformation. The original arms were, therefore, extended on the opposite side to the rod accordingly to accommodate such a need. A slope of $30^{\circ}$ was created to prevent the upper and lower arms from interference in the extremely close position. Additional engineering of rigid arm involved shortening loading arm into $101.6 \mathrm{~mm}$ to optimize the dynamic behavior of the Uframe. This alternative loading arm for the bearing shafts of the straddle legs was made available simply by drilling an additional hole to the rigid arms. Shortening the loading arms drives up the resonant frequency of the U-frame and significantly enhances the stress level in rod as validated by the FEM study. ${ }^{30}$

Although pins were used in our FEM simulation, precision ball bearings have been shown to be a better solution for pivoting corners. The bearings are durable and do not require special maintenance like oiling for pins. Bearing 6302 was selected on the basis of the anticipated loading requirement $(890 \mathrm{~N})$. The bearing had a static and dynamic load rating of $5338 \mathrm{~N}$ and $8585 \mathrm{~N}$, respectively. The lifetime (millions of revolutions) of the bearing for the application is estimated as $8.98 \times 10^{8}$ cycles. A pair of $\phi 15 \mathrm{~mm}$ shafts was made symmetrically on both sides of the rigid arm for mounting the bearings. The shear stress of the shaft under the required loading capacity is critical and was found to be much lower than the shear yield stress of SS 304 (based on Mises criterion).

\subsection{Side connecting plates}

The purpose of side connecting plates is twofold. First, they connect the upper and lower rigid arms and, therefore, house the ball bearings used in pivoting corners. The cross section of the side plates was thus designed to measure $50.8 \times 13 \mathrm{~mm}$, with a thickness $(13 \mathrm{~mm})$ same as that of ball bearings. Second, they are subjected to push-pull motions transferred from the rigid arms. Thus, the tensile stress at the maximum cut of the section near the bearing shaft holes needs to be examined. The calculation under the designed load $(890 \mathrm{~N})$ indicated that the stress on the plates (8 MPa) was again far less than the yield stress of SS 304 (290 MPa). 


\subsection{Link to testing machine}

The linkage of the rigid arm to the loading rod is achieved by use of a straddle structure. The cross member of the straddle was a thick T-shaped beam equipped with two legs at the side. A hinge connection was used between the rigid arm and the straddle by using the same bearings as those in the pivoting corners. However, the bearing shaft is not built in but coupled with the rigid arm through a set screw. The link of the U-frame setup to the testing machine depends on the platen of the testing machine. For the MTS hydraulic testing machine with loading frame 810, collets are available for coupling the loading rod of the testing setup to the testing machine. The overall size of the completed U-frame setup including mounts and linkages is $319.74 \times 409.4 \times$ $116.8 \mathrm{~mm}$.

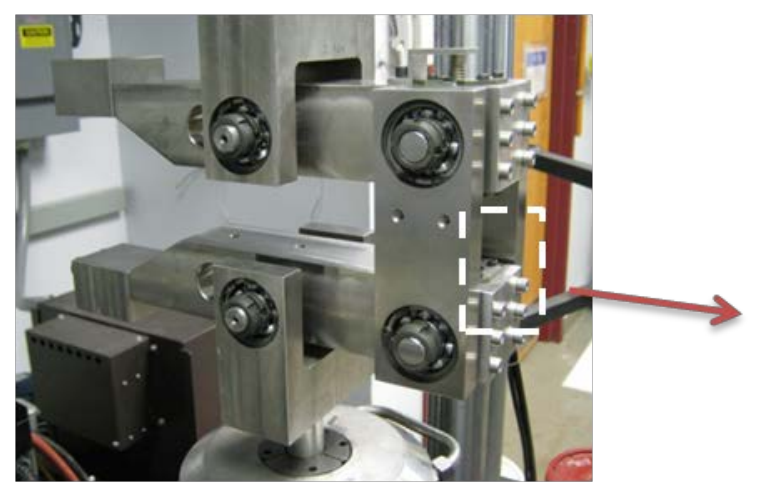

(a)

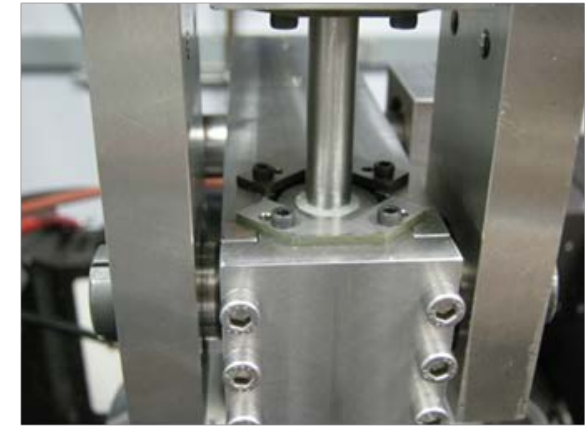

(b)

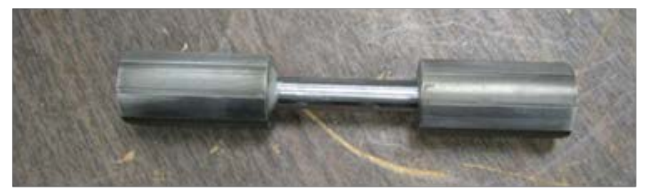

(c)

Figure 6 (a) U-frame setup equipped with linear roller bearings (LRBs) that are preloaded by bolting the end blocks. The enlarged view in (b) shows the rod inserted. The rigid sleeves have an octagonal shape and are mounted to the rod with cast epoxy as shown in (c).

\subsection{Specimen preparation}

\subsubsection{Incorporation of rigid sleeves/ end caps}

As mentioned above, the use of rigid sleeves in the entire U-frame setup was driven by the concept of specimen drop-in and the requirement of pure bending. In the latter, the rod needs to 
be free of axial force, for which the linear bearing has been shown to be the best solution. Assembling rigid sleeves to spent fuel rods plays a critical role in overall project because it is the first step of testing.

Several assembling methods were studied in this project.

1) Press-fitting: This approach applies to the case when the engineering plastics such, for example, Teflon, serve as the compliant layers. The assembly depends on the misfit between the ID of Teflon tube and the OD of rod and, that between the Teflon tube and the rigid sleeve.

2) Epoxy casting: The approach is suitable for the case when the epoxy is used as a compliant layer material. The assembly depends on the casting and setting.

3) Press-fitting with epoxy casting: This is the combination of the press-fitting and epoxy casting discussed above.

The trials showed that the machining of Teflon tube into the designed dimensions and tolerance is difficult to control. Further examination also indicated that to sandwich the Teflon tube between the rod and rigid sleeves is not easy to carry out in the hot cell. The investigations thus ruled out 1) and 3), and only left 2).

The assembly of rod to rigid sleeves could be achieved by dipping the ends of the fuel rod into a cup of epoxy, inserting the rod into the rigid sleeves, and laying the assembly down to a centerline gadget. The concept for epoxy casting was evolved into a self-aligning device through a couple of design cycles. The device was made of two halves with grooves that had matching dimensions to those of rod and the rigid sleeves.

\subsubsection{Mounting end caps to specimen using epoxy}

An advanced mold concept has been proposed and engineered by using a vise as shown in Figure 7. ${ }^{32}$ Two mold halves are integrated into a machine vise. A handle is used to facilitate the detachment of fuel rod through rotating to drive the halves apart. The base of the vise is mounted to a frame and can be rotated as required.

The procedure of assembling two rigid sleeves involves the following steps: 1 ) rotate the vise mold upright; 2) place the rod into the mold; 3) cast the predetermined amount of epoxy into the inside of rigid sleeve; 4) insert the rigid sleeve loaded with fresh epoxy into the lower chamber; 5) re-oriented the vise mold to set the second chamber in the lower end; 6) repeat steps 3) and 4) to mount the second rigid sleeve; 7) when hardening time of epoxy reaches, release the rod assembly from the mold using the handle.

The vise mold and epoxy casting procedure developed in the out-of-cell study have been modified for final hot cell testing as will be discussed in the following. 


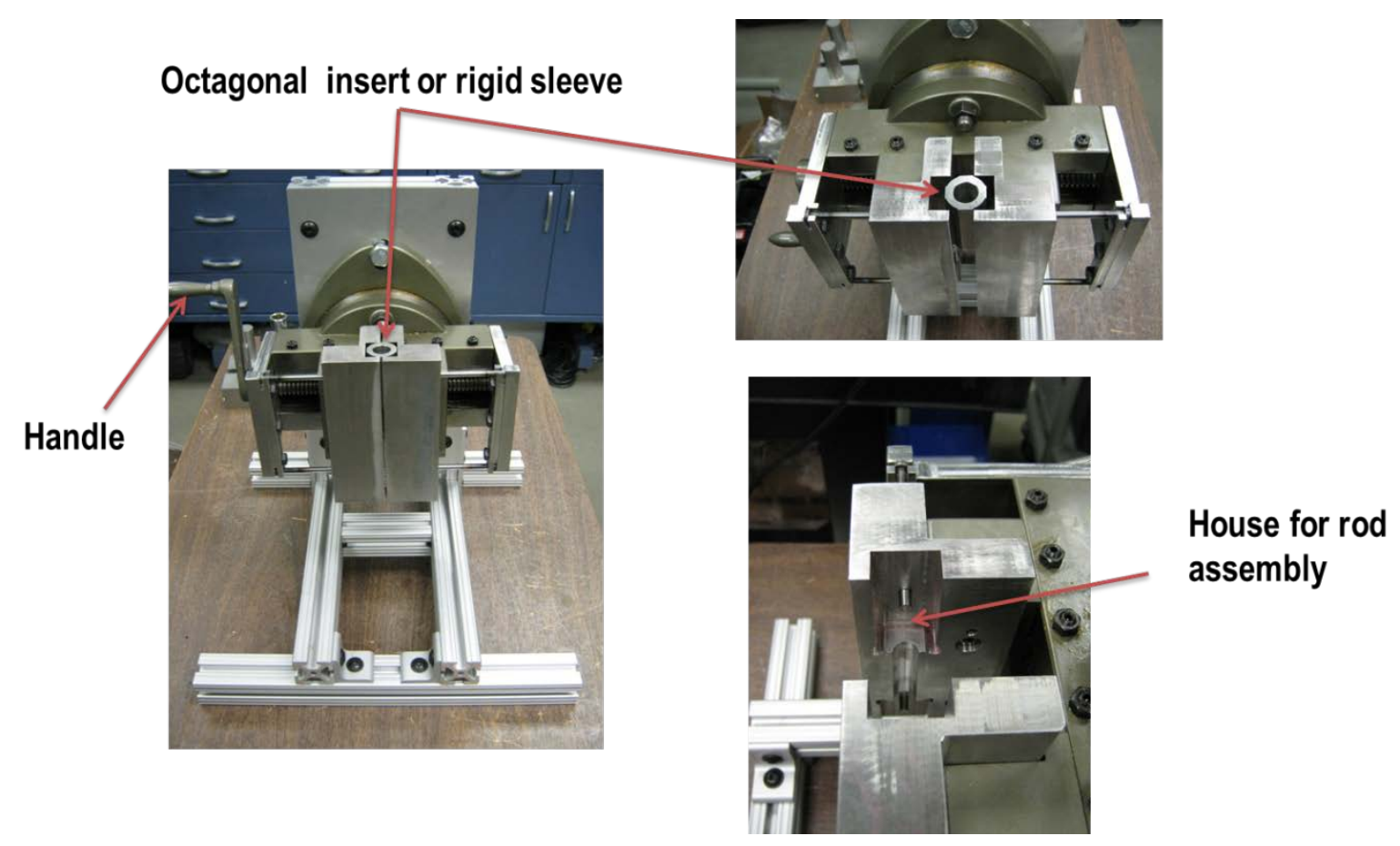

Figure 7 Vise mold for assembling octagonal rigid sleeves into a rod.

\subsection{Measurement of mechanical deformation of SNF rods}

\subsubsection{Selection of robust sensors for hot cell testing}

Under an input load, instrumentation must accurately measure the deflection of the rod being bent. Non-contact measurement methods including laser vibrometry and digital image correlation (DIC) were examined but were not found to be feasible because of the restrictions that these methods impose. For example, the effect of the hot-cell window on the laser beam is unknown should the laser vibrometer be used. Second, speckles of paint are usually needed in DIC on the surface of the fuel rod to track displacement, and uncertainty exists as the surface of a spent fuel rod may be damaged during the test. Among the contact methods, strain gages require dedicated mounting procedures, and the rough surface of spent fuel prevents, in fact, an effective mounting.

Both LVCs (linear variable capacitors) and LVDTs (linear variable differential transducers) were evaluated as final candidates for deformation measurement in hot-cell. ${ }^{23,24}$ LVCs were tested in the earlier stage of the project for calibrating the setup, but LVDTs were finally chosen because they have been demonstrated to work in hot cell environment. With the built-in spring, the probe 
or armature of LVDTs can maintain contact with the surface to be measured. To avoid wobbling of the probe around the cylindrical rod, a disk-shaped flat head is used.

\subsubsection{Three-point rod displacement measurement using LVDTs}

With the presence of the compliant material, how will the deformation of the rod be measured? Theoretically, the bending radius $\mathrm{R}$ and maximum strain $\varepsilon_{\max }$ of a rod can be estimated on the basis of the displacement at the loading end of the rigid arm. The displacement measured, however, contains the contribution of the compliant layers, depending on the materials used in the compliant layers and the level of loading.

To address this issue, Bjorkman proposed a three-point measurement method to evaluate the curvature of a bending rod. ${ }^{33}$ The three-point measurement was implemented in this study through the following approach. ${ }^{23,24}$ 1) Three LVDTs were used to capture the deflection of the rod. 2) A clamping mechanism integrated three $C$ clamps with alternating openings to accommodate three sensors. 3) The sensor clamp was mounted on the side connecting plates of the U-frame to eliminate any unwanted rigid-body motion. A three-point measurement setup on the MTS 810 is illustrated in Figure 8. A series of static tests were performed by using a surrogate rod composed of SS tube only was used. Octagonal rigid sleeves were integrated to the SS tube (ID $9.525 \mathrm{~mm}$, OD $11.07 \mathrm{~mm}$, and length $152.4 \mathrm{~mm}$ ) by use of epoxy. The tests were conducted on the MTS servo-hydraulic machine 810 using $101.6 \mathrm{~mm}$ U-frame under peaks \pm 180 $\mathrm{N}$ at a rate of $\pm 10 \mathrm{~N} / \mathrm{s}$. The time series are shown in Figure 9 for load, LVDT 1, 2, and 3, converted moment, and calculated curvature. The curvature of rod can be seen clearly as a response of applied moment. The flexural rigidity obtained by using the three-LVDT method has been shown to correspond well to that calculated based on given inertia moment and Young's modulus for various materials. ${ }^{24}$

It has been realized that the use of the disk-shaped probes introduces the error in deducing curvature of a bending rod based on three-point measurement. This is because sensor spacing $h$ is affected by the relative position of sensors to the curvature. The $h$ will be decreased when the rod is bent towards the sensors, and increased when it is bent away from the sensors. The degree of changes of sensor spacing remains unknown. 


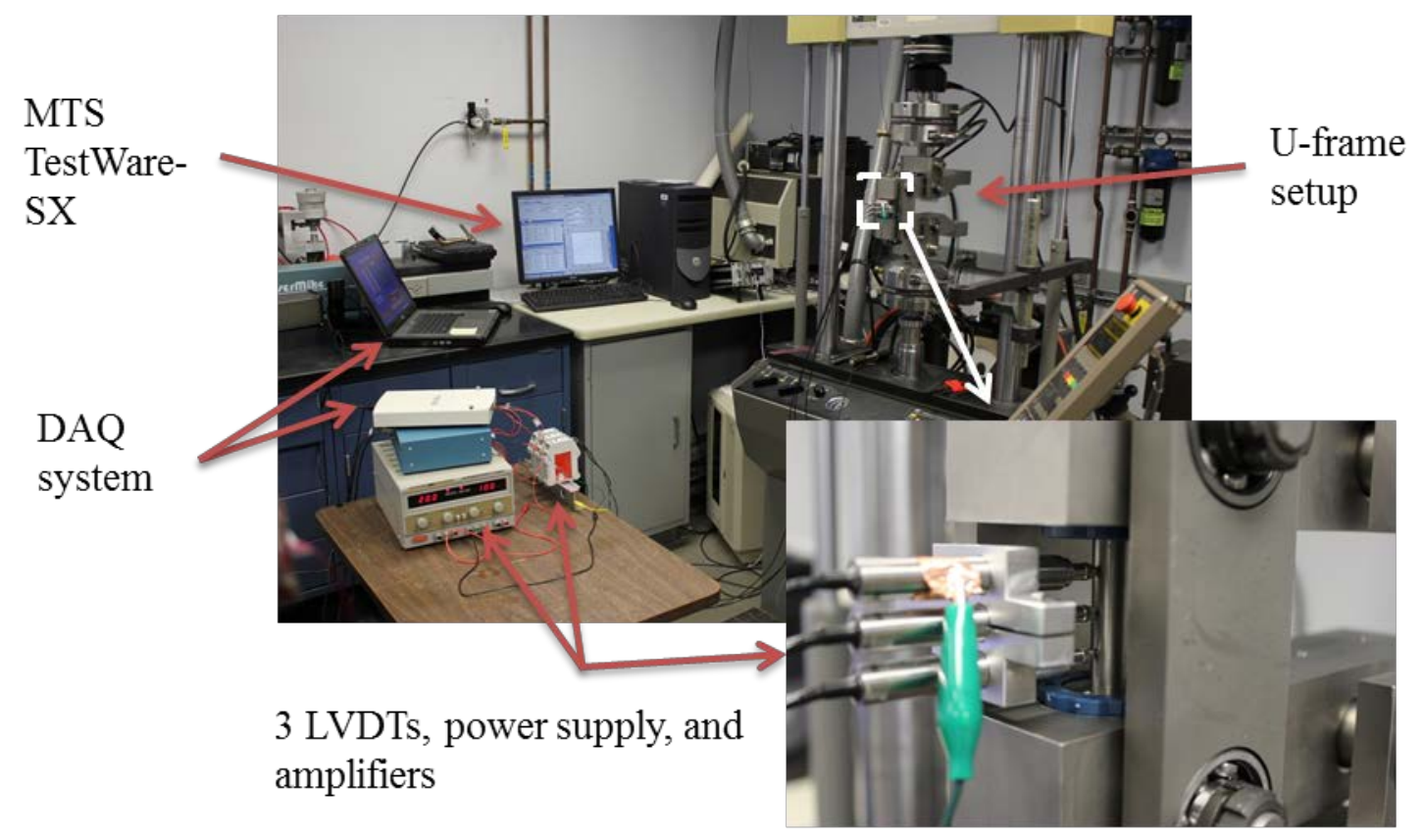

Figure 8 Demonstration of the three-point measurement method using three LVDTs. The Uframe setup is equipped with LBBs and integrated on a MTS 810 servo-hydraulic testing machine.

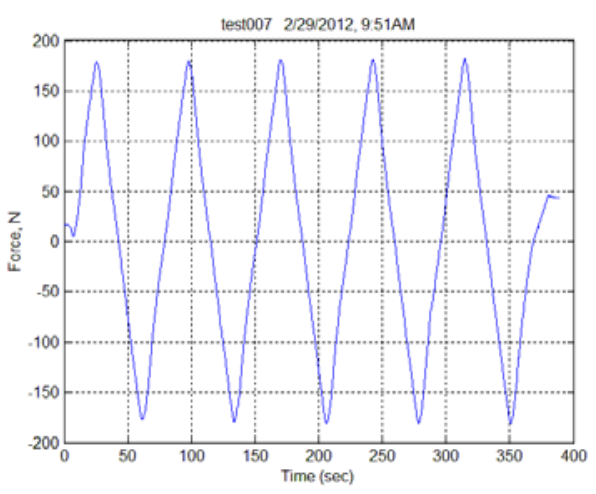

(a)

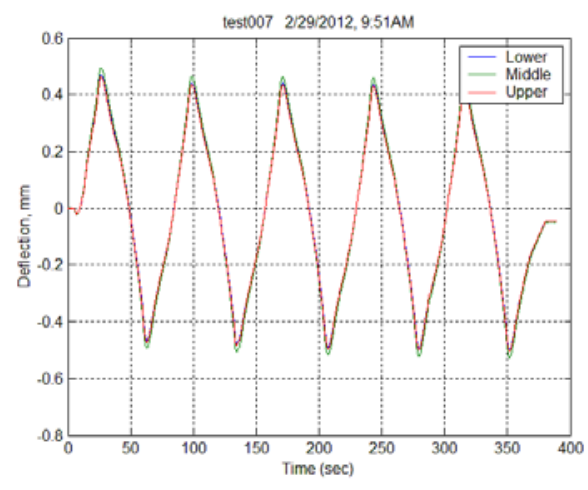

(b) 


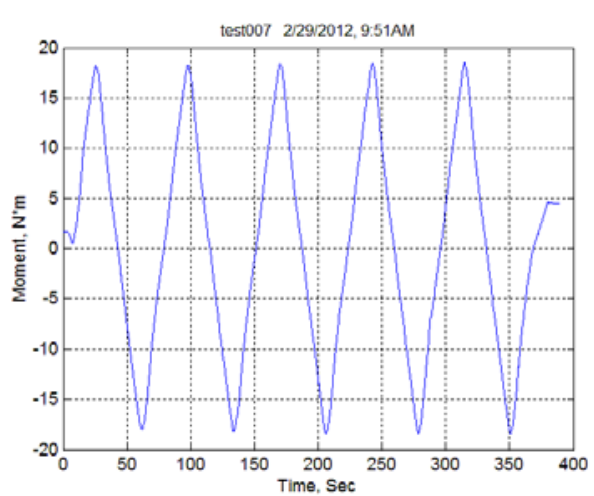

(c)

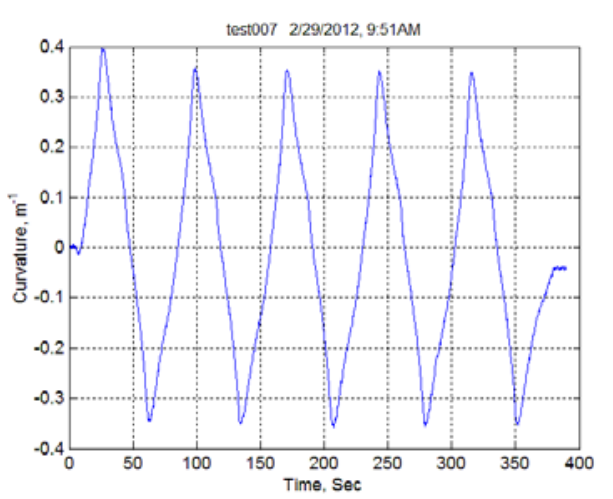

(d)

Figure 9 Time series for (a) load, (b) LVDT1, 2, and 3, (c) converted moment, and (d) calculated curvature. A surrogate rod composed of SS tube only was used. Octagonal rigid sleeves were integrated to the SS tube (ID $9.525 \mathrm{~mm}$, OD $11.07 \mathrm{~mm}$, and length $152.4 \mathrm{~mm}$ ) by use of epoxy. The tests were conducted on the MTS servo-hydraulic machine 810 using $101.6 \mathrm{~mm}$ U-frame under peaks $\pm 180 \mathrm{~N}$ at a rate of $\pm 10 \mathrm{~N} / \mathrm{s}$.

\subsection{Testing machine and integration of ORNL testing setup}

\subsubsection{Selection of Bose dual linear motors testing bench}

Hydraulic servo testing systems were considered as one of candidates in the earlier stages of this project because of the long history in materials mechanical testing. However, several issues have been found that appear to be critical to the application in hot cell. Particularly, the hydraulic components used in the system are susceptible to radiation-induced degradation. Oil leakage due to aging of the components can be problematic in a hot cell. In addition, the standard systems are generally bulky and costly.

Electromechanical test systems, on the other hand, rely on a cylindrical electrical stator and rotor as driving mechanism. The screw and nut have to be coupled to convert the rotation of motor into linear motion. The linear motion is employed to load the specimen under test. The major problem with this category of systems is the intensive wear related to the mechanical contact between the screw and nut. Thus, electromechanical test machines cannot deliver the required performance for the high cycle fatigue test in high frequency.

Linear motors use magnetic force as a drive mechanism for linear motion without any conversion system. So, no contact wear exists as encountered in an electromechanical test system. At the same time, the linear motor is oil-free; it avoids the concerns related to hydraulic servo system. It can be seen that the magnetic force-based linear motors meet the requirements of testing in hot cell environment. Nowadays, commercial universal testing machines based on linear motors include Bose ElelctroForce systems and Instron ElectroPuls systems. 
In the Bose ElectroForce series, the magnet is arranged between the poles of magnetic fields and is supported by the flexures. The coupling between the magnet and magnetic field provides the original driving force to the magnet. Two versions of linear motor-based test machines fall in our target range: ElectroForce 3510 and 3520. Both are equipped with same rating of linear motor, $\pm 7500 \mathrm{~N}$ maximum force and $\pm 25 \mathrm{~mm}$ maximum displacement. However, the linear motor is installed in different position: the cross head in 3510 and the base in 3520. Performance curves for the ElectroForce 3510 are given in Figure 10. Under force amplitude $\pm 1875 \mathrm{~N}$, the ElectroForce 3510 can output a dynamic displacement (peak to peak) of $\pm 25 \mathrm{~mm}$ at $0.1 \mathrm{~Hz}$, and $\pm 6.3 \mathrm{~mm}$ at $20 \mathrm{~Hz}$. The overall size of $3510 / 3520$ is larger than that of the hot cell door at ORNL. The concepts proposed by Bose to modify the ElectroForce 3520 include removing the column and cross head and building a base with a T- slot to mount the test frame on the top.

Dual motor systems have been shown to be a good option in the application where the stroke required exceeds the capability of a single motor but the force requirement is still within the single motor's capacity. For example, one LM2 can only output $\pm 12.5 \mathrm{~mm}$ stroke, but the $\pm 3000 \mathrm{~N}$ force of the motor is still within desired range. Use of a dual LM2 system can output $\pm 25 \mathrm{~mm}$ stroke compensating such shortage, which is actually equivalent to that of 3510/ 3520 . The small motors have an appealing feature on cooling as it can be readily accomplished by open air. On the other hand, the cooling for large motors calls for more involved systems such as liquid cooling. The introduction of liquid offsets the advantage of using liner electromagnet motors in a hot cell environment.

In the Instron ElectroPuls system, the system involves a magnet tube driven by the surrounding magnetic field. The tube is coupled with external loading rod through a plate on the right end. Instron has several ElectroPuls systems available on the market. Among them, ElectroPuls E3000 has the capacity comparable to the Bose dual system: $\pm 3000 \mathrm{~N}$ dynamic load capacity and $\pm 30 \mathrm{~mm}$ displacement. Under amplitude of $\pm 1800 \mathrm{~N}$, the E3000 can output $\pm 30 \mathrm{~mm}$ at $1 \mathrm{~Hz}$, and $\pm 5 \mathrm{~mm}$ at $20 \mathrm{~Hz}$. The height of E3000 can be adjusted to 1,287mm (4.22”), which is within the door size of the hot-cell.

Based on the review, it can be seen that three categories of commercial test systems have their own unique features. In terms of testing spent fuel rods in a hot cell, the following conclusions can be drawn.

- Hydraulic testing systems are well established. The use of fluid as a transfer medium is a major concern. Hydraulic components, especially pipes and valves, are susceptible to radiation-induced degradation. Oil leakage due to aging of the system can be troublesome.

- Electromechanical testing systems are also well established. Due to the use of screws and nuts in converting rotation of DC or AC motors into linear motion, the systems are subjected to severe wear in reciprocal movement. The working frequency of electromechanical system is significantly limited. 
- Magnetic force is used in linear motor systems to drive a permanent magnet mover. The mover acts directly on the loading rod in the testing system. No converting mechanism is involved. The test system is reliable and robust in the high cycle fatigue testing.

The specifications of both Bose and Instron test systems are summarized in Table 4.

As will be discussed below, a dual Bose linear motor approach meets the requirements on setup layout and the symmetrical loading requirement and has been selected to pursue in this project.

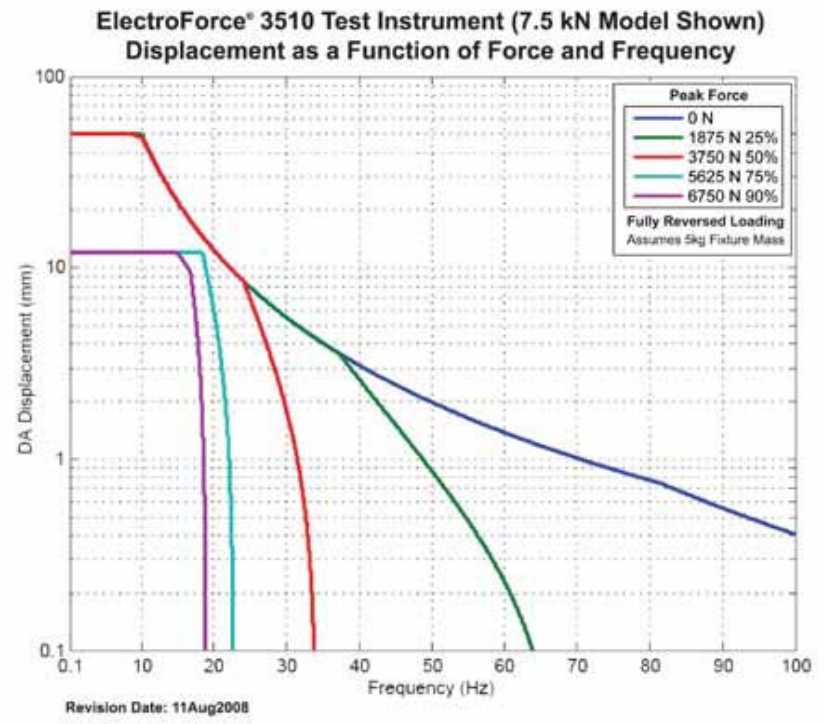

Figure 10 Performance curves of Bose ElectroForce 3510.

Table 4 Specifications of linear motor testing system

\begin{tabular}{|l|l|l|}
\hline Items & Parameters & Range \\
\hline $\begin{array}{l}\text { ElectroForce } \\
\text { 3510/3520 (Bose) }\end{array}$ & Frequency (Hz) & $0-50$ \\
\hline & Force amplitude (N) & $\pm 7,500$ \\
\hline & Displacement, static (mm) & \pm 25 \\
\hline & Displacement under $\pm 1,875 N, 20 H z(m m)$ & \pm 6.35 \\
\hline $\begin{array}{l}\text { Dual motor } \\
\text { (Bose) }\end{array}$ & Frequency (Hz) & $0-100$ \\
\hline & Force amplitude (N) & $\pm 3,000$ \\
\hline
\end{tabular}




\begin{tabular}{|l|l|l}
\hline & Displacement, static (mm) & \pm 25 \\
\hline $\begin{array}{l}\text { ElectroPuls } \\
\text { E3000 (Instron) }\end{array}$ & Frequency (Hz) & $0-100$ \\
\hline & Force (N) & $\pm 3,000$ \\
\hline & Displacement, static (mm) & \pm 30 \\
\hline & Displacement under $\pm 1,800 \mathrm{~N}, 20 \mathrm{~Hz}(\mathrm{~mm})$ & \pm 5.00
\end{tabular}

\subsubsection{Design of U-frame integration}

A horizontal layout of testing setup with two linear motors as shown in Figure 11 is recommended for universal testing. ${ }^{32}$

- Two LM2 motors are used to load the rigid arms symmetrically from both sides.

- Performance: $\pm 25 \mathrm{~mm}, \pm 3000 \mathrm{~N}$ at $0.1 \mathrm{~Hz}$; working frequency $0.1-100 \mathrm{~Hz}$; air cooling.

- U-frame setup is laid horizontally and integrated to Bose test bench.

The proposed integration of U-frame to Bose test bench addresses the issues related to driving mode and performance of U-frame as discussed above.

- The horizontal layout eliminates the self-weight effect on rod specimen bending. Counterweights used in vertical setup of U-fame can be removed, and thus the size of the rigid arms can be reduced. Dynamic performance of the setup can be improved attributed to the reduced inertial effects.

- The dual motors provide a symmetrical loading at from both sides through synchronizing the movement of magnet. Furthermore, such arrangement eliminates the effect of the single-side loading on the deformation of rod. The Bose bench design can be used asreceived without any modification.

\subsubsection{Implementation of $U$-frame integration}

Necessary modifications were made to the U-frame setup to accommodate the requirements from horizontal layout. Particularly, tapered roller bearings are substituted for ball bearings within all the hinges of U-frame and additional thrust bearings introduced to the hinges of side plate-torigid arms. Through these bearings, the weights from setup components can be readily transferred to the breadboard, while, at the same time, the hinges function as designed.

Integration of U-frame to the Bose dual LM2 TB (test bench) involves the following interfaces. ${ }^{32}$

- The interface of U-frame to Bose breadboard. To ensure the mobility and alignment of Uframe during the reverse bending test, high precision linear bearing (INA LFKL20SF) are used under both the rigid arms and side connection plates. In the case of rigid arms, a 
bracket makes the attachment of the linear bearing to the arms. Three stands are designed to support the linear bearings, on the top of which is attached the rails.

- The interface of U-frame to Bose load cells. Two turnbuckles are used to link the Uframe to load cells. The original Y-shaped linkage is modified into a U-shaped one.

The interface components were fabricated and assembled on Bose dual LM2 TB based on the design in Figure 11. The offset of INA linear bearings from the upfront U-shaped linkage results in an eccentric loading to the bearing sets themselves. The bending from the eccentric loading would accelerate the wear of wheel rollers within the linear bearings. Subsequently, the two rear stands have been moved underneath the U-shaped linkage.

It has been found out, later on, the wear of wheel rollers was substantial, even though the loading condition of bearings had been improved with the shifted supports. A cartridge embedded with THK linear roller bearings was then evaluated. The cartridges are fixed on the top of two supports to replace the wheel-rail contact pairs. The new interface design apparently enables more efficient sliding and transferring of the load due to the multiple surface-to-line contacts obtained with linear roller bearings. The U-frame setup integrated to Bose dual LM2 test bench with all the modifications realized is shown in Figure 12.

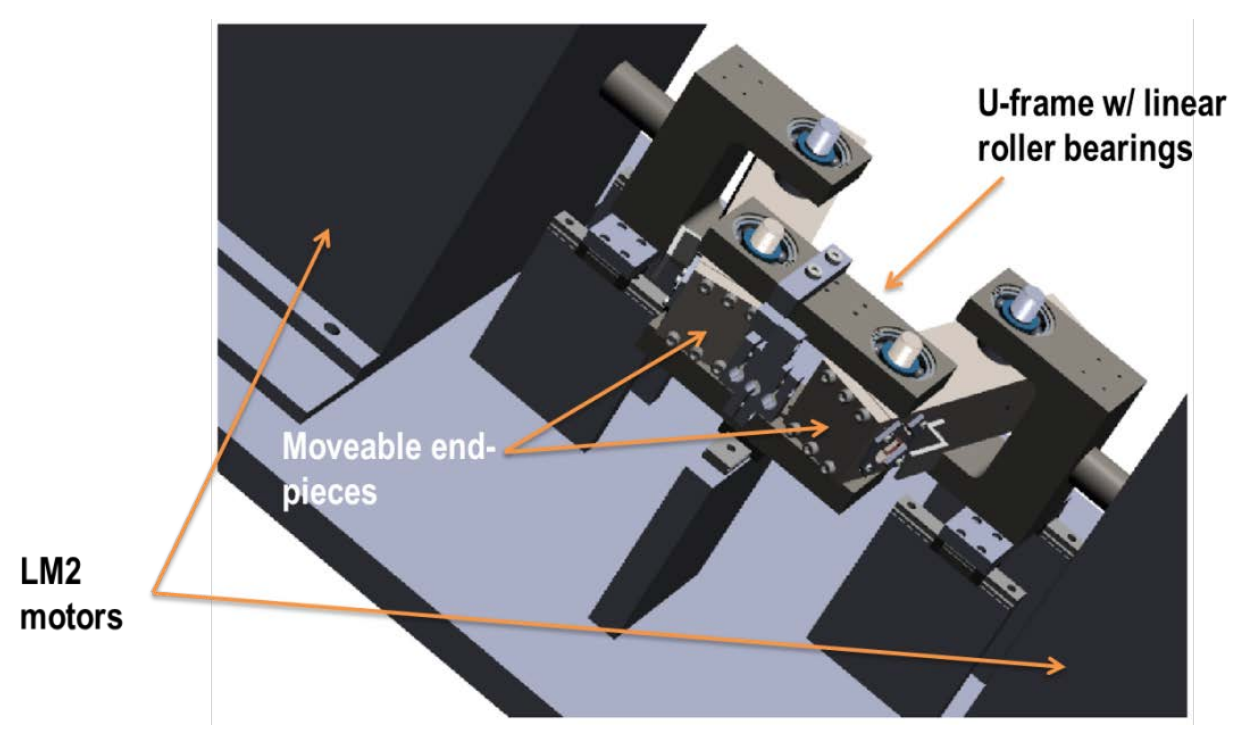

Figure 11 ORNL's recommendation for two linear motors in a horizontal plane. 


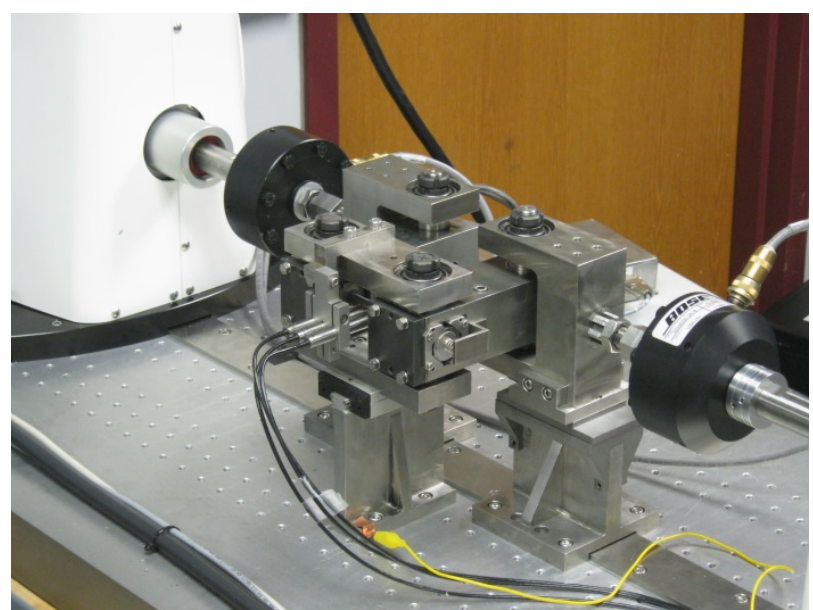

(a)

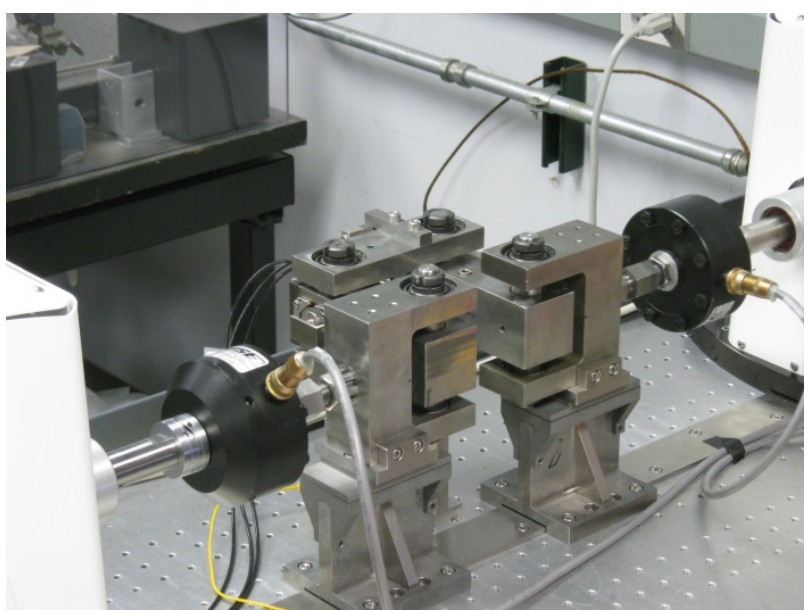

(b)

Figure 12 ORNL U-frame setup integrated into Bose dual LM2 test bench. (a) Frontal view. (b) Back view.

\subsection{Instrumentation for hot cell testing}

\subsubsection{Special requirements}

The initial examination of Bose system showed that several important issues needed to be addressed before the system can be delivered to hot cell.

- A central panel is needed to integrate the power cables and transducer wires to facilitate the assembly of system in hot cell.

- A shield plate is needed to set up near each of the interfaces between the specimen section of spent fuel rod and the power heads of Bose machine.

- Plastic components in as-received Bose system need to be replaced for hot cell delivery.

\subsubsection{Central panel and cable modification}

A meeting in November 2012 with I\&C group occurred to discuss the integration of cables and wires into a center panel. The panel (Figure 13) integrates the power cables from axial motors 1 \& 2, and wires from displacement transducers 1 and 2, load cells 1 and 2, auxiliary 1 and 2, and rod curvature measurement LVDTs 1,2 , and 3. The cables and wires coming out of central panel shall be at least 15 feet long, passing through an alpha plug to the power modules and amplifiers outside of the hot cell. ${ }^{34}$

The design in February 2012 for the central panel consists of two connectors for two power heads, one for the Bose LVDTs and auxiliaries, and one for the Bose load cells and ORNL LVDTs. A number of problems were encountered in the modification of Bose cables. Particularly, a high-pitch noise came out of motor 1 in several circumstances: a) system was set 
to run under a displacement control without a specimen installed; b) motor powers were turned on after an emergent stop; c) TuneIQ was finished under displacement control for either linear motor 1 or linear motor 2 (after WinTest 7 was restarted and motor powers were turned on).

The troubleshooting on the cable noises of testing system demonstrated that the central panel needs to be re-designed to have an improved shielding and grounding of electric connectors. A new central panel was fabricated in March 2012. The new panel uses a self-aligning mechanism to facilitate the assembly of the panel components in hot-cell and is shown to be easily to handle in assembling and disassembling (Figure 14).

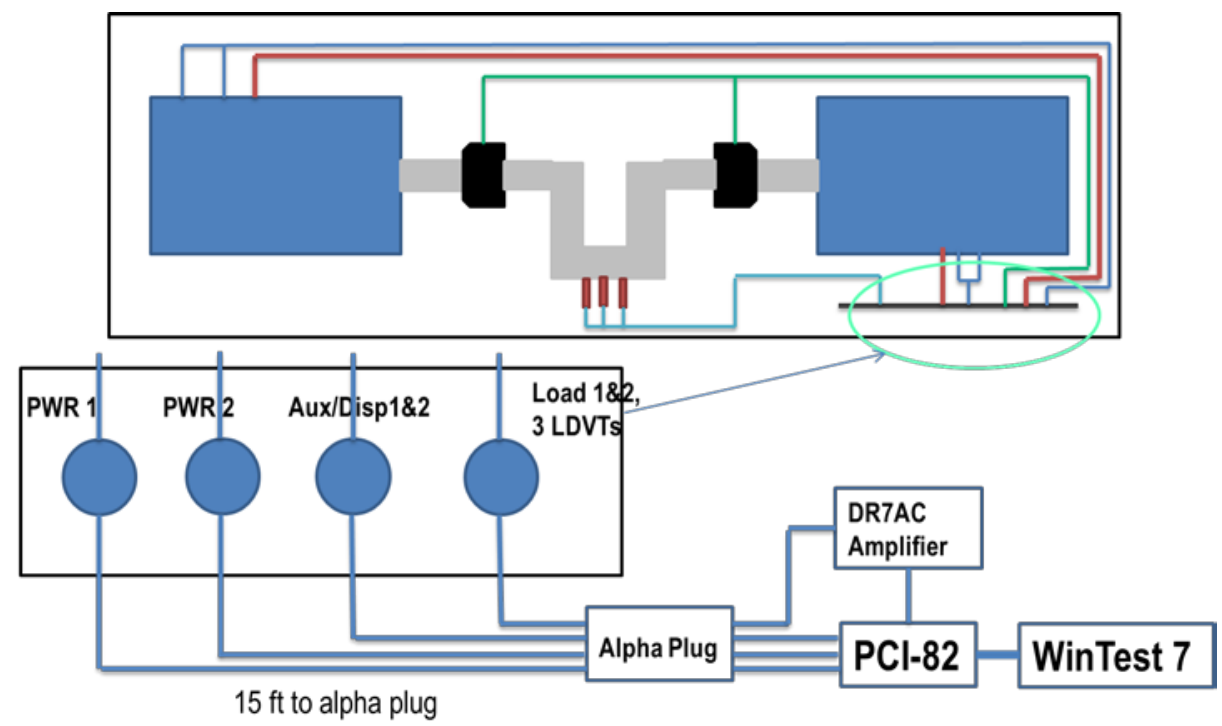

Figure 13 Concept of central panel for bending fatigue testing system 


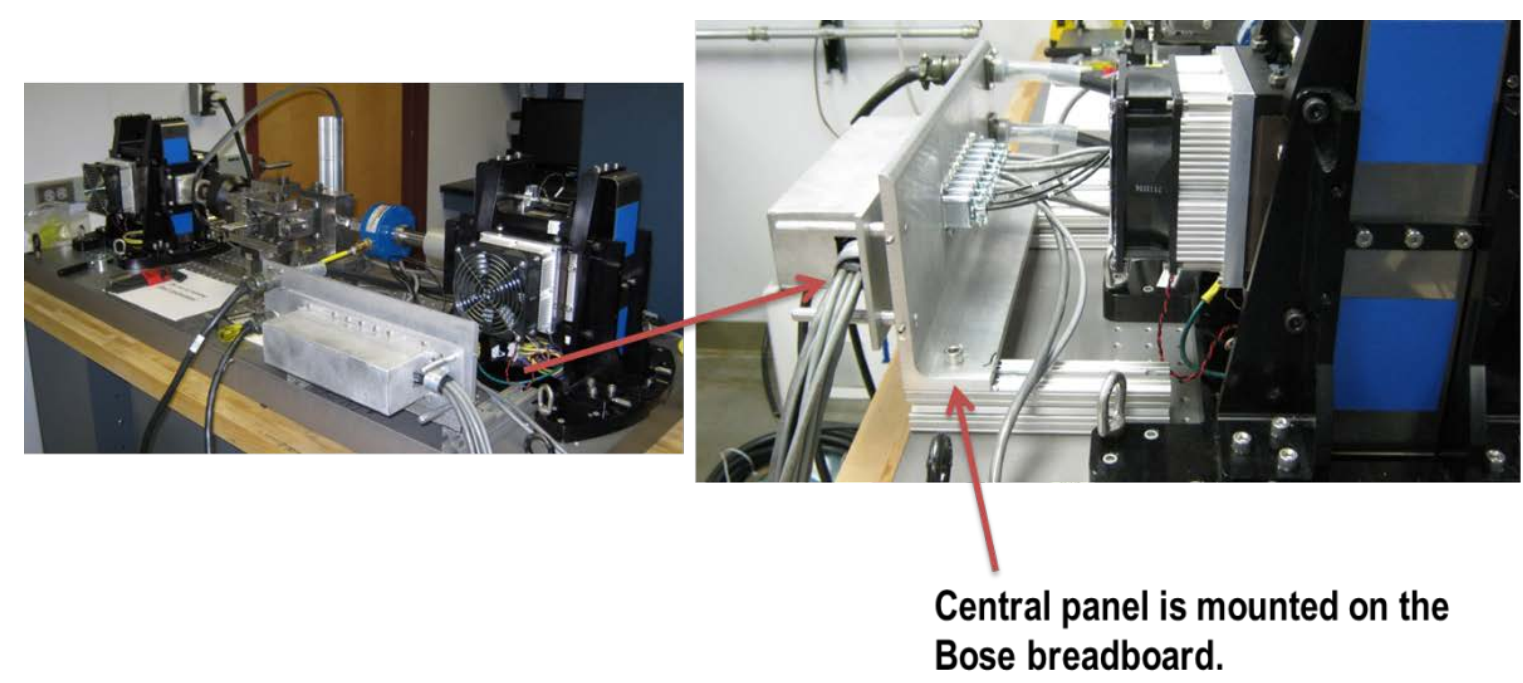

Figure 14 Central panel mounted to the Bose breadboard.

\subsubsection{Integration of RDP LVDTs}

The calibration of three RDP LVDTs (D5/200AG-337, 100M Rads, $\pm 5 \mathrm{~mm}$ ) ${ }^{35}$ for the curvature measurement of the spent fuel rod was completed in May 2012. A separate power module was used to power the RDP amplifier (DR7AC) ${ }^{36}$ because the Bose PCI controller couldn’t provide the sufficient electric current as required.

A couple of problems were encountered when incorporating the RDP LDTVs into Bose system.

1) The mounting of three LVDTs into the sensor clamp introduced a significant amount of oscillatory noises. The re-wiring based on the manufacturer controls the noise has been under control to a certain extent but not completely eliminated. The evaluation on the effect of the noise is ongoing.

2) The calibration also indicated that both the WinTest meters and readouts of PCI controller didn't give a linear response to the input for RDP LVDTs. The wires of connectors to PCI were investigated and modified as necessarily according to the Reference Manual (2012). ${ }^{37}$

\subsubsection{Upgrade of Bose LVDTs and load cells}

The examination of testing setup showed that the shielding design of instruments in hot cell testing using lead plates is not feasible. This is because the shielding plates block the operation of manipulators.

The removal of the shielding plates exposes the transducers to the radiation from the spent fuel rod. The LVDTs and load cells in the Bose machine should, therefore, be able to withstand the radiation. The MHR500 $\mathrm{LVDTs}^{38}$ with 10M radiation resistance were selected to replace existing LVDTs. At the same time, the existing load cells have a limited resistant capability 
against the radiation. As result, the Model 47 type Honeywell load cells with a steel case material were selected to replace the Bose load cells. ${ }^{39}$ Both rad-hardened LVDTs and load cells were received in earlier August 2013, and integrated into the Bose testing system thereafter. 


\section{Demonstration of test equipment using surrogate rods}

\subsection{Static testing results}

Surrogate rod made of SS (stainless steel) tube and alumina pellets are used extensively in the out-of-cell development of fatigue testing system. In this report, the surrogate rod specimens are labeled as SSAPxx (SS tube + Alumina pellet) and last two digits xx correspond to the specimen number. A summary of verification tests by using SSAP rods is given in Table $5 .{ }^{34}$

Three static tests of SSAP surrogate rods were conducted as a part of the proof of methodology test plan. The displacement control with rate $0.2 \mathrm{~mm} / \mathrm{s}$ at the loading points was used. The maximum relative displacement was $16 \mathrm{~mm}$ for the first test and $20 \mathrm{~mm}$ for other two. The latter reached $79 \%$ of the displacement capacity of the system.

Generally, the results are repeatable as seen in Figure 15. The initial linear range was quite short as expected. It has been shown from the moment-curvature relation that the apparent yielding range is located between 20 to $35 \mathrm{~N}^{*} \mathrm{~m}$. At the same time, the local fluctuations were also observed on the moment-curvature curve, but they could hardly be related to any micro process within the rod. 
Table 5 Summary of verification tests using surrogate rods*

\begin{tabular}{|c|c|c|c|c|c|c|c|c|}
\hline Date & No & Mach & Mode & $\begin{array}{l}\mathrm{mm} \\
\mathrm{N}^{* *}\end{array}$ & $\mathrm{~Hz}$ & $\mathrm{~N} / \mathrm{N}_{\mathrm{f}}$ & Note & Rigid sleeve, C/P epoxy bonding \\
\hline $\begin{array}{l}4 / 3,4 / 20- \\
21 / 2012\end{array}$ & 1 & MTS & Сyc, disp & 4 & 2 & $1.25 \mathrm{E}+05$ & fractured & $\begin{array}{l}\text { octagonal, teflon strips, no } \\
\text { bonding }\end{array}$ \\
\hline $4 / 24 / 2012$ & 2 & MTS & Сус, disp & 4 & 2 & $2.62 \mathrm{E}+04$ & fractured & $\begin{array}{l}\text { octagonal, teflon strips, no } \\
\text { bonding }\end{array}$ \\
\hline $\begin{array}{l}\text { 6/11- } \\
6 / 26 / 2012\end{array}$ & 3 & MTS & Сус, disp & 1 & 2 & $2.00 \mathrm{E}+06$ & no fracture & $\begin{array}{l}\text { octagonal, w/o teflon strip, } \\
\text { bonded }\end{array}$ \\
\hline $\begin{array}{l}6 / 28- \\
29 / 2012\end{array}$ & 4 & MTS & Сyc, disp & 2.5 & 2 & $7.25 \mathrm{E}+04$ & fractured & $\begin{array}{l}\text { octagonal, w/o teflon strip, } \\
\text { bonded }\end{array}$ \\
\hline 7/3- 4/2012 & 5 & MTS & Cyc, disp & 3 & 2 & $3.70 \mathrm{E}+04$ & $\begin{array}{l}\text { fractured into } \\
\text { halves }\end{array}$ & $\begin{array}{l}\text { octagonal, w/o teflon strip, } \\
\text { bonded }\end{array}$ \\
\hline 7/9/2012 & 6 & MTS & Сус, disp & 3.5 & 2 & $2.35 \mathrm{E}+03$ & $\begin{array}{l}\text { fractured into } \\
\text { halves }\end{array}$ & $\begin{array}{l}\text { octagonal, w/o teflon strip, } \\
\text { bonded }\end{array}$ \\
\hline $\begin{array}{l}\text { 7/12- 19; } \\
\text { 8/14- } \\
\text { 21/2012 }\end{array}$ & 7 & MTS & Cyc, disp & 2 & 2 & $1.00 \mathrm{E}+06$ & no fracture & $\begin{array}{l}\text { octagonal, w/o teflon strip, } \\
\text { bonded }\end{array}$ \\
\hline 8/28/2012 & 8 & MTS & Сус, disp & 3 & 2 & $1.41 \mathrm{E}+04$ & $\begin{array}{l}\text { fractured to } \\
\text { halves }\end{array}$ & $\begin{array}{l}\text { octagonal, w/o teflon strip, } \\
\text { bonded }\end{array}$ \\
\hline $\begin{array}{l}9 / 19- \\
20 / 2012\end{array}$ & 9 & MTS & Сус, disp & 3 & 2 & $1.78 \mathrm{E}+04$ & $\begin{array}{l}\text { fractured to } \\
\text { halves }\end{array}$ & $\begin{array}{l}\text { octagonal, w/o teflon strip, } \\
\text { bonded }\end{array}$ \\
\hline 9/1/2012 & 10 & Bose & Cal, load & 200 & 5 & $* * *$ & fractured & $\begin{array}{l}\text { octagonal, w/o teflon strip, } \\
\text { bonded }\end{array}$ \\
\hline $\begin{array}{l}9 / 19- \\
28 / 2012\end{array}$ & 11 & Bose & Cyc, load & 200 & 5 & $6.78 \mathrm{E}+05$ & $\begin{array}{l}\text { fractured, } \\
\text { trip at }-4 \mathrm{~mm}\end{array}$ & $\begin{array}{l}\text { octagonal, w/o teflon strip, } \\
\text { bonded }\end{array}$ \\
\hline $\begin{array}{l}10 / 11- \\
15 / 2012\end{array}$ & 12 & Bose & Cyc, load & 200 & 5 & $9.36 \mathrm{E}+05$ & $\begin{array}{l}\text { fractured, } \\
\text { trip at } 4 \mathrm{~mm}\end{array}$ & $\begin{array}{l}\text { octagonal, w/o teflon strip, } \\
\text { bonded }\end{array}$ \\
\hline $\begin{array}{l}10 / 19- \\
28 / 2012\end{array}$ & 13 & Bose & Сус, load & 200 & 5 & $2.60 \mathrm{E}+06$ & no failure & $\begin{array}{l}\text { octagonal, w/o teflon strip, } \\
\text { bonded }\end{array}$ \\
\hline
\end{tabular}




\begin{tabular}{|c|c|c|c|c|c|c|c|c|}
\hline 10/29/2012 & 131 & Bose & Сус, load & 300 & 5 & $3.30 \mathrm{E}+03$ & $\begin{array}{l}\text { fractured, } \\
\text { from No. } 13\end{array}$ & $\begin{array}{l}\text { octagonal, w/o teflon strip, } \\
\text { bonded }\end{array}$ \\
\hline 11/5/2012 & 14 & Bose & Сyc, load & 250 & 5 & $1.48 E+04$ & $\begin{array}{l}\text { fractured, } \\
\text { trip at }-4 \mathrm{~mm}\end{array}$ & $\begin{array}{l}\text { octagonal, w/o teflon strip, } \\
\text { bonded }\end{array}$ \\
\hline 11/6/2012 & 71 & Bose & Суc, load & 250 & 5 & $2.58 \mathrm{E}+04$ & $\begin{array}{l}\text { fractured, } \\
\text { from No. } 7\end{array}$ & $\begin{array}{l}\text { octagonal, w/o teflon strip, } \\
\text { bonded }\end{array}$ \\
\hline $11 / 28 / 2012$ & 15 & Bose & Сус, load & 250 & 5 & $8.00 \mathrm{E}+03$ & $\begin{array}{l}\text { fractured, } \\
\text { trip at }-4 \mathrm{~mm}\end{array}$ & $\begin{array}{l}\text { octagonal, w/o teflon strip, } \\
\text { bonded }\end{array}$ \\
\hline 11/30/2012 & 16 & Bose & Сyc, load & 300 & 5 & $2.50 \mathrm{E}+03$ & $\begin{array}{l}\text { fractured, } \\
\text { trip at }(+/-) \\
4 \mathrm{~mm}\end{array}$ & $\begin{array}{l}\text { octagonal, w/o teflon strip, } \\
\text { bonded }\end{array}$ \\
\hline 12/3/2012 & 17 & Bose & Сус, load & 300 & 5 & $1.79 \mathrm{E}+03$ & $\begin{array}{l}\text { broken to } \\
\text { halves, demo } \\
\text { for NRC }\end{array}$ & $\begin{array}{l}\text { octagonal, w/o teflon strip, } \\
\text { bonded }\end{array}$ \\
\hline 12/13/2012 & 18 & Bose & Mon, disp & 16 & 0.2 & $1.00 \mathrm{E}+00$ & & $\begin{array}{l}\text { octagonal, w/o teflon strip, } \\
\text { bonded }\end{array}$ \\
\hline $12 / 14 / 2012$ & 19 & Bose & Mon, disp & 20 & 0.2 & $1.00 \mathrm{E}+00$ & & $\begin{array}{l}\text { octagonal, w/o teflon strip, } \\
\text { bonded }\end{array}$ \\
\hline 12/17/2012 & 20 & Bose & Mon, disp & 20 & 0.2 & $1.00 \mathrm{E}+00$ & & $\begin{array}{l}\text { octagonal, w/o teflon strip, } \\
\text { bonded }\end{array}$ \\
\hline $\begin{array}{l}12 / 19- \\
1 / 6 / 2013\end{array}$ & 21 & Bose & Сyc, load & 200 & 5 & $4.20 \mathrm{E}+06$ & no failure & $\begin{array}{l}\text { octagonal, w/ graphene strip, } \\
\text { bonded }\end{array}$ \\
\hline $1 / 7 / 2013$ & 23 & Bose & Суc, load & 250 & 5 & $1.96 \mathrm{E}+04$ & $\begin{array}{l}\text { fractured, } \\
\text { trip at } 4 \mathrm{~mm}\end{array}$ & $\begin{array}{l}\text { octagonal, w/o teflon strip, } \\
\text { bonded }\end{array}$ \\
\hline 1/7/2013 & 24 & Bose & Сус, load & 300 & 5 & $2.95 E+03$ & $\begin{array}{l}\text { fractured } \\
\text { near r.s., trip } \\
\text { at } 4 \mathrm{~mm}\end{array}$ & $\begin{array}{l}\text { octagonal, w/o teflon strip, } \\
\text { bonded }\end{array}$ \\
\hline $1 / 8 / 2013$ & 25 & Bose & Сyc, load & 300 & 5 & $8.56 \mathrm{E}+02$ & trip at $-4 \mathrm{~mm}$ & $\begin{array}{l}\text { irradiated, octagonal, w/o teflon } \\
\text { strip, bonded }\end{array}$ \\
\hline $\begin{array}{l}1 / 8- \\
3 / 18 / 2013\end{array}$ & 26 & Bose & Cyc, load & 200 & 5 & $8.50 \mathrm{E}+06$ & $\begin{array}{l}\text { fractured, } \\
\text { trip at } 4 \mathrm{~mm}\end{array}$ & $\begin{array}{l}\text { octagonal, w/o teflon strip, } \\
\text { bonded }\end{array}$ \\
\hline $1 / 29 / 2013$ & 27 & Bose & Cyc, load & 300 & 5 & $2.20 \mathrm{E}+03$ & $\begin{array}{l}\text { broke into } \\
\text { halves }\end{array}$ & $\begin{array}{l}\text { irradiated, octagonal, w/o teflon } \\
\text { strip, bonded }\end{array}$ \\
\hline
\end{tabular}




\begin{tabular}{|l|l|l|l|l|l|l|l|l|}
\hline $2 / 14 / 2013$ & 28 & MTS & Cyc, load & 250 & 2 & $2.85 \mathrm{E}+04$ & $\begin{array}{l}\text { distorted, } \\
\text { z0=58.76, } \\
\text { trip at 70 }\end{array}$ & $\begin{array}{l}\text { octagonal, w/o teflon strip, } \\
\text { bonded }\end{array}$ \\
\hline $2 / 18 / 2013$ & 29 & MTS & Cyc, load & 250 & 2 & $2.10 \mathrm{E}+04$ & $\begin{array}{l}\text { fractured, } \\
\text { z0=58.76, } \\
\text { trip at 50 }\end{array}$ & $\begin{array}{l}\text { octagonal, w/o teflon strip, } \\
\text { bonded }\end{array}$ \\
\hline $2 / 20 / 2013$ & 30 & MTS & Cyc, load & 250 & 2 & $4.85 \mathrm{E}+04$ & $\begin{array}{l}\text { fractured, } \\
\text { z0=58.76, } \\
\text { trip at 70 }\end{array}$ & $\begin{array}{l}\text { octagonal 440C w/o teflon strip, } \\
\text { bonded }\end{array}$ \\
\hline $2 / 21 / 2013$ & 31 & MTS & Cyc, load & 300 & 2 & $2.25 \mathrm{E}+03$ & $\begin{array}{l}\text { fractured, } \\
\text { trip at 50.8 }\end{array}$ & octagonal, w/o teflon strip, \\
bonded
\end{tabular}

* Surrogate rods have a length of 6" and are made of SS tube (ID $0.382 "$ or 9.70mm, OD 0.436" or 11.07mm) and ten alumina pellets ( $\phi 0.375$ ” or $9.525 \mathrm{~mm}$, and length of 0.598 ” or $15.2 \mathrm{~mm})$.

** +/- amplitude for cycle tests; peak value for monotonic tests; mm is for displacement control and $\mathrm{N}$ is for load control.

*** SSAP10 was used in the calibration of Bose system and no cycle number was tracked. 

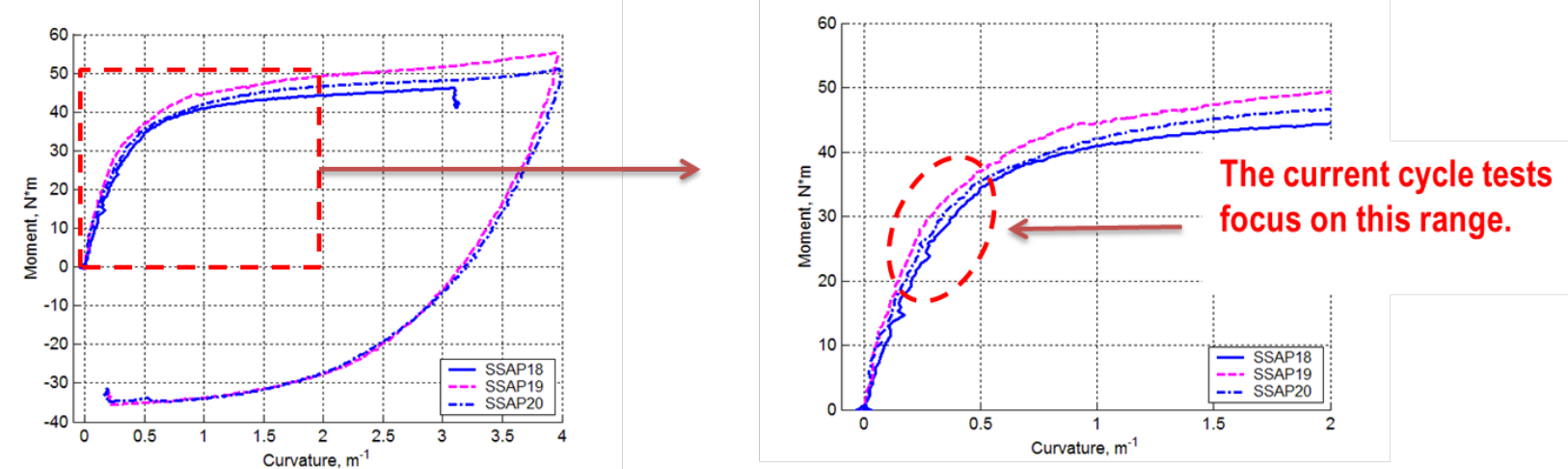

Figure 15 Three static bending tests were completed with maximum relative displacement $20 \mathrm{~mm}$ at loading points of U-frame setup.

\subsection{Dynamic testing procedure}

Dynamic cyclic testing procedure consists of two major steps.

- Measurement

- Measurement is required to establish baseline data and monitor the performance of the test specimen during cycling.

- Input: displacement control mode; triangular or sine waveforms with amplitude depends on designed load levels, 0.01- $0.05 \mathrm{~Hz}$.

- Measurement channel: load and displacement readouts, LVTD1, LVDT2, and LVDT3.

- Cycling

- Input: force control; sine wave with amplitude depends on designed load levels, $2-5 \mathrm{~Hz}$

- Monitoring: load and displacement readout, three LVDTs.

- The cycling was interrupted for measurement at the following points: $10^{0}, 10^{3}$, $10^{4}, 10^{5}, 3 \times 10^{5}, 8 \times 10^{5}, 10^{6}$

\subsection{Dynamic testing results}

The verification test using SSAP surrogate rods on Bose machines was started in October 2012. The load control through Cycle Indirect along with the pinning of U-frame setup has been used. Cycle tests using SSAP11, SSAP12, and SSAP13 were conducted under $\pm 200 \mathrm{~N}$ or $20.32 \mathrm{Nm} 5$ $\mathrm{Hz}$. The output indicated a quite consistent load level during all of the cycle tests. The tests on SSAP11 and SSAP12 generated lifetimes of 678K and 936 cycles with about 40 to $42 \%$ drop of flexural rigidity before fractures. The fractures all occurred within the gage sections, and the 
specimen hold areas appeared to be fine. The SSAP13 was still working with about only $11 \%$ drop of rigidity after more $1.7 \mathrm{M}$ cycles. The observed difference in lifetimes was perhaps due to the compositions and machining of specimen.

The amplitude was then raised to \pm 250 and $\pm 300 \mathrm{~N}$ or 25.40 and $30.48 \mathrm{Nm}$ with on-line monitoring enabled. The lifetimes in terms of number of cycles to failure are shown in Figure 16 for various loads or moments. The lifetimes of the surrogate rods are shown to be similar to that of the surrogate rods obtained at equivalent strain levels under displacement control (Wang et al., 2012). ${ }^{32,40}$ The variations of curvature and flexural rigidity based on on-line monitoring and measurements can be found elsewhere. ${ }^{34}$

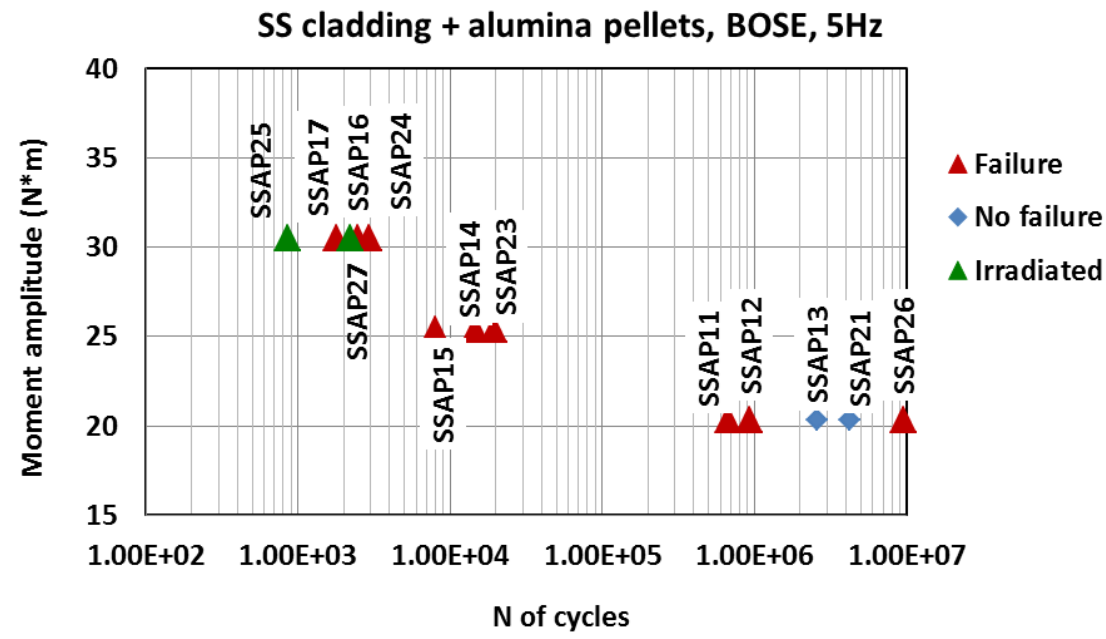

Figure 16 Moment as a function of cycles or cycles to failure. No failure was observed for SSAP13, SSAP21, and SSAP26. The SSAP26 was continued at $10 \mathrm{~Hz}$ after $4 \times 10^{6}$ cycles at 5 Hz. SSAP25 was irradiated 2 weeks under a sandwich configuration between 6- and 7-fuel rod layers. SSAP27 irradiated 4 weeks.

\subsection{Verification of Bose testing}

The cycle testing on MTS servo-hydraulic testing machine was conducted to verify the results on the Bose machine. The objective of this activity is to complete a test matrix with three loads each with three test tests. ${ }^{34}$

The cycle tests were conducted under load control using $2 \mathrm{~Hz}$, and the part of results are summarized in Figure 17. In general, the results based on the tests on MTS machine agree with those on Bose machine (Figure 16). The variation of curvature and flexural rigidity can also be found elsewhere. 


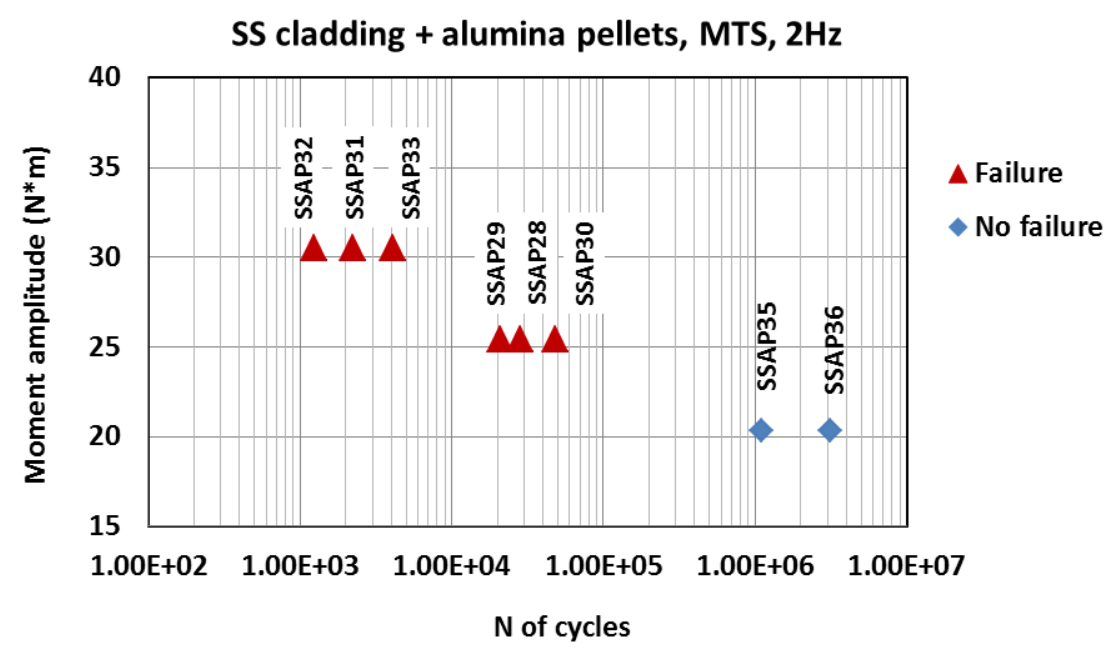

Figure 17 Moment as a function of cycles or cycles to failure. SSAP30, SSAP33 and SSAP36 had 440C hardened rigid sleeves. 


\section{As-received spent fuel rod specimens}

\subsection{Inventory of specimens}

The hot cell test plan mainly consists of calibration, static tests and dynamic tests. The rod specimens proposed for the test plan of this project are given in Table $6 .{ }^{41}$

Measurement on the diameter of rod has been performed on one of fuel segment R5 (606B3C) by using a dedicated setup in hot-cell. The readings were taken each half inch from one end of the rod and three degrees $\left(0^{\circ}, 120^{\circ}\right.$, and $\left.240^{\circ}\right)$ at each reading distance. ${ }^{42}$ The mean value and standard deviation of the readings on diameter were found out to be $10.772 \mathrm{~mm}(0.4241 \mathrm{in}$.) and $0.008 \mathrm{~mm}$ (0.0003 in.), respectively. It can be seen that the obtained mean value is a little higher than but still close to the nominal diameter $(10.70 \mathrm{~mm})$ of fuel clad in H. B. Robson. ${ }^{22}$ 
Table 6 In cell test plan

\begin{tabular}{|c|c|c|c|c|c|c|c|c|c|c|}
\hline & & \# & Source & $\begin{array}{l}\text { Sample on } \\
\text { sheets } \\
\text { below }\end{array}$ & $\begin{array}{c}\text { ORNL } \\
\text { Inventory } \\
\text { Label ("Seg. } \\
\text { ID") }\end{array}$ & Span & $\begin{array}{c}\text { Burnup } \\
\text { (rod } \\
\text { average, } \\
\text { GWd/M } \\
\text { TU }\end{array}$ & $\begin{array}{c}\text { Estimate } \\
\text { d Oxide } \\
(\mu \mathrm{m})\end{array}$ & $\begin{array}{c}\text { Estimated } \\
\text { Hydrogen } \\
\text { of Span } \\
\text { (wppm) }\end{array}$ & $\begin{array}{c}\text { Estimate } \\
\text { d Local } \\
\text { Hydroge } \\
n \\
\text { (wppm) }\end{array}$ \\
\hline \multirow{5}{*}{\multicolumn{2}{|c|}{ 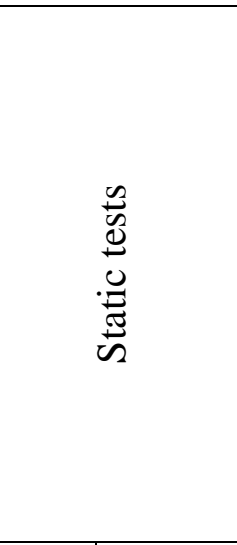 }} & $\begin{array}{c}\text { First static } \\
\text { (was S3, now } \\
\text { listed as S1) }\end{array}$ & $\begin{array}{c}\text { H.B } \\
\text { Robinson }\end{array}$ & $606-C$ & 606С3С & 4 & 66.8 & $70-100$ & $550-750$ & 650 \\
\hline & & S2 & $\begin{array}{c}\text { H.B } \\
\text { Robinson }\end{array}$ & 605-D & 605D1E & $2-3$ & 66.5 & $40-70$ & $360-550$ & 400 \\
\hline & & $\begin{array}{l}\text { Third static } \\
\text { (was Dcal) }\end{array}$ & $\begin{array}{c}\text { H.B } \\
\text { Robinson }\end{array}$ & 609-C & 609C5 & 4 & 66.5 & $70-100$ & $550-750$ & 550 \\
\hline & & $\begin{array}{c}\text { Fourth static } \\
\text { (was Scal) }\end{array}$ & $\begin{array}{c}\text { H.B } \\
\text { Robinson }\end{array}$ & 609-C & 609C6 & 4 & 66.5 & $70-100$ & $550-750$ & 550 \\
\hline & & S5 & $\begin{array}{c}\text { H.B } \\
\text { Robinson }\end{array}$ & 606-C & 606C3A & 4 & 66.8 & $70-100$ & $550-750$ & 750 \\
\hline \multirow{8}{*}{ 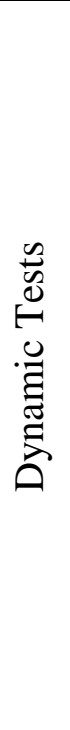 } & \multirow{3}{*}{$\begin{array}{l}\mathscr{n} \\
\stackrel{D}{5} \\
\omega \\
\frac{1}{\infty 0} \\
: 1\end{array}$} & DH1 & $\begin{array}{c}\text { H.B } \\
\text { Robinson }\end{array}$ & 609-C & 609C4 & 4 & 66.5 & $70-100$ & $550-750$ & 700 \\
\hline & & DH2 & $\begin{array}{c}\text { H.B } \\
\text { Robinson }\end{array}$ & 609-C & 609C3 & 4 & 66.5 & $70-100$ & $550-750$ & 750 \\
\hline & & DH3 & $\begin{array}{c}\text { H.B } \\
\text { Robinson }\end{array}$ & 609-C & $609 C 7$ & 4 & 66.5 & $70-100$ & $550-750$ & 550 \\
\hline & \multirow{3}{*}{ 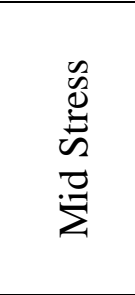 } & DM1 & $\begin{array}{c}\text { H.B } \\
\text { Robinson }\end{array}$ & 605-D & 605D1C & $2-3$ & 66.5 & $40-70$ & $360-550$ & 500 \\
\hline & & DM2 & $\begin{array}{c}\text { H.B } \\
\text { Robinson }\end{array}$ & 605-D & 605D1B & $2-3$ & 66.5 & $40-70$ & $360-550$ & 550 \\
\hline & & DM3 & $\begin{array}{c}\text { H.B } \\
\text { Robinson }\end{array}$ & 606-C & 606C3E & 4 & 66.8 & $70-100$ & $550-750$ & 550 \\
\hline & \multirow{2}{*}{ 范总 } & DL1 & $\begin{array}{c}\text { H.B } \\
\text { Robinson }\end{array}$ & 607-C4 & 607C4B & 4 & 63.8 & $70-100$ & $550-750$ & 700 \\
\hline & & DL2 & H.B & 608-C4 & 608C4B & 4 & 63.8 & $70-100$ & $550-750$ & 700 \\
\hline
\end{tabular}




\begin{tabular}{|c|c|c|c|c|c|c|c|c|c|c|}
\hline & & & Robinson & & & & & & & \\
\hline & & DL3 & $\begin{array}{c}\text { H.B } \\
\text { Robinson }\end{array}$ & $605-C$ & $605 \mathrm{C} 10 \mathrm{~A}$ & 4 & 66.5 & $70-100$ & $550-750$ & 550 \\
\hline \multirow{3}{*}{ لَّ } & 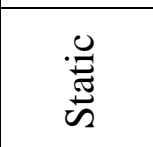 & $\begin{array}{l}\text { Static Cal } \\
\text { (was } \\
\text { DEMO2) }\end{array}$ & $\begin{array}{c}\text { H.B } \\
\text { Robinson }\end{array}$ & 606-B & 606B3В & 5 & 66.5 & $100-110$ & $750-800$ & 750 \\
\hline & 穴 芚 & $\begin{array}{c}\text { Dynamic Cal } \\
\text { (was S3) }\end{array}$ & $\begin{array}{c}\text { H.B } \\
\text { Robinson }\end{array}$ & 605-D & $605 \mathrm{D} 1 \mathrm{~F}$ & $2-3$ & 66.5 & $40-70$ & $360-550$ & 360 \\
\hline & $\underset{x}{\mathbb{x}} \mathbb{x}$ & $\begin{array}{c}\text { Scal/Dcal } \\
\text { (was S4) }\end{array}$ & $\begin{array}{c}\text { H.B } \\
\text { Robinson }\end{array}$ & 606-C & 606C3B & 4 & 66.8 & $70-100$ & $550-750$ & 700 \\
\hline \multirow{2}{*}{\multicolumn{2}{|c|}{$\begin{array}{l}\text { Scrap segment } \\
\text { for full } \\
\text { operator } \\
\text { handling } \\
\text { demonstration } \\
\text { in-cell } \\
\end{array}$}} & Demo 1 & $\begin{array}{c}\text { H.B } \\
\text { Robinson }\end{array}$ & 606-B & 606B2 & 5 & 66.5 & $100-110$ & $750-800$ & 750 \\
\hline & & $\begin{array}{c}\text { only } 1 \\
\text { performed }\end{array}$ & - & - & - & - & - & - & - & - \\
\hline \multirow{5}{*}{\multicolumn{2}{|c|}{$\begin{array}{c}\text { Extra cut } \\
\text { samples that } \\
\text { could replace } \\
\text { above } \\
\text { segments }\end{array}$}} & $\mathrm{R} 1$ & $\begin{array}{c}\text { H.B } \\
\text { Robinson }\end{array}$ & 607-C4 & $607 \mathrm{C} 4 \mathrm{~A}$ & 4 & 63.8 & $70-100$ & $550-750$ & 700 \\
\hline & & $\mathrm{R} 2$ & $\begin{array}{c}\text { H.B } \\
\text { Robinson } \\
\end{array}$ & 608-C4 & $608 C 4 A$ & 4 & 63.8 & $70-100$ & $550-750$ & 700 \\
\hline & & R3 & $\begin{array}{c}\text { H.B } \\
\text { Robinson }\end{array}$ & 606-B & 606B3E & 5 & 66.5 & $100-110$ & $750-800$ & 750 \\
\hline & & $\mathrm{R} 4$ & $\begin{array}{c}\text { H.B } \\
\text { Robinson }\end{array}$ & 606-B & 606B3D & 5 & 66.5 & $100-110$ & $750-800$ & 750 \\
\hline & & R5 & $\begin{array}{c}\text { H.B } \\
\text { Robinson }\end{array}$ & 606-B & 606B3C & 5 & 66.5 & $100-110$ & $750-800$ & 750 \\
\hline
\end{tabular}




\section{In-cell installation, calibration and benchmarking of testing system}

\subsection{Adaptation and installation of testing system}

The ORNL testing system was officially named as CIRFT (Cyclic Integrated ReversibleBending Fatigue Tester) while being moved inside the hot cell.

- The CIRFT was temporally set up in the operational areas for the further verification of the system, training of operators, and examination of procedures in hot cell testing. The epoxy casting of alpha plug was also carried out.

- Additional modifications were made mainly to the tools to be used in hot cell testing, including wing nuts, T-handle hex keys, hex keys with U-grooved handle, and torque wrenches with extended handle.

- The CIRFT was finally moved into east station 12 of ORNL hot cell facility on 9/18/2013 as shown in Figure 18. At the same time, the epoxy cast of alpha plug was completed, and installed the second day. The initial run of the CIRFT showed to be quite stable.

ORNL manipulators have been demonstrated to be able to complete the designed operation procedures in hot cell testing, including

- Taking out tested specimen HZRAP05 from the setup,

- Installing the specimen SSAPdm1, and

- Re-mounting LVDT clamp.

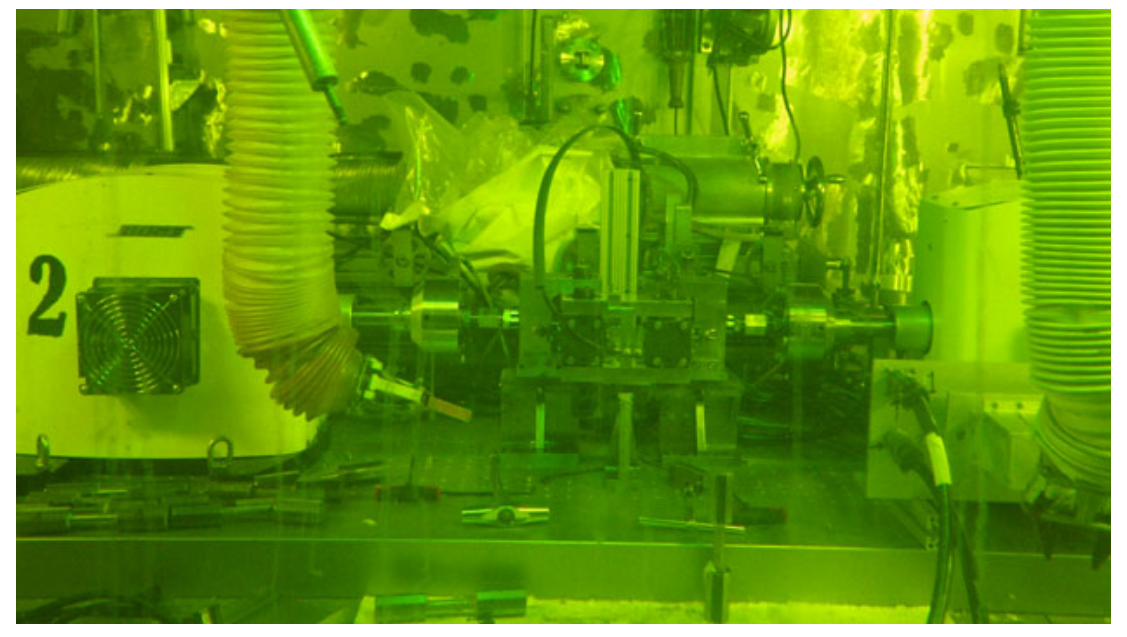

Figure 18 View of CIRFT installed at ORNL hot cell. 


\subsection{Verification tests using SSAP surrogate rods}

The initial run with SSAPdemo1 was conducted under $\pm 250 \mathrm{~N}$ or $25.40 \mathrm{Nm} 5 \mathrm{~Hz}$. The monitoring of loading showed the system was quite stable as shown in Figure 19. The surrogate rod was finished with a lifetime of $9.5 \times 10^{4}$ cycles, which is a little longer than those observed in the tests of out-of-cell development. However, it is believed that such discrepancy in life time came from the difference of surrogate rods themselves. A static test was also carried out to verify the performance of CIRFT in hot cell by using SSAPdemo2. Moment-curvature response of the rod has been demonstrated to be quite similar to those of out-of-cell tests under same test condition as shown in Figure 20.

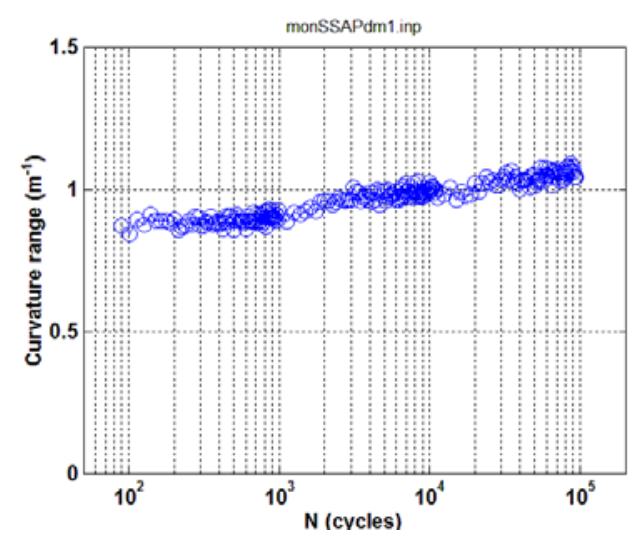

(a)

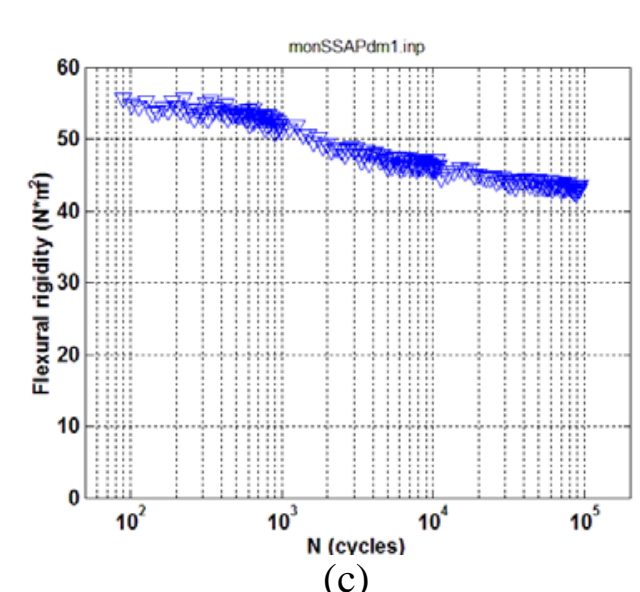

(c)

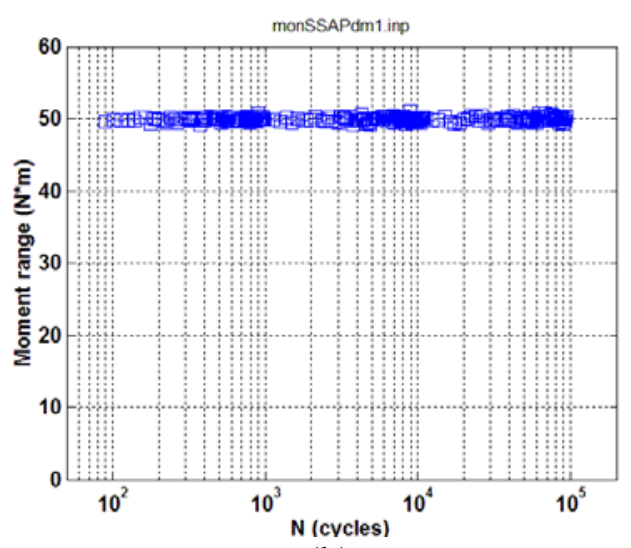

(b)

Figure 19 Variations of (a) curvature range, (b) applied moment range, (c) flexural rigidity as a function of number of cycles for SSAPdemo1, SS cladding with 10 alumina pellets, under $\pm 25.40 \mathrm{Nm} 5 \mathrm{~Hz} ; \mathrm{N}_{\mathrm{f}}=9.5 \times 10^{4}$ cycles. 


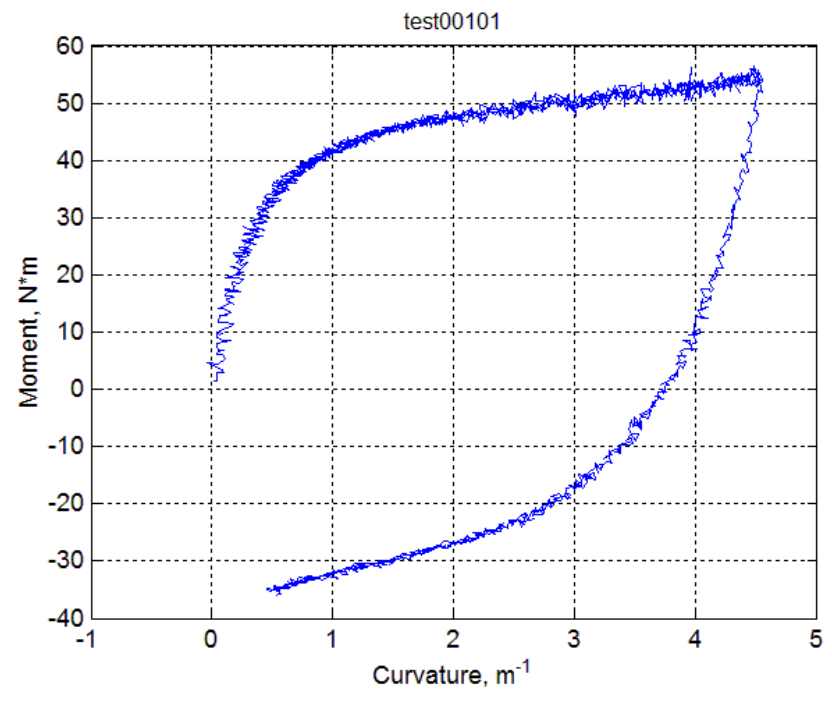

Figure 20 Curve of moment versus curvature for SSAPdemo2 with maximum relative displacement $24 \mathrm{~mm}$; rate was set at $0.1 \mathrm{~mm} / \mathrm{sec}$ at loading points of U-frame.

\subsection{In-cell preparation of specimens}

The vise mold for the specimen preparation was also moved into the hot cell at the same time. It has been realized the extra epoxy overflowed the chamber of mold during the epoxy casting, and that caused a lot of problem for the next cycle of epoxy casting. The engine oil was used to coat the inside of chamber, and it has been found out such measure is very effective.

The manipulators have also been demonstrated to be able to complete all the procedures for specimen preparation through epoxy casting in hot cell, including

- Inserting the rod into the mold and securing the rod,

- Receiving the end cap loaded with fresh epoxy,

- Inserting the end cap into the lower chamber of mold and securing the end cap, and

- Re-orienting the mold and finishing the second end cap epoxy casting.

Figure 21 illustrates two snapshots when the fuel rod (Demo1) and an end cap with epoxy were being inserted, respectively. 


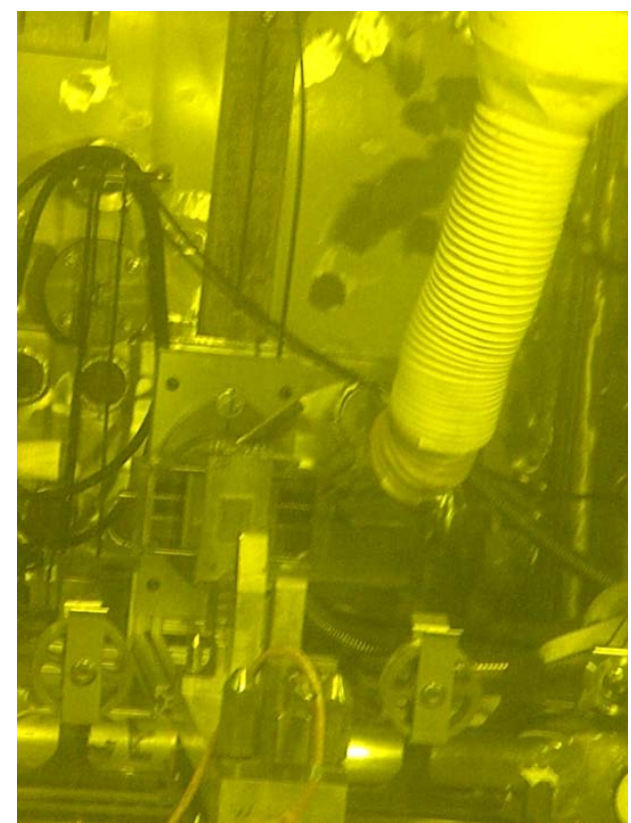

(a)

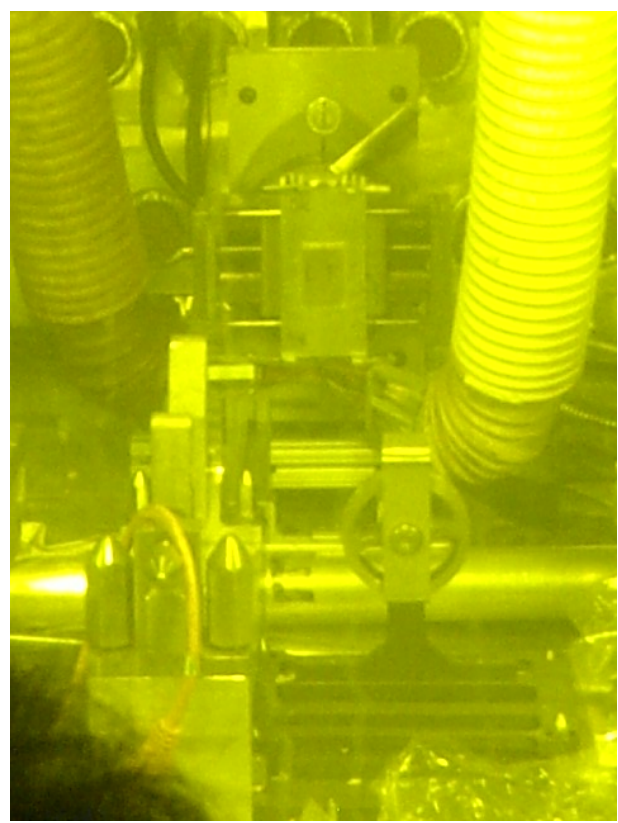

(b)

Figure 21 (a) Rod (Demo1, 606B2) was inserted. (b) One pin was turned away and end-cap loaded with epoxy inserted into the lower chamber.

\subsection{Benchmarking of test system}

\subsubsection{Tuning using Demo1}

The tuning was completed using Demo1 (606B2) by using TuneIQ on both motors on 9/23/2013 (Table 7).

Table 7 Tuning parameters obtained by using Demo1

\begin{tabular}{|c|c|c|c|}
\hline \multicolumn{2}{|c|}{ Axial 1 } & \multicolumn{2}{c|}{ Axial 2 } \\
\hline TuneIQ1 & 1.5860 & TuneIQ1 & 1.8869 \\
\hline TuneIQ2 & 0.0192 & TuneIQ2 & 0.0193 \\
\hline TuneIQ3 & -9.6663 & TuneIQ3 & -11.0162 \\
\hline
\end{tabular}




\subsubsection{Static on Demo1/ 606B2 (+ dynamic)}

The Demo1 (606B2, 66.5 GWd/MTU burnup, 100-110 $\mu$ m oxide layer, 750 ppm H content) was initially tested to the relative displacement of $2 \mathrm{~mm}$, at rate $0.1 \mathrm{~mm} / \mathrm{s}$ at each loading point of Uframe. Such displacement level was quite low so as to serve as a pilot test to detect the response of the rod. The rod was then tested 11 cycles with an increased relative displacement $20 \mathrm{~mm}$, corresponding to moment $82 \mathrm{Nm}$ (no load correction applied) and the rod appeared to be quite stable. 4 additional cycles were carried out with further increased displacement $24 \mathrm{~mm}$ (moment $90 \mathrm{Nm}$ ), and the rod was found out to be still working fine. The responses of rod during the above loading processes are given in Figure 22.

A follow up cycle test was conducted by using $\pm 300 \mathrm{~N}$ or $30.48 \mathrm{Nm} 5 \mathrm{~Hz}$. The rod eventually fractured in the gage section near motor 1 around $3.96 \times 10^{3}$ cycles. The monitored curvature, moment and deduced flexural rigidity as a function of number of cycles are given in Figure 23. The fracture surfaces ${ }^{43}$ (Figure 24) of the rod indicate that the failure likely involved the fracture of a fuel pellet or failure of interface layer as can be seen from the attached fragments.

It has been observed that at the low displacement level, the rod exhibited a linear response. A flexural rigidity of $40 \mathrm{Nm}^{2}$ was obtained from the slope of curvature-moment curve. A nonlinear response was exhibited under the increased displacement. Three deformation stages can be delineated with two turning points near 20 and $55 \mathrm{Nm}$, at which the slope of curve subjected to discontinuous variation. Below the first turning level, the response appeared repeatable under loading. Beyond the second turning level, the response of the rod became significantly nonlinear. Unloading -loading curves mostly overlaid if the loading level is less than the previous maximum level; or, loading curve would follow the response of the rod in a monotonic loading process.

It thus can be seen from testing of the first fuel rod that:

- The testing system worked stably for both the static and dynamic loading by using the tuning parameters generated above.

- A three-stage deformation process existed when the deformation was substantially large.

- No failure was seen on the Demo1 under static loading, even though the displacement imposed almost reached the system capacity $(25 \mathrm{~mm})$. Therefore, a cyclic loading process is required to observe the failure mode of rod.

- Testing setup worked as designed to have the final failure confined within the gage section of rod. 


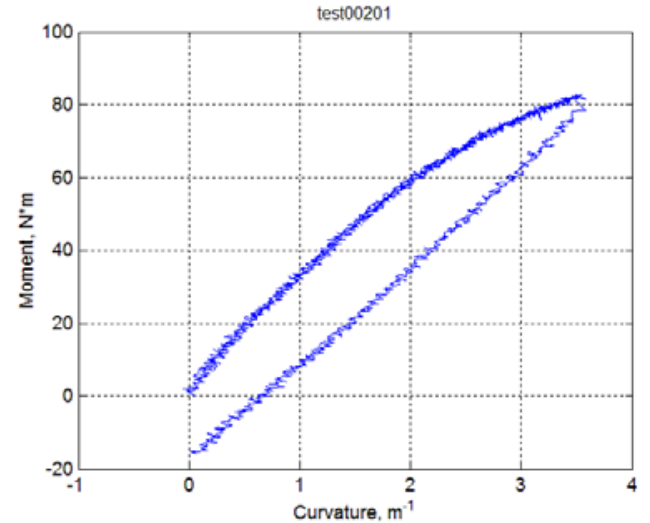

(a)

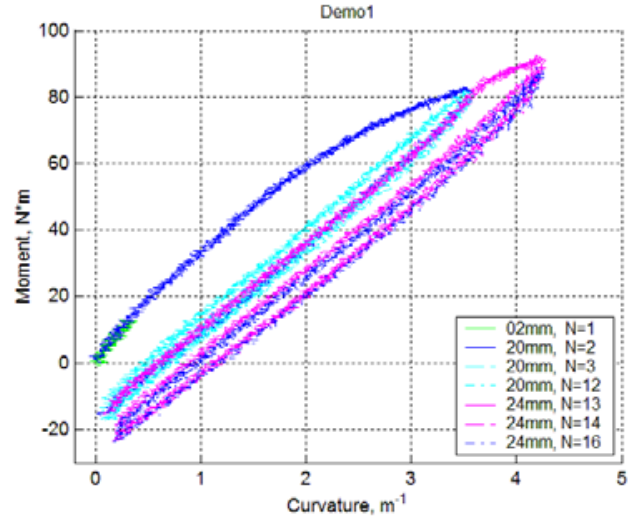

(b)

Figure 22 (a) Curve of moment versus curvature with maximum relative displacement 20mm, and (b) moment versus curvature in the subsequent repeated static tests with relative displacement 20 or $24 \mathrm{~mm}$ for Demo1 (606B2). The rate at loading points of U-frame was set at 0.1 and $0.2 \mathrm{~mm} / \mathrm{s}$ in loading and unloading, respectively.

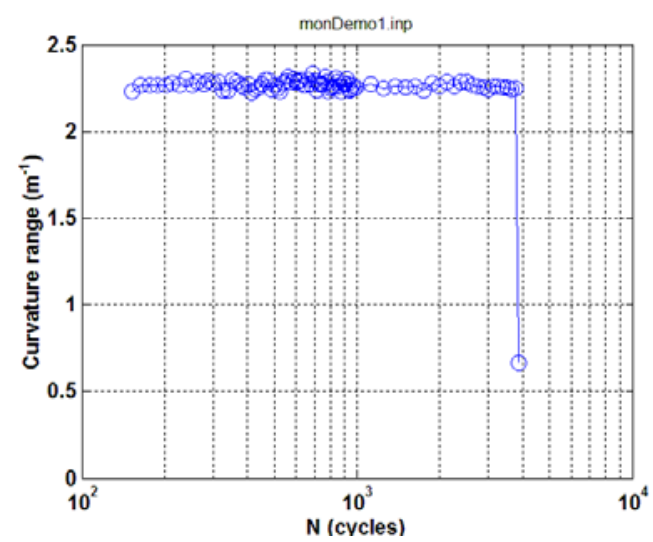

(a)

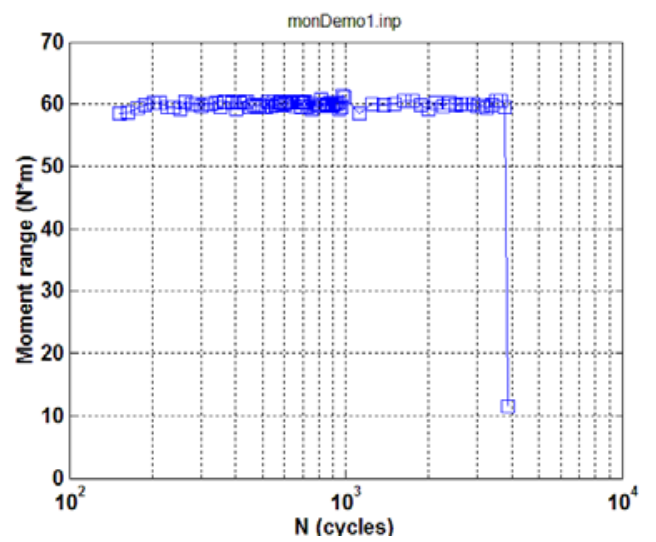

(b)

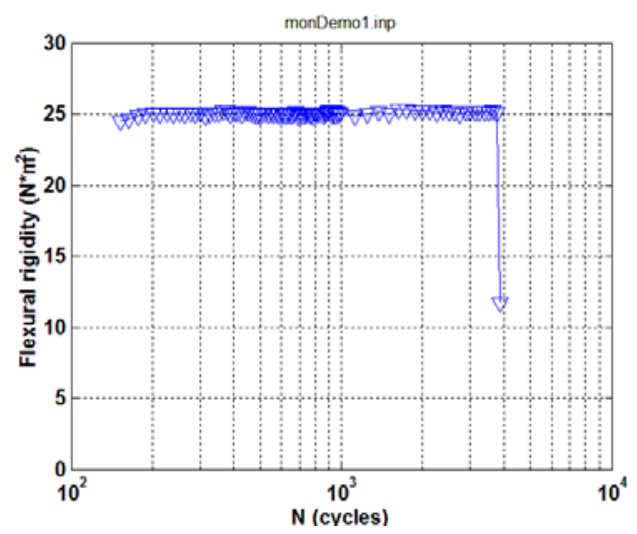

(c) 
Figure 23 Variations of (a) curvature range, (b) applied moment range, (c) flexural rigidity as a function of number of cycles for Demo1 (606B2); $\mathrm{N}_{\mathrm{f}}=3.96 \times 10^{3}$ cycles under $\pm 30.48 \mathrm{Nm} 5 \mathrm{~Hz}$. The specimen had been subjected to repeated static loading before the cycle test.

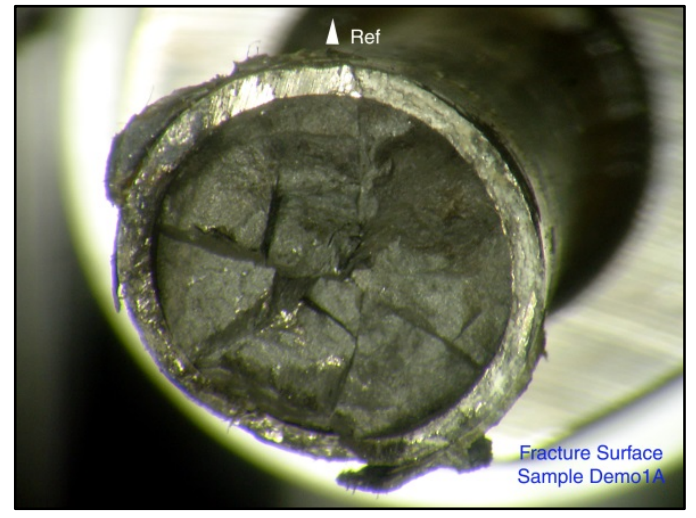

(a)

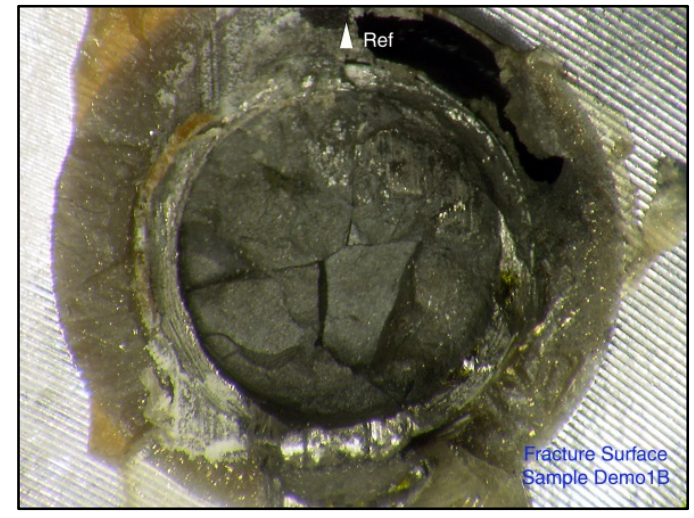

(b)

Figure 24 Mating fracture surfaces of Demo1 (606B2); reference marker indicates the frontal maximum stress line (facing the operator). $\mathrm{N}_{\mathrm{f}}=3.96 \times 10^{3}$ cycles under $\pm 30.48 \mathrm{Nm} 5 \mathrm{~Hz}$. The specimen had been subjected to repeated static loading cycles before the dynamic cycle test.

\subsubsection{Static on Demo2/ 606B3B}

The test on Demo2 (606B3B, 66.5 GWd/MTU burnup, 100-110 $\mu$ m oxide layer, 750 ppm H content) was conducted at $0.1 \mathrm{~mm} / \mathrm{s}$ at each loading point of U-frame. The rod fractured when the relative displacement reached $22.920 \mathrm{~mm}$ corresponding to a fracture moment of $83 \mathrm{Nm}$. Again, two turning points can be defined clearly near 20 and $50 \mathrm{Nm}$ prior to the failure as shown in Figure 25. The failure occurred at the middle of gage section. The fracture surface of clad (Figure 26) appeared to be very serrated with a large tooth-shaped attachment on the compressive side of the rod (that was broken off during specimen handling), and final fracture of the rod was seemingly related to the fracture of a fuel pellet.

The observations on Demo2 can be summarized as follows.

- The moment at fracture of Demo2 is lower than the maximum moment experienced by Demo1 as discussed above. So, there is a substantial difference of mechanical property between the two rods, although they have same thickness of oxide layer and same level of H content.

- Lateral surfaces of rod were covered with a large number of equally-spaced circumferential cracks throughout the gage section on both frontal (facing operator) and back sides of the rod. It is not sure if they were linked around the whole periphery of rod. 
- The extensive subsurface spalling can be seen over the back or tensile side of rod. It is worthwhile noting that the circumferential cracks and the spalling also occurred to Demo1 and several other rods as will be discussed below.

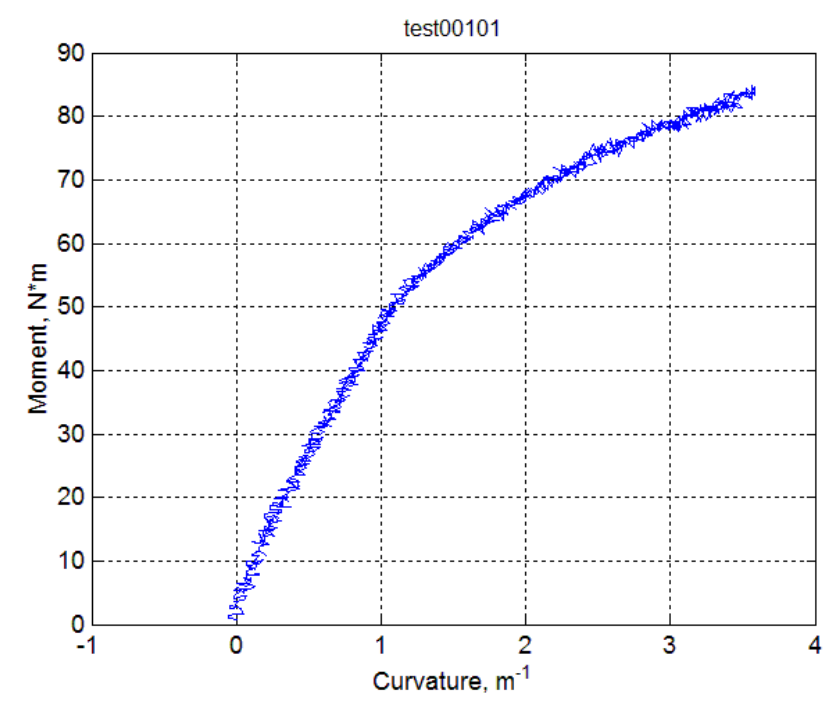

Figure 25 Moment-curvature curve for Demo2 (606B3B) with rate $0.1 \mathrm{~mm} / \mathrm{sec}$ at the loading points of U-frame; the rod was broken, peak moment $=83 \mathrm{~N} * \mathrm{~m}$.

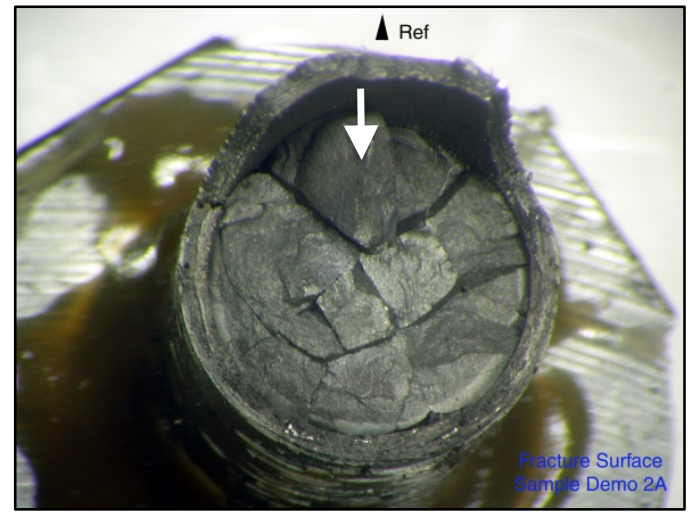

(a)

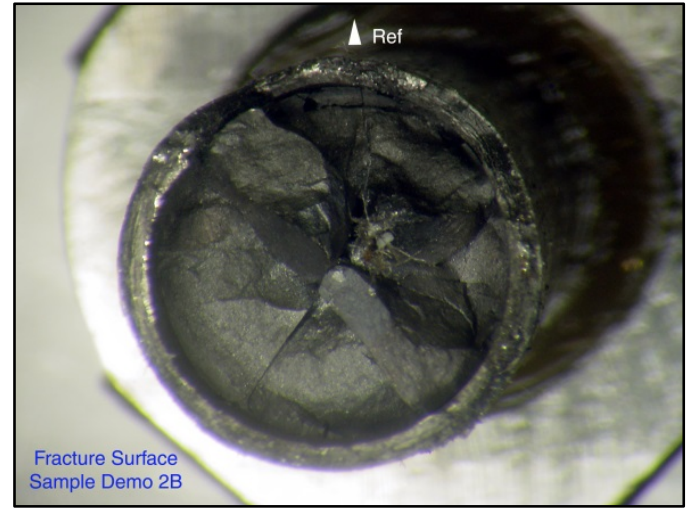

(b) 


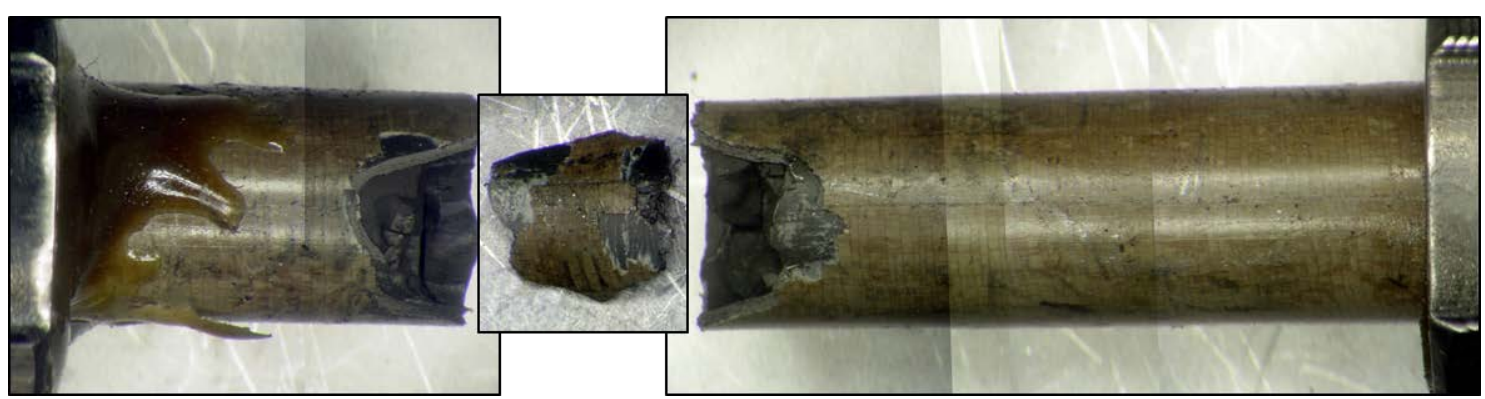

(c)
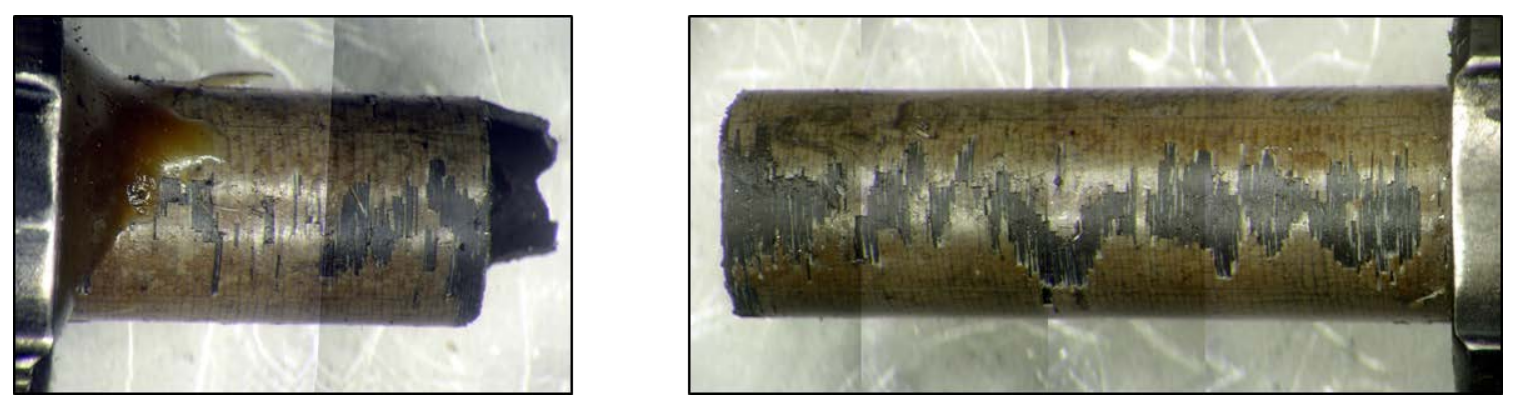

(d)

Figure 26 (a) and (b) Mating fracture surfaces, (c) frontal (compressive) and (d) back side (tensile) of Demo2 (606B3B). The rate was $0.1 \mathrm{~mm} / \mathrm{sec}$ at the loading points of U-frame; the rod was broken, peak moment $=83 \mathrm{Nm}$.

\subsubsection{Static on S4/ 606C3B}

S4 (606C3B, 66.8 GWd/MTU burnup, 70-100 $\mu$ m oxide layer, 700 ppm H content) fractured at the peak moment near 83 to $85 \mathrm{Nm}$ during the loading with $0.1 \mathrm{~mm} / \mathrm{s}$. A large variety of fragment size was revealed in the postmortem analysis (Figure 27).

- An end face of pellet can be seen clearly from the brownish haze zone. So, the failure took place near a pellet-to-pellet interface with fracture involved in a neighboring pellet.

- Besides the circumferential cracks, a sharp attachment of clad was outstanding on frontal or compressive side. On the other side, the spalling was not seen as extensive as in Demo1 and Demo2.

- Compared to Demo1 and Demo2 from the same rod but different segment (606B), the slightly higher failure moment and less spalling in S4 are coincident with the lower levels of oxide layer and $\mathrm{H}$ content of the rod segment. 


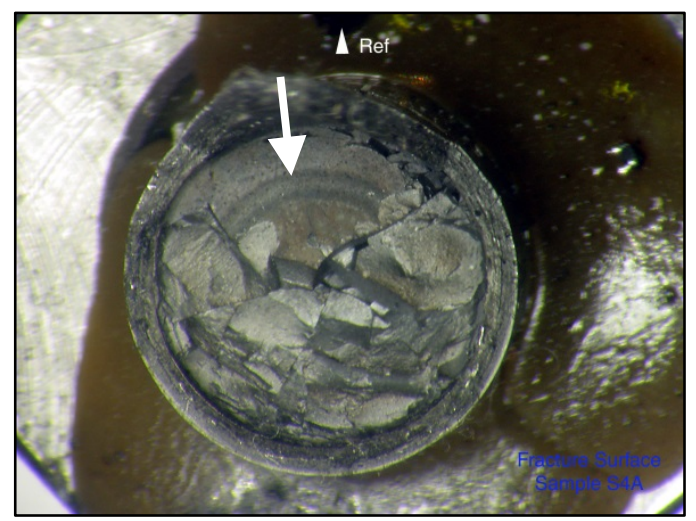

(a)
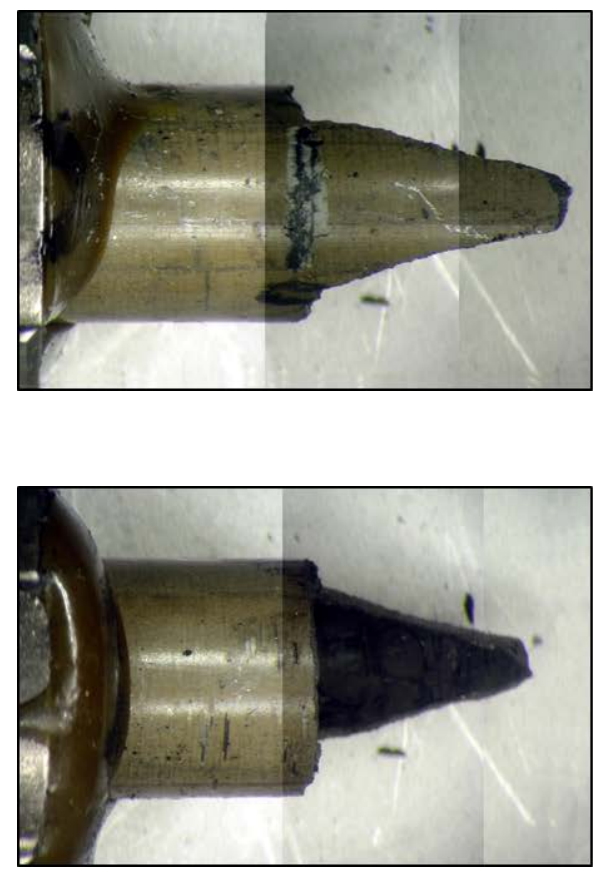

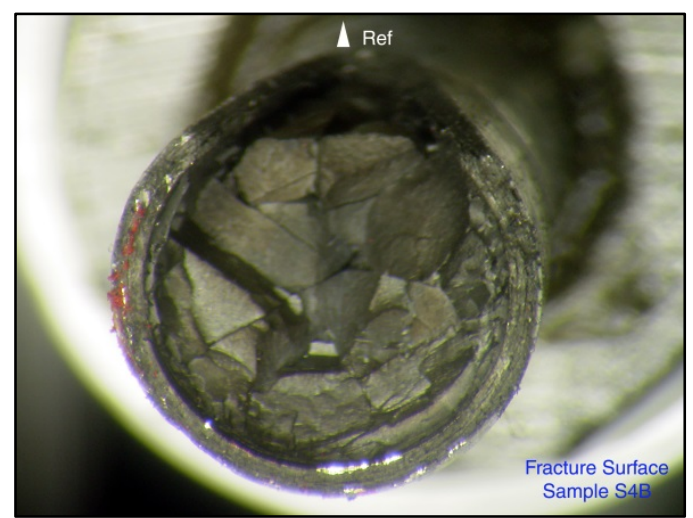

(b)

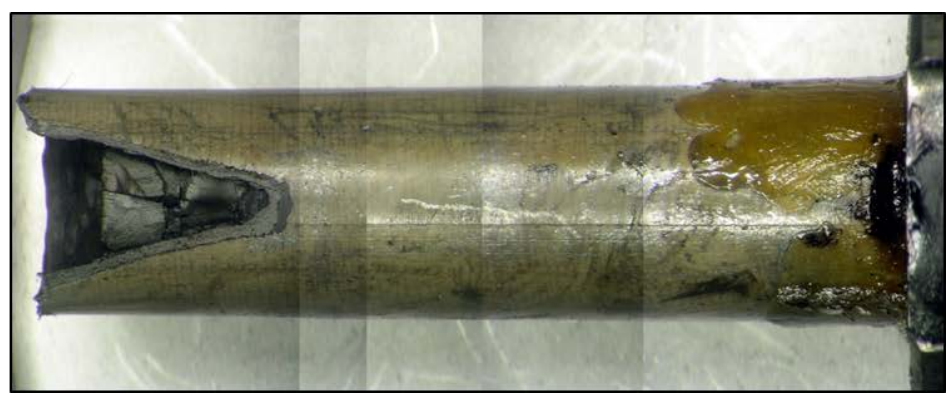

(c)

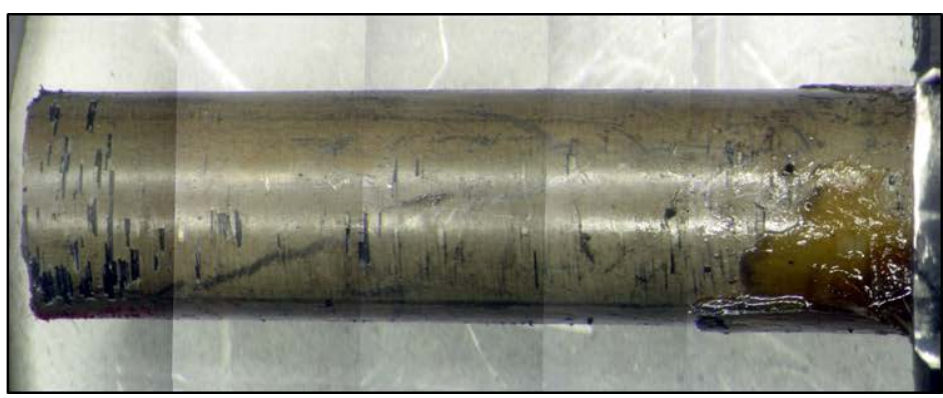

(d)

Figure 27 (a) and (b) Mating fracture surfaces, (c) frontal (compressive) and (d) back (tensile) side of S4 (606C3B). The rate was $0.1 \mathrm{~mm} / \mathrm{sec}$ at the loading points of U-frame; the rod was broken, peak moment $=85 \mathrm{Nm}$.

\subsubsection{Dynamic on S3 / 605D1F $( \pm 25.4 \mathrm{Nm} 5 \mathrm{~Hz})$}

The dynamic cycle testing was conducted by using rod S3 (605D1F, 66.5 GWd/MTU burnup, 40-70 $\mu$ m oxide layer, $360 \mathrm{ppm} \mathrm{H}$ content) as a part of benchmarking of the system. The cycle test was conducted under $\pm 250 \mathrm{~N}$ or $25.40 \mathrm{Nm} 5 \mathrm{~Hz}$. The system has been demonstrated to be able to meet the testing requirements on loading and monitoring. A life time of $2.5 \times 10^{4}$ cycles was observed. The flexural rigidity was shown to be pretty stable along with the accumulation of 
cycles prior to the final fracture as shown in Figure 28. The failure was observed in the gage section near motor 2 . A clear cut can be seen from the exposed end faces of neighboring pellets as seen in Figure 29.

- The failure of the rod was dominated by the pellet-to-pellet interface.

- The lateral surface of the rod was shown to be free of the cracks or spalling as observed in Demo1, Demo2 and S4. It is not clear if the absence of circular cracks was related to the small loading amplitude or the less degree of pre-existing oxidation and hydrides in S3.

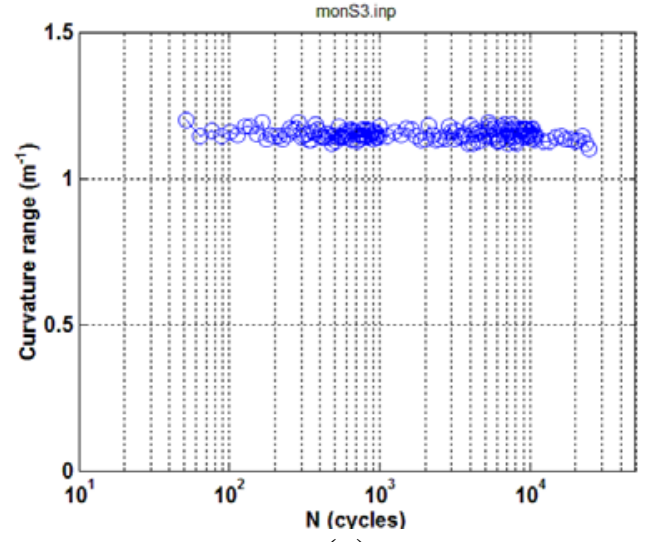

(a)

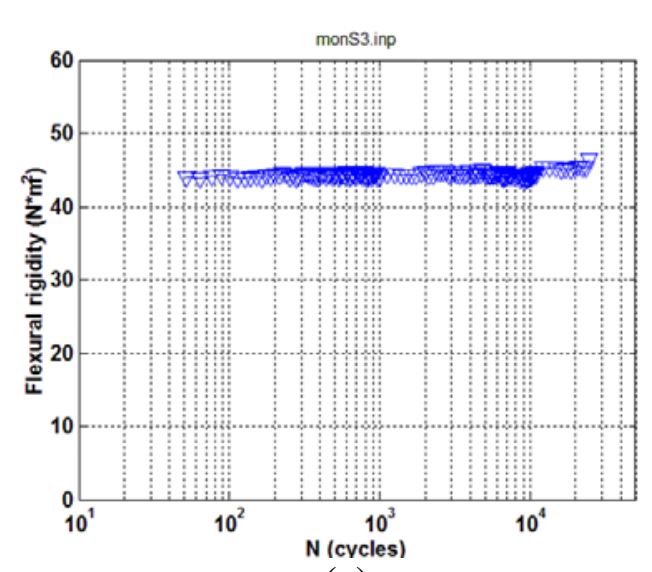

(c)

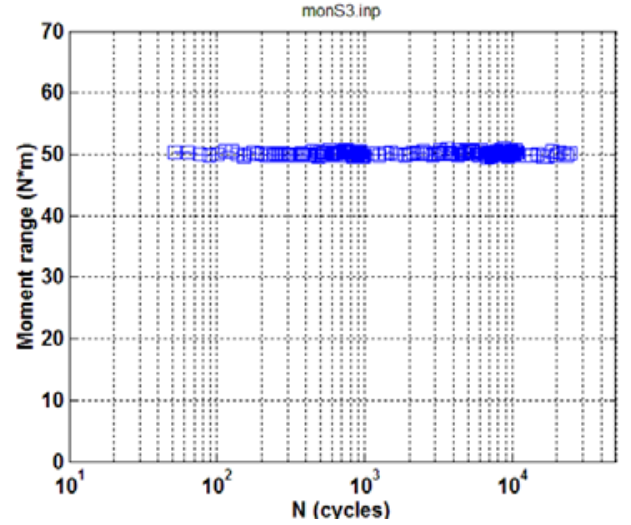

(b) 


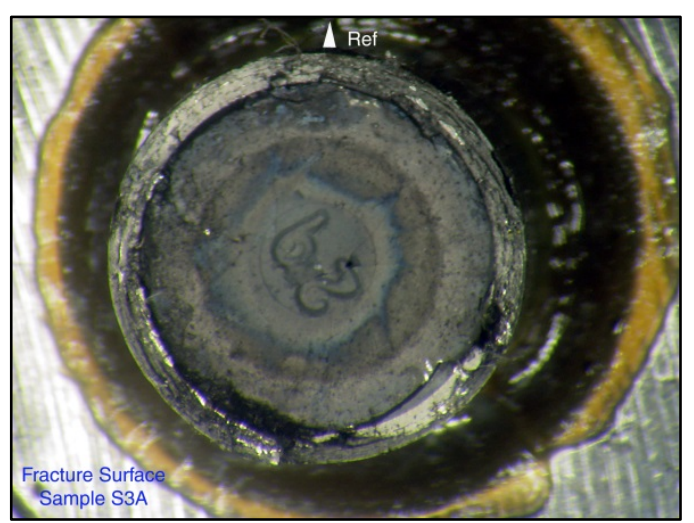

(a)

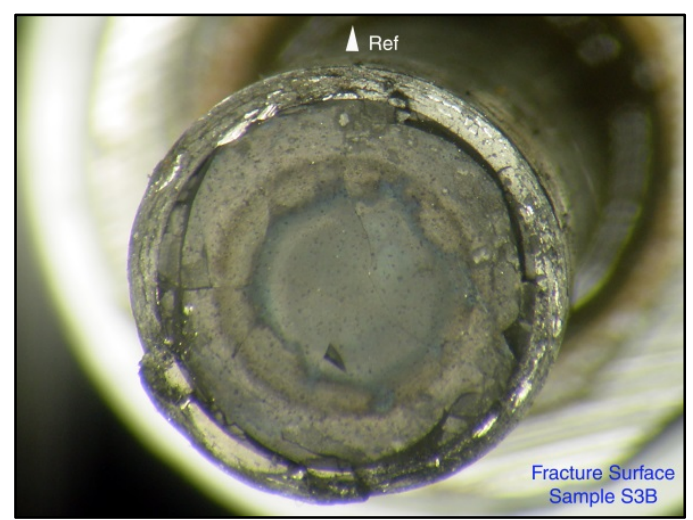

(b)
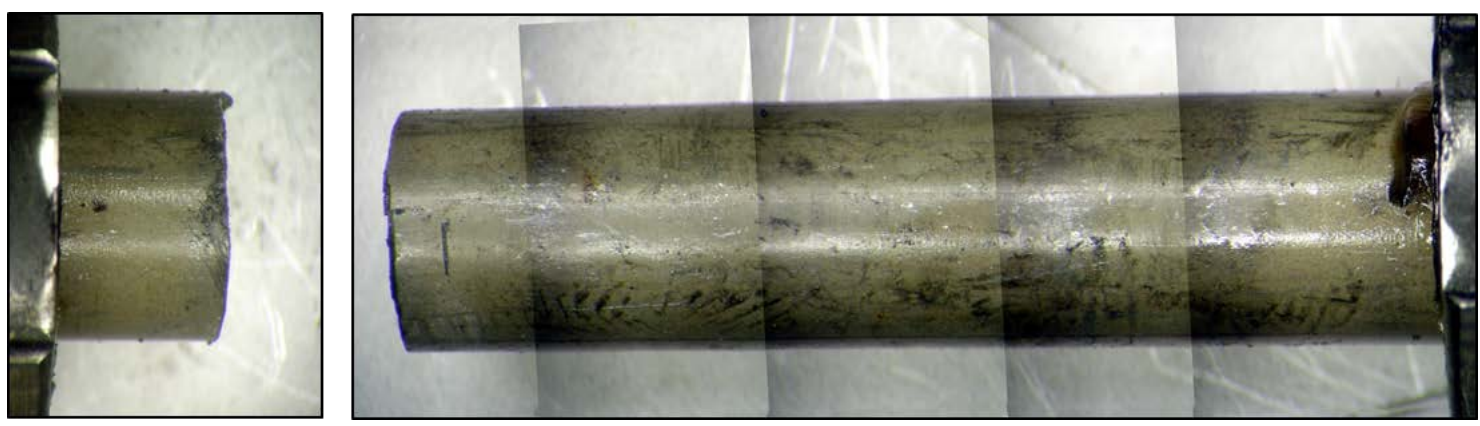

(c)
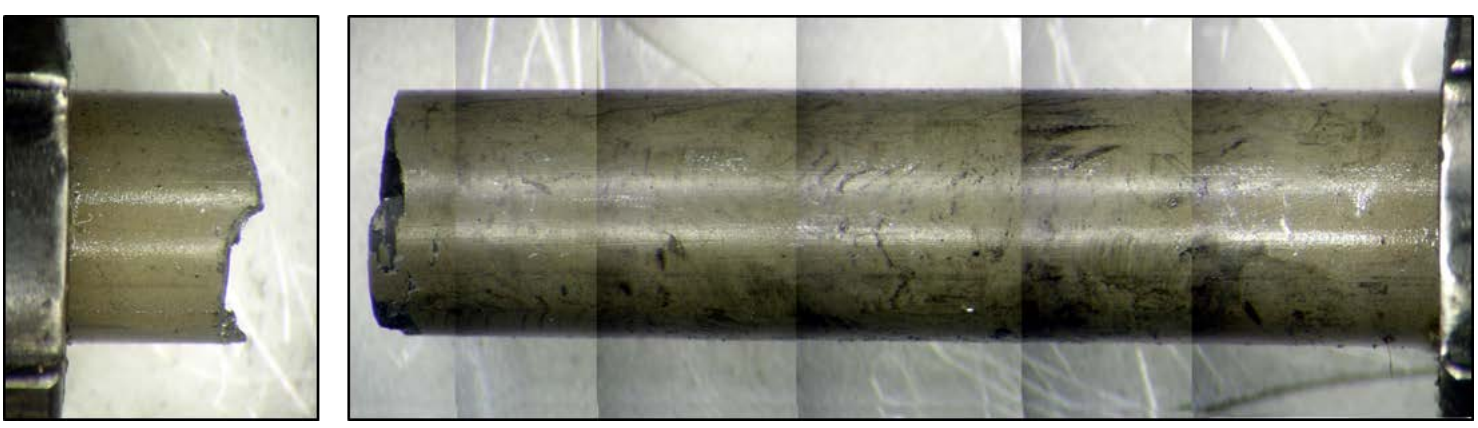

(d)

Figure 29 (a) and (b) Mating fracture surfaces, (c) frontal and (d) back sides of S3 (605D1F). $\mathrm{N}_{\mathrm{f}}$ $=2.5 \times 10^{4}$ cycles under $\pm 25.40 \mathrm{Nm} 5 \mathrm{~Hz}$. 


\section{In-cell bending test of SNF rods}

\subsection{Test procedure and data processing}

\subsubsection{Test procedure}

Static and dynamic testing proceeded with the following considerations.

- Static testing involves ramping both disp1 and disp2 of Bose machine or U-frame arms at $0.1 \mathrm{~mm} / \mathrm{s}$ to $12 \mathrm{~mm}$, and then down to the original position.

o If the rod sustains the loading-unloading cycle, a repeated static loading tests are performed using same condition for two to three cycles.

o A follow up dynamic loading is then applied to observe the failure if the specimen survives the repeated loading cycles.

o The collected fuel particles are weighed.

- Dynamic testing consists of two steps as mentioned above, including:

o Measurement of the rod using low frequency $0.05 \mathrm{~Hz}$ and small amplitude;

o Cycling of the rod under a designed loading condition. While the cycle frequency is set at $5 \mathrm{~Hz}$, the amplitudes of individual cycle tests are selected to target the lifetimes of the specimens ranging from $10^{3}$ to $10^{7}$ cycles.

o Dynamic test stops whenever the fracture occurs or the cycles reach a defined number.

o The fuel particles are weighed if they are collected.

\subsubsection{Data processing}

Measurement data and on-line monitoring data are converted into the applied moment and the curvature, based on the load channels (load 1 and 2) and given loading arm (101.60 mm), and LVDT channels (LVDT1, 2, and 3).

- For the static testing data, curvature-moment curves are given along with the equivalent strain-stress curves.

o The equivalent stress was calculated by: stress $=M y_{\max } / I, I=I_{c}+I_{p} \cdot I_{c}$ and $I_{p}$ are moments of inertia of clad and pellet. $y_{\max }$ is the maximum y of the section and measured by the radius of clad.

o The equivalent strain was according to: strain $=\kappa^{*} \mathrm{y}_{\operatorname{man}} . \kappa$ is the curvature based on the three LVDT measurements.

o The applied loads to the U-frame at the loading points have been corrected by considering the effect of the resistance from system. Such resistance was shown to be substantial when the loading point displacement is high.

- For the dynamic testing data, the variations of curvature range, moment range, and flexural rigidity as a function of the number of accumulated cycles are presented. 


\subsection{Static test results and analysis}

Static tests were conducted from 10/7/2013 to 10/8/2013. A description of four static tests and their results is given below.

\subsubsection{S1/ 606C3C (+ dynamic)}

S1 (606C3C, $66.8 \mathrm{GWd} / \mathrm{MTU}$ burnup, 70-100 $\mu \mathrm{m}$ oxide layer, $650 \mathrm{ppm} \mathrm{H}$ content) was tested with 4 repeated static loading cycles before being put into the cycle test. The moment-curvature curve and equivalent stress-strain curve for the initial cycle are presented in Figure 30 (the curves of subsequent cycles overlaid to a great extent and are not plotted for clarity). Again, the turning points were revealed near 20 and $60 \mathrm{Nm}$. The rod fractured in a follow-up cyclic loading under \pm 25.40 to $30.48 \mathrm{Nm} 5 \mathrm{~Hz}$ near $1.4 \times 10^{4}$ cycles.

The fracture took place near motor 1 with a fuel release of 0.9 grams. The fractography using optical microscope as shown in Figure 31 revealed that the failure of the rod was related to the fractures of the pellet adjacent to a pellet-to-pellet interface. The exit of pellet end face can be identified from the haze zone characterized with brown bluish color. At the same time, a serrated fracture surface of clad was observed with a slender attachment (about 1 in. length) aside.

The lateral surfaces [Figure 31 (c) and (d)] near the neutral axis of bending rod are shown to be free of circumferential cracks to a great extent. On the other hand, one of the stressed lateral surfaces is covered with a large number of circumferential cracks and related subsurface spalling [Figure 31 (d)]. It is not sure if the spalling was related to tensile stress in static loading as the specimen ID to be $90^{\circ}$ off to the stressed sides.

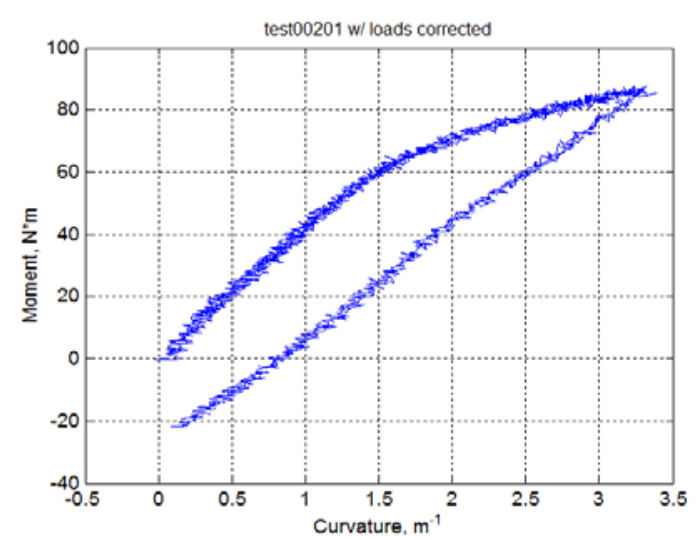

(a)

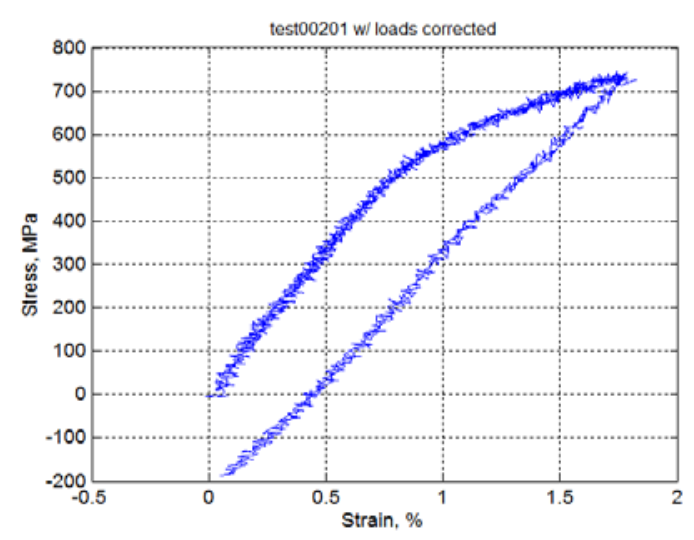

(b)

Figure 30 (a) Curve of moment versus curvature, and (b) equivalent strain- stress curve for S1 (606C3C); based on static loading cycle in which maximum relative displacement was $24 \mathrm{~mm}$ and rate at loading points of U-frame set at 0.1 and $0.2 \mathrm{~mm} / \mathrm{s}$ in loading and unloading, respectively. 


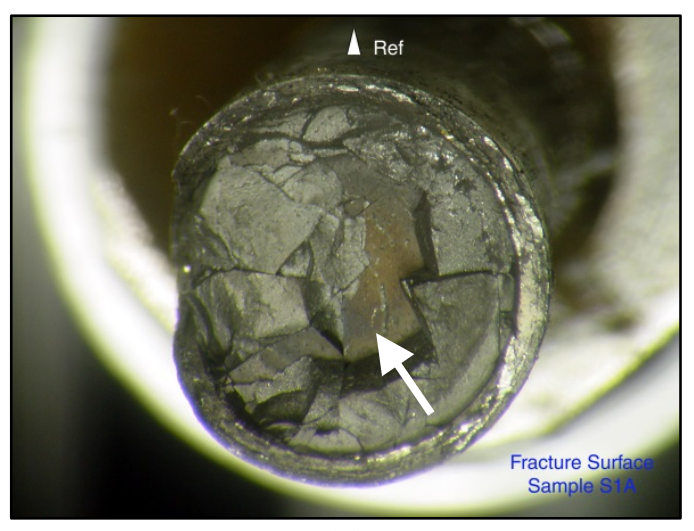

(a)

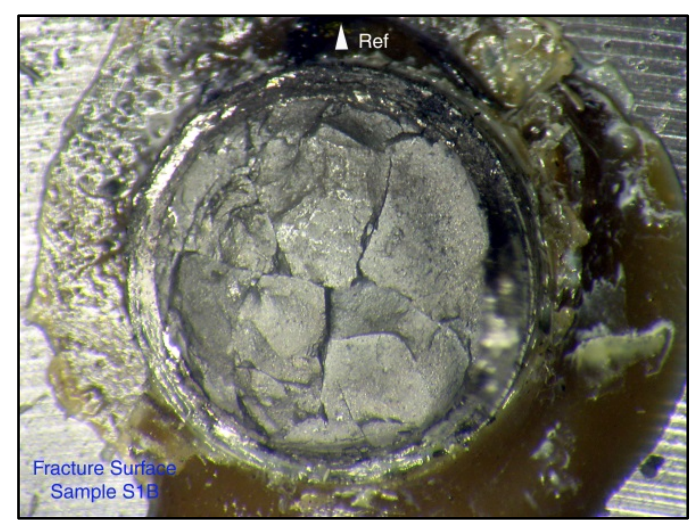

(b)

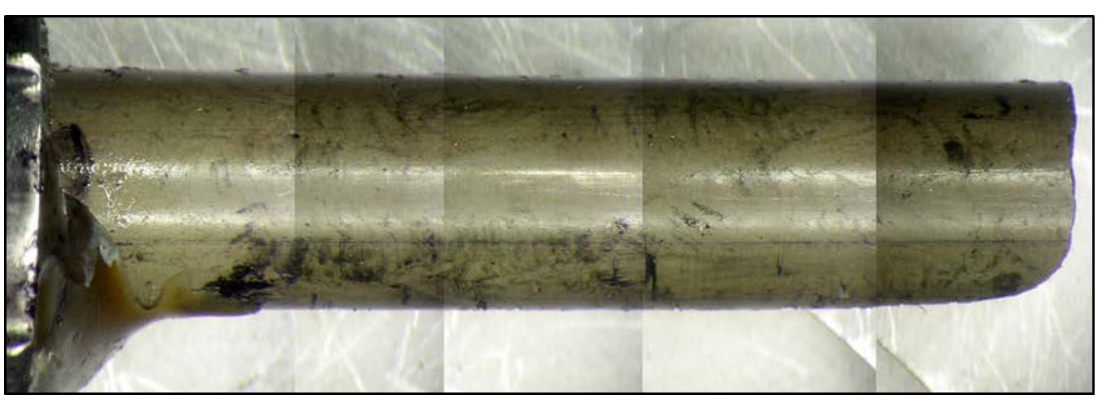

(c)

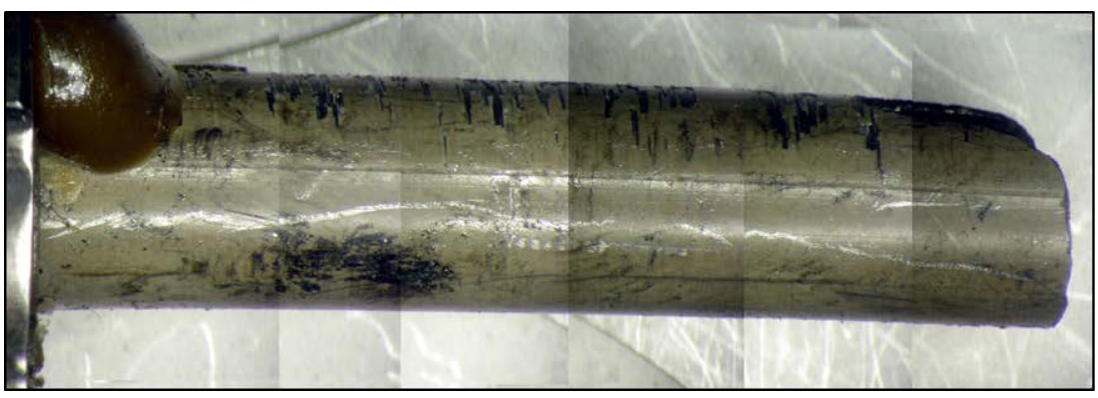

(d)

(I)
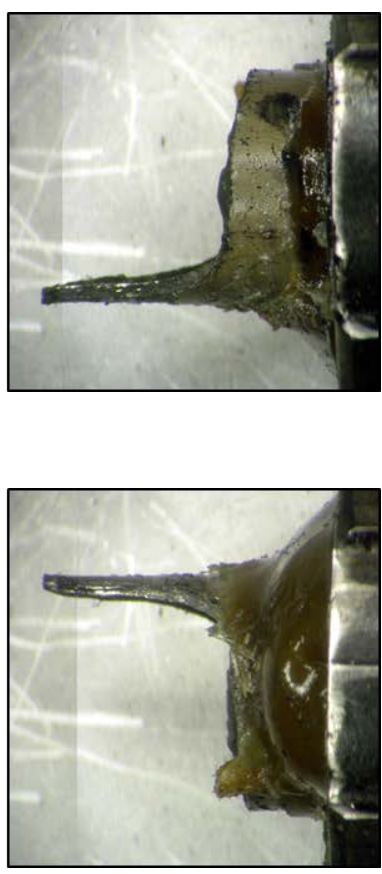

Figure 31 (a) and (c) Mating fracture surfaces, (c) and (d) lateral sides near the neutral axis of bending rod for S1 (606C3C), which was subjected to 4 repeated static cycles to $24 \mathrm{~mm}$ maximum relative displacement followed by dynamic cyclic loading \pm 25.40 to $30.48 \mathrm{Nm} 5 \mathrm{~Hz}$; $1.4 \times 10^{4}$ failure cycles, 0.9 gram fuel particles collected. 


\subsubsection{S2/ 605D1E (+ dynamic)}

S2 (605D1E, $66.5 \mathrm{GWd} / \mathrm{MTU}$ burnup, 40-70 $\mu$ m oxide layer, $400 \mathrm{ppm} \mathrm{H}$ content) was tested by following a routine similar to $\mathrm{S} 1$. The specimen survived 3 cycles of large displacement loading and $7.2 \times 10^{3}$ cycles under $\pm 30.48 \mathrm{Nm} 5 \mathrm{~Hz}$ before failure at the middle of section.

The moment-curvature curve and equivalent stress-strain curve for the initial cycle are presented in Figure 32. Again, the turning points were revealed near 20 and $60 \mathrm{Nm}$.

The fracture took place on a pellet-to-pellet interface as can be seen from Figure 33, in which a smooth brownish end face of the adjacent pellet can be seen clearly. One of the attachments [Figure 23(a)] is convex-shaped and covers almost $1 / 3$ of the end face, and several small ones around the peripheral area. Thus, the interface bonding was significant.

The fracture of clad appeared very serrated with a sizable tooth-shaped attachment on the compressive side of the rod. The lateral stressed surface of the rod was covered by sparsely distributed circumferential spalling. The minor damaged lateral surface of bending rod agrees with the results of S3 as they were prepared from same segment 605D with same level of preexisting oxides and hydrides.

Fuel release was about 0.6 grams.

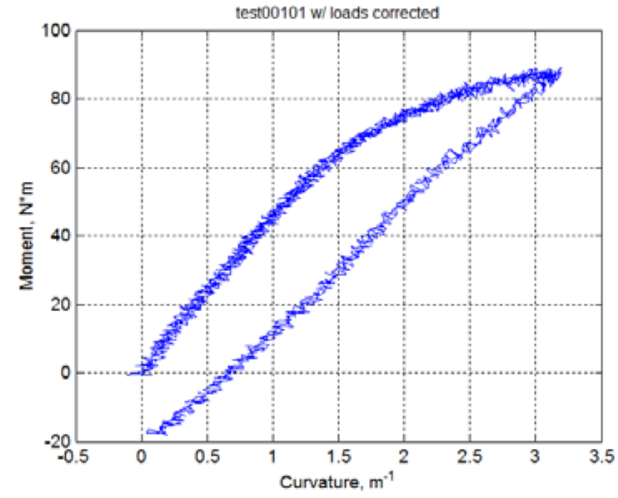

(a)

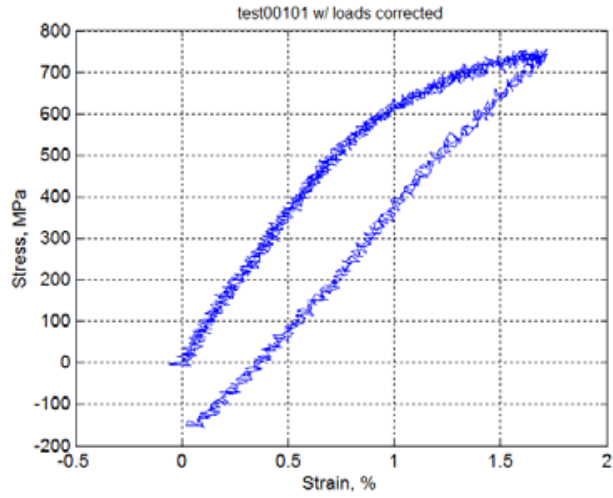

(b)

Figure 32 (a) Curve of moment versus curvature, and (b) equivalent strain- stress curve for S2 (605D1E); based on static loading cycle in which maximum relative displacement was $24 \mathrm{~mm}$ and rate at loading points of U-frame set at 0.1 and $0.2 \mathrm{~mm} / \mathrm{s}$ in loading and unloading, respectively. 


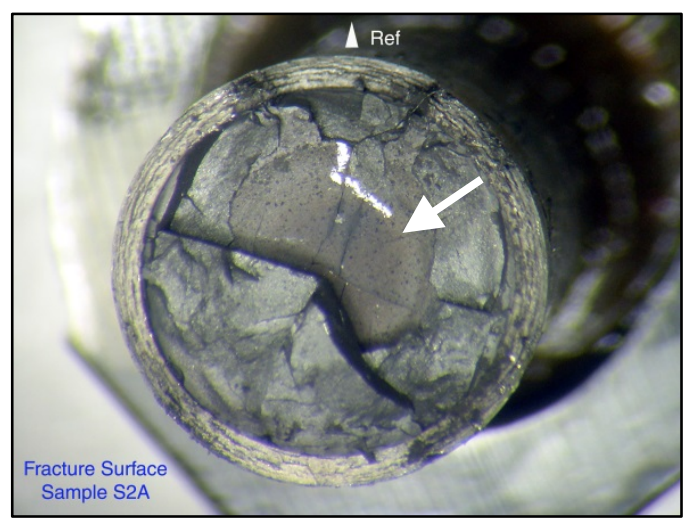

(a)

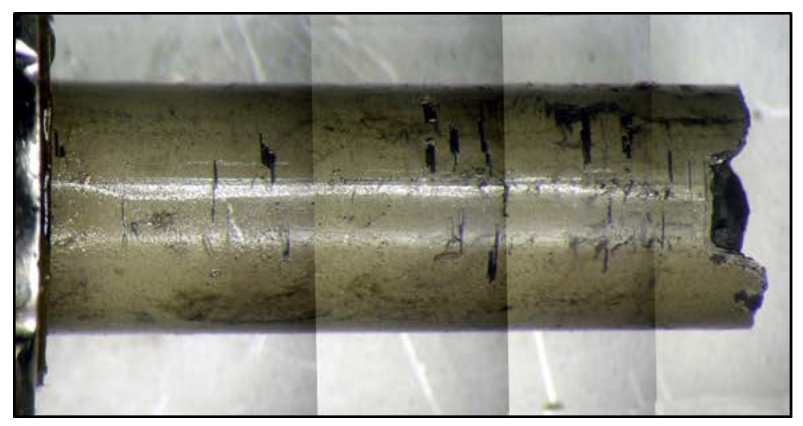

(c)

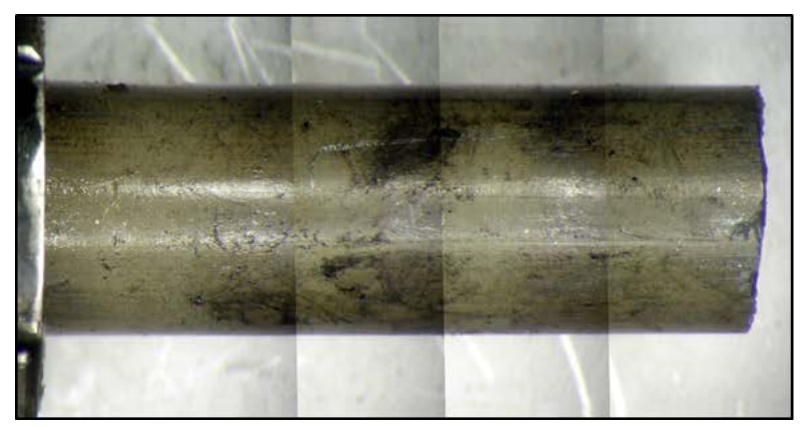

(d)

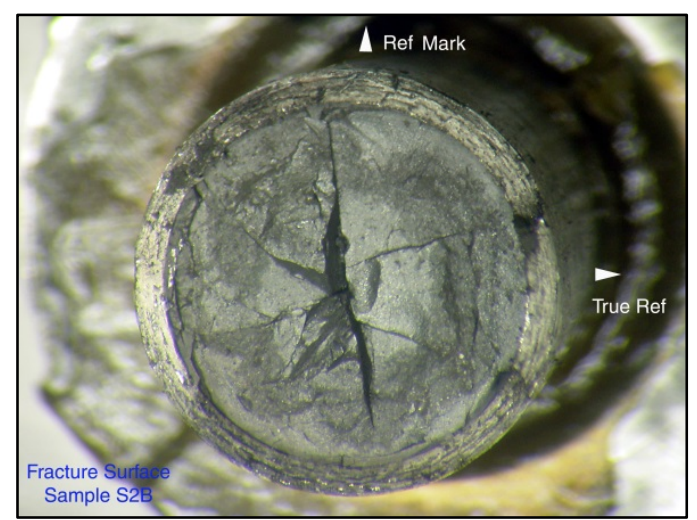

(b)
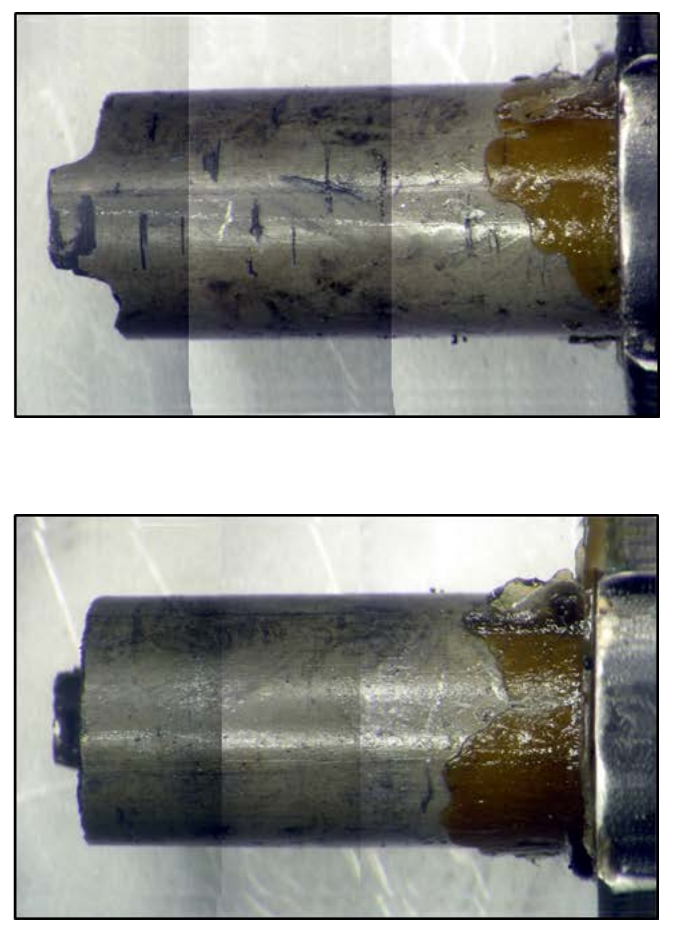

Figure 33 (a) and (b) Mating fracture surfaces, (c) frontal and (d) back sides for S2 (605D1E), which was subjected to 3 repeated static cycles to $24 \mathrm{~mm}$ maximum relative displacement followed by dynamic cyclic loading $\pm 30.48 \mathrm{Nm} 5 \mathrm{~Hz} ; 7.2 \times 10^{3}$ failure cycles, 0.6 gram fuel particles collected.

\subsubsection{Scal/ 609C6}

Scal (609C6, 66.5 GWd/MTU burnup, 70-100 $\mu$ m oxide layer, 550 ppm H content) sustained 3 cycles of loading with relative displacement $24 \mathrm{~mm}$ on U-frame and an additional load with 25 $\mathrm{mm}$ before failure. The failure occurred around peak moment $93.5 \mathrm{Nm}$. The curves for the initial 
cycle exhibits a quite smooth transit from linear to non-linear stage as shown in Figure 34. However, a turning point near $20 \mathrm{Nm}$ is still appreciable based on the discontinuous change of slope of moment-curvature curve.

The fracture occurred near the motor 2 and was shown to be related to pellet fractures near a pellet-to-pellet interface as illustrated in Figure 35. The exit of end face of involved pellet can be seen clearly from the bluish haze zone. A serrated fracture surface of clap can be seen also.

The specimen ID was found out $90^{\circ}$ off the stressed surfaces of the rod. However, the conspicuous sharp attachment on one side suggests where the intensified compression once resided inducing the shearing fracture. The opposite side is covered a certain amount of spalling as discussed above. The less stressed lateral side near the neutral axis of bending rod appeared to be clear of circumferential cracks.

The failure of rod involved a lot of fragmentation in the fractured pellet. 1.3 grams of fuel released were obtained.

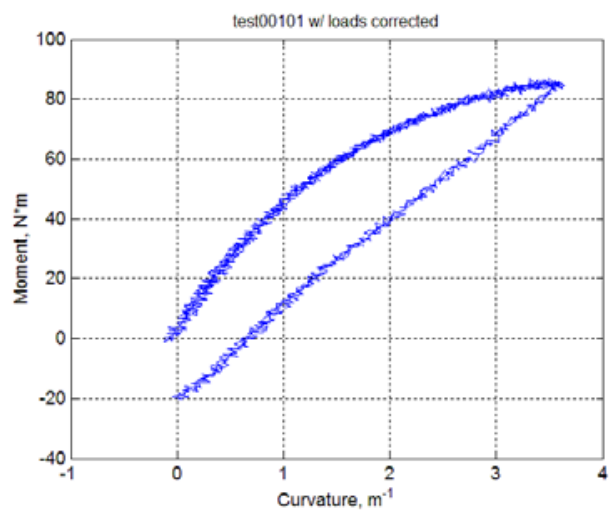

(a)

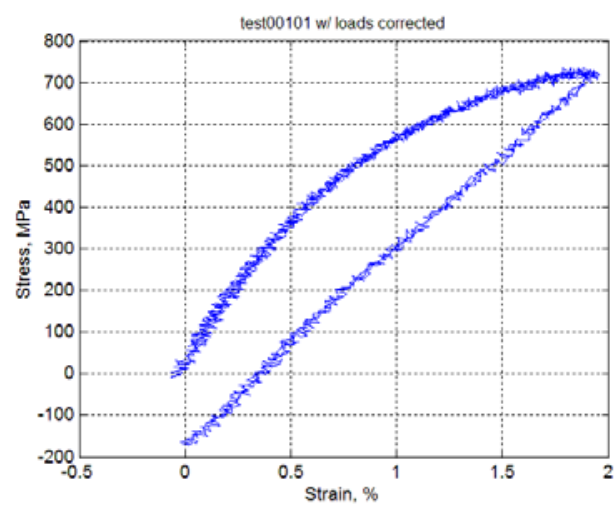

(b)

Figure 34 (a) Curve of moment versus curvature, and (b) equivalent strain- stress curve for Scal (609C6); based on static loading cycle in which maximum relative displacement was $24 \mathrm{~mm}$ and rate at loading points of $U$-frame set at 0.1 and $0.2 \mathrm{~mm} / \mathrm{s}$ in loading and unloading, respectively. 


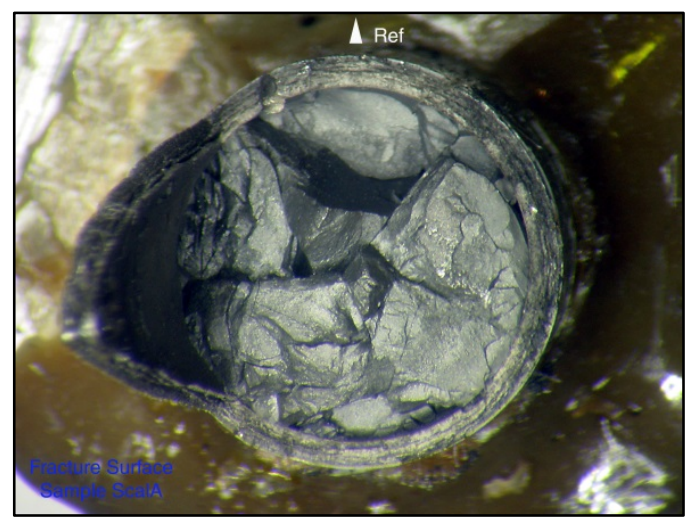

(a)
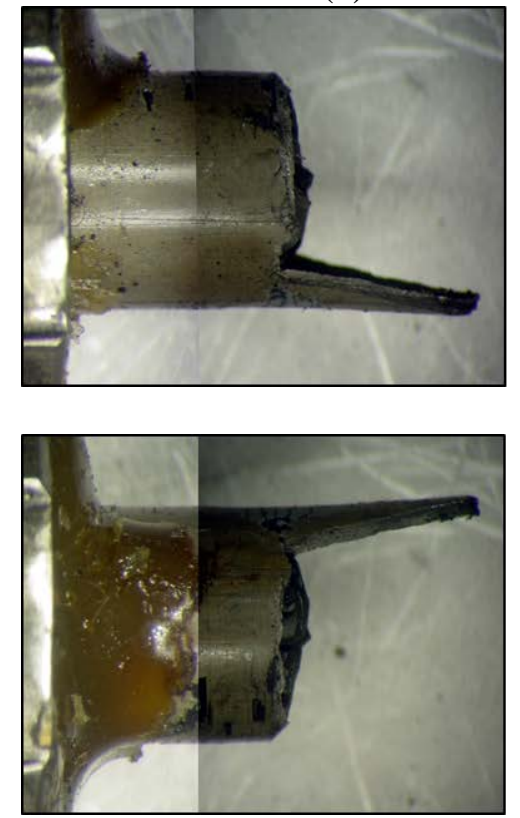

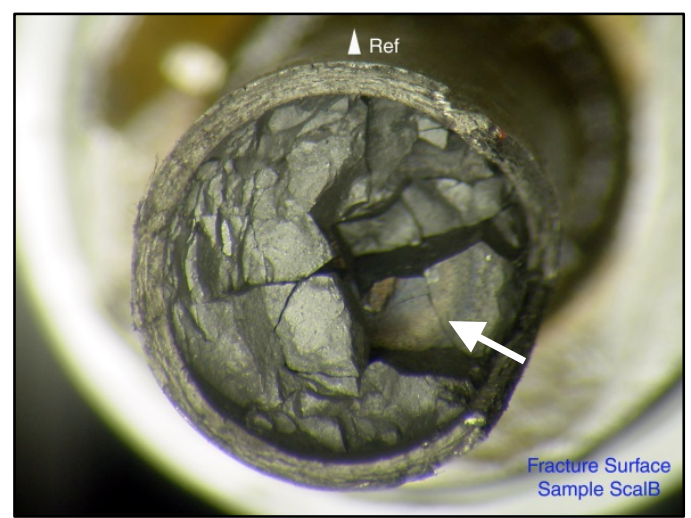

(b)

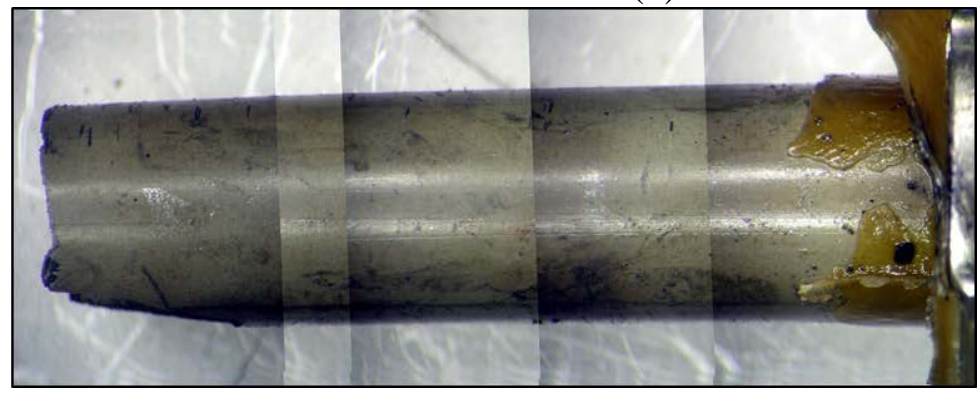

(c)

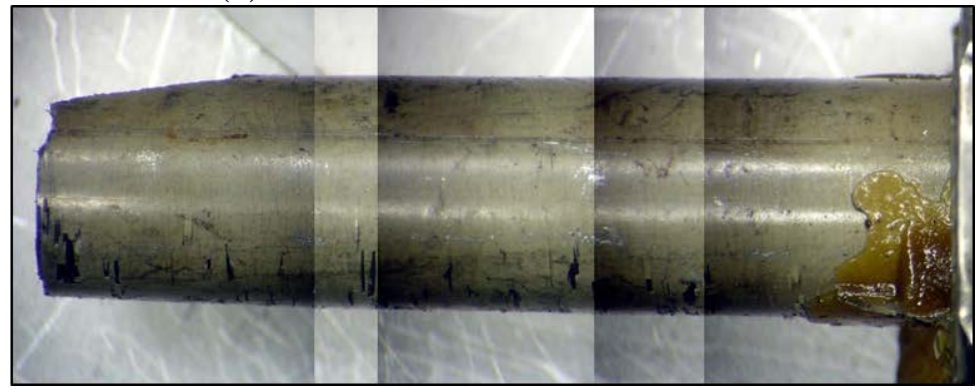

(d)

Figure 35 (a) and (b) Mating fracture surfaces, (c) and (d) laterals sides near the neutral axis of bending rod for Scal (609C6), which was subjected to repeated static loading to $24 \mathrm{~mm}$ maximum relative displacement and failed at $93.5 \mathrm{~N}^{*} \mathrm{~m}$ in the 4 th cycle, 1.3 gram fuel particles collected.

\subsubsection{Dcal/ 609C5 (+ dynamic)}

Dcal (609C5, 66.5 GWd/MTU burnup, 70-100 $\mu$ m oxide layer, 550 ppm H content) were subjected to 3 repeated static cycles of $24 \mathrm{~mm}$ displacement loading followed by cyclic loading $\pm 30.48 \mathrm{Nm} 5 \mathrm{~Hz}$. The Dcal failed around $9.6 \times 10^{3}$ cycles at the middle of gage section with about 0.2 grams fuel released.

A three stage moment-curvature curve was obtained as shown in Figure 36 in which two turning points can be seen near 20 and $60 \mathrm{Nm}$. 
The failure of rod was mainly related to the fracture of pellet (Figure 37). No involvement of pellet-to-pellet interface can be seen. The fracture surface of pellet was characterized with blocks whose size was about quarter diameter of pellet.

A serrated fracture surface was seen again on clad. Furthermore, the fracture surface was tilted to a certain degree to the longitudinal axis of rod. This is in contrast to those where the failure actively involves the pellet-to-pellet interface whose fracture surfaces are more or less normal to the longitudinal axis of rod. Circumferential cracks and spalling can be observed on lateral stressed sides, especially on the tensile side in static loading. The spalls had an extended dimension in the circumferential direction, some of which were overlaid in the longitudinal axis of rod. However, the extent of overlaying is not as large as seen in Demo1 and Demo2, attributed to the smaller size of oxide and hydrides.

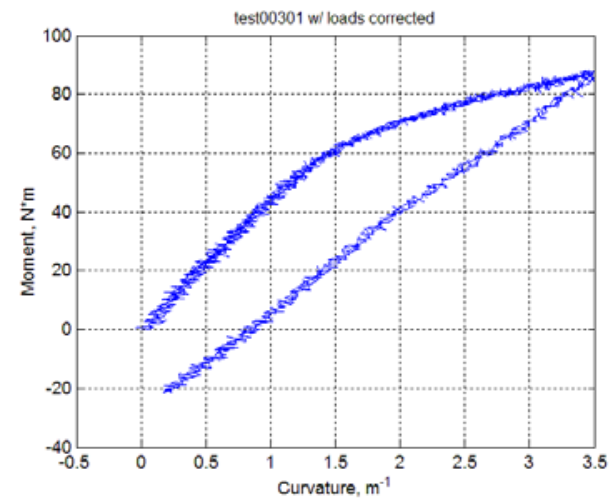

(a)

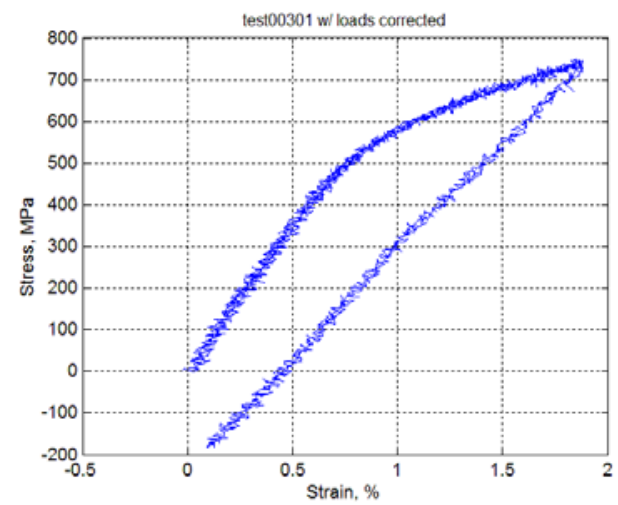

(b)

Figure 36 (a) Curve of moment versus curvature, and (b) equivalent strain- stress curve for Dcal (609C5); based on static loading cycle in which maximum relative displacement was $24 \mathrm{~mm}$ and rate at loading points of $U$-frame set at 0.1 and $0.2 \mathrm{~mm} / \mathrm{s}$ in loading and unloading, respectively. 


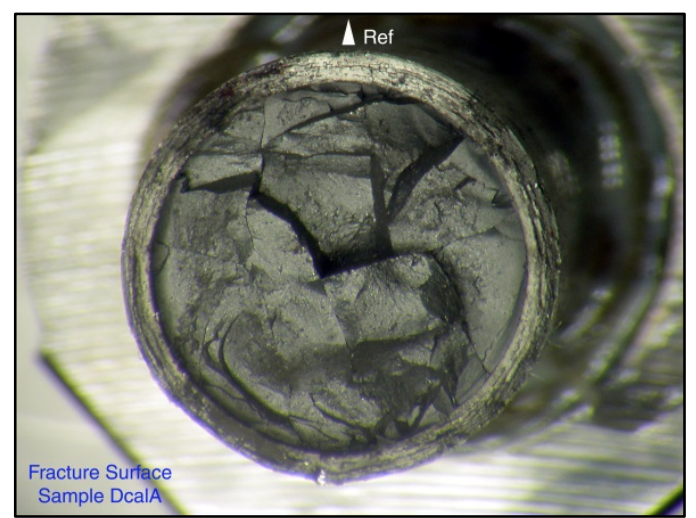

(a)

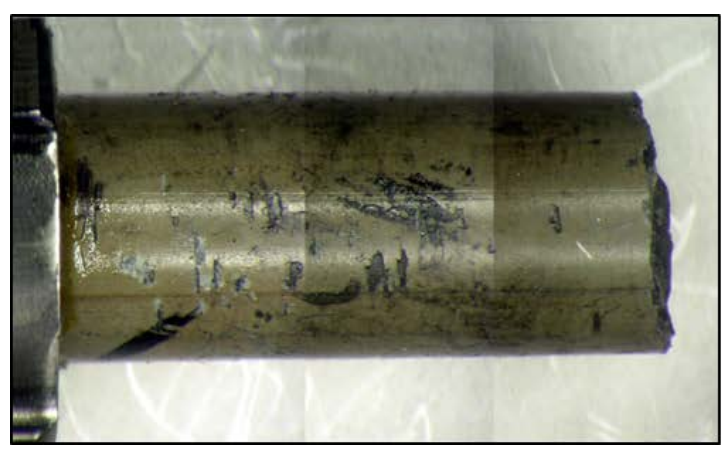

\section{(c)}

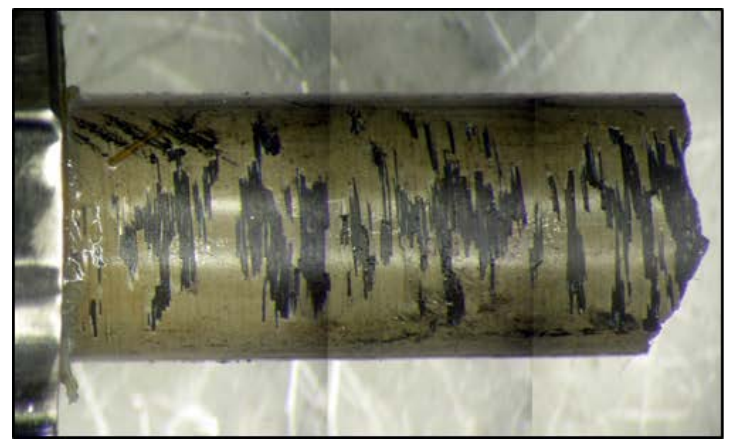

(d)
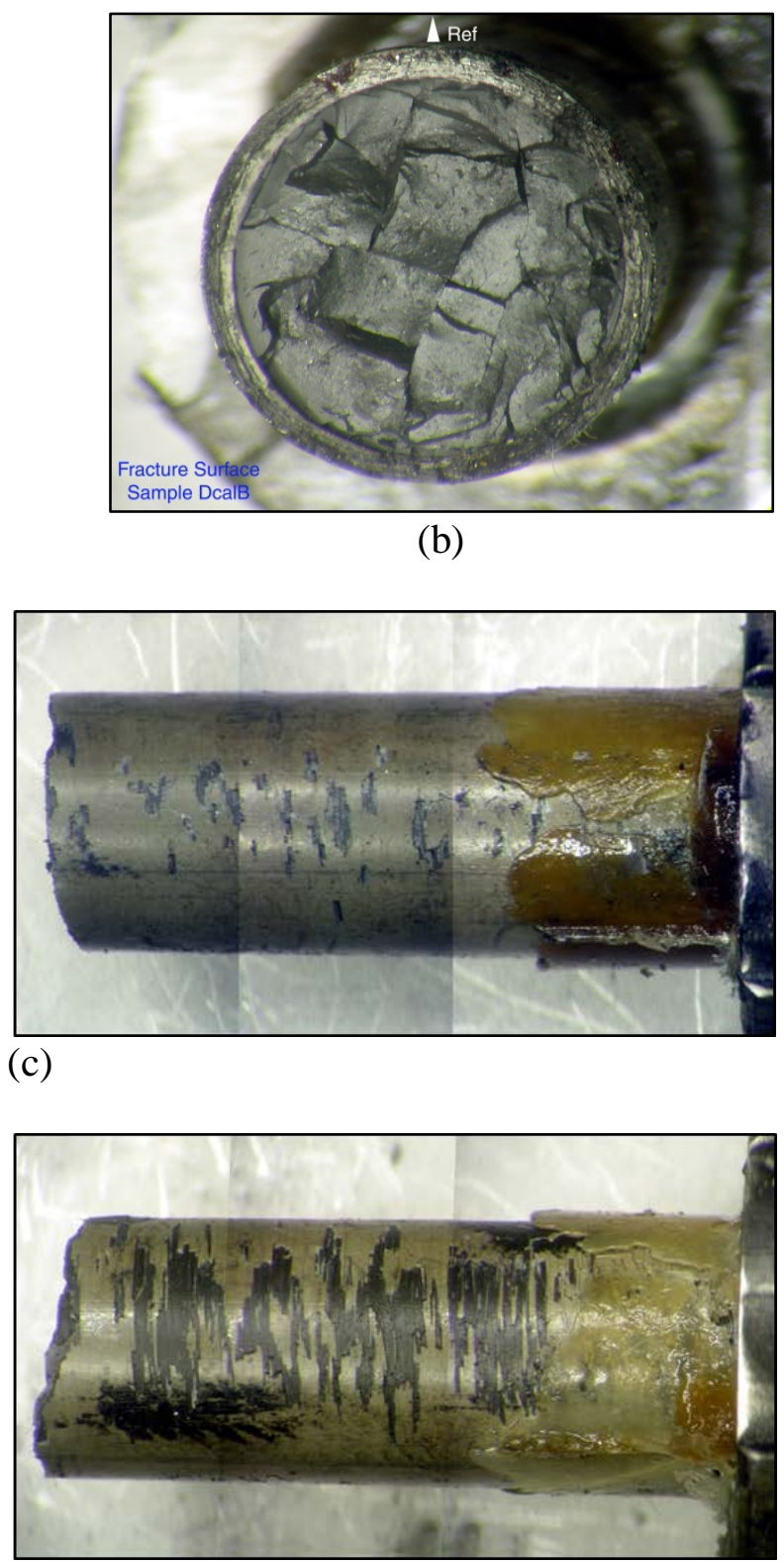

(b)

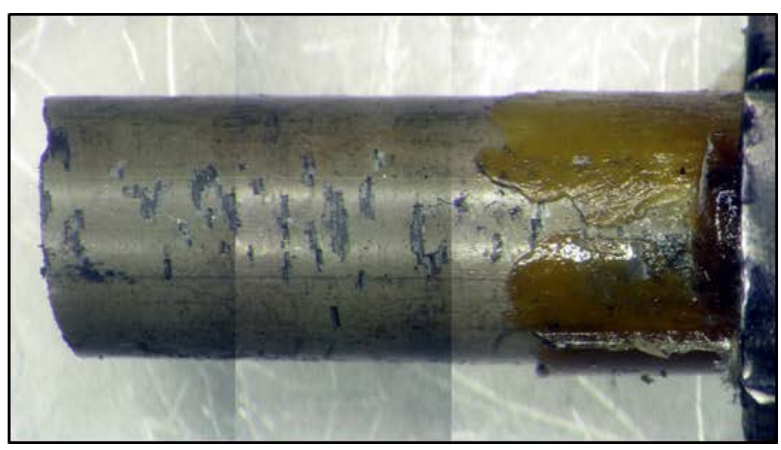

Figure 37 (a) and (b) Mating fracture surfaces, (c) frontal and (d) back side for Dcal (609C5), which was subjected to 3 repeated static loading to $24 \mathrm{~mm}$ maximum relative displacement followed by dynamic loading: $\pm 30.48 \mathrm{Nm} 5 \mathrm{~Hz}$; $9.6 \times 10^{3}$ failure cycles, 0.2 gram fuel particles collected.

\subsection{Dynamic test results and analysis}

Dynamic testing started on 10/22/2013 and is ongoing. A description of completed dynamic tests and their results is given below. 


\subsubsection{DL1/ 607C4B $( \pm 15.24 \mathrm{Nm} 5 \mathrm{~Hz})$}

The test on DL1 (607C4B, 63.8 GWd/MTU burnup, 70-100 $\mu$ m oxide layer, 700 ppm H content) was conducted under $\pm 15.24 \mathrm{Nm} 5 \mathrm{~Hz}$. A lifetime of $1.1 \times 10^{5}$ cycles was obtained with less than 1 gram fuel particles collected. The cycle to failure of DL1 is apparently longer than that obtained for S3. The latter was subjected to a higher amplitude load, $25.40 \mathrm{Nm}$.

The curvature, moment, and flexural rigidity based on on-line monitoring data are presented in Figure 38. A quite stable response of rod exhibited without any sign of failure prior to the final breakage. The measurements at all the paused moments indicated the equivalent fluctuation, whilst the rigidity around 1000 cycles revealed some degree of degradation as seen in Figure 39.

The failure was observed in the gage section near motor 2. The failure occurred at the pellet-topellet interface as illustrated in Figure 40. The end faces of two neighboring pellets were essentially quite clean. At the same time, the fracture surfaces of clad are serrated. Some layered fractures were developed in the circumferential direction but they are hardly differentiated at this magnification scale.

Both the lateral stressed sides of rod were found to have been covered with equally-spaced circumferential cracks throughout the gage section. Spalling only occurred to the local area near the fracture. The similarity in the damage of lateral stressed sides shown in DL1 is different from those that were experienced a unidirectional bending. The large deformation arising from the unidirectional bending can produce a greater scale of damage or spalling in one side, but a less scale on other side as seen, for example, in Dcal (Figure 37).

It is our interest, at this point of time, to compare the response of DL1 to that of S3 as both were subjected to pure cyclic test without any large unidirectional loading. The lateral stressed surfaces of rod S3, as discussed above, were quite free of the circumferential damages, even though the load amplitude to S3 was higher. However, the S3 was prepared from a segment with less subsurface damage from high burnup. It has been thus demonstrated that the prevailing circumferential cracks only occurs to the rods that have a substantial development of oxides and hydrides. 


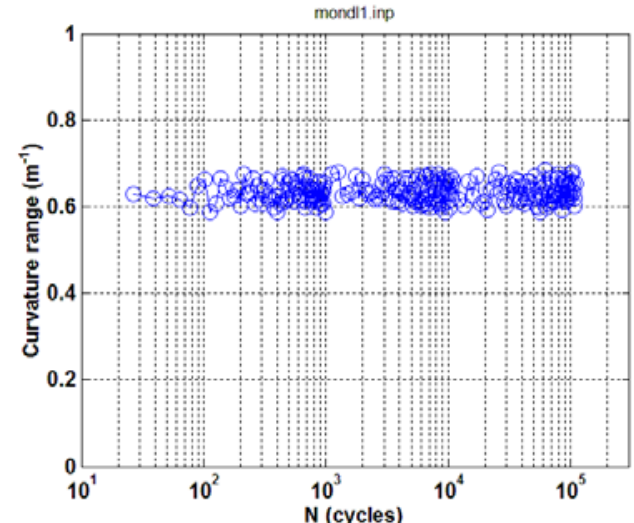

(a)

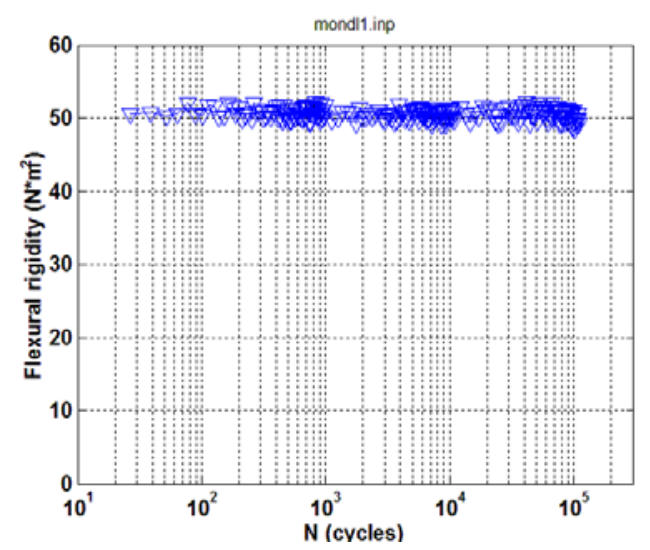

(c)

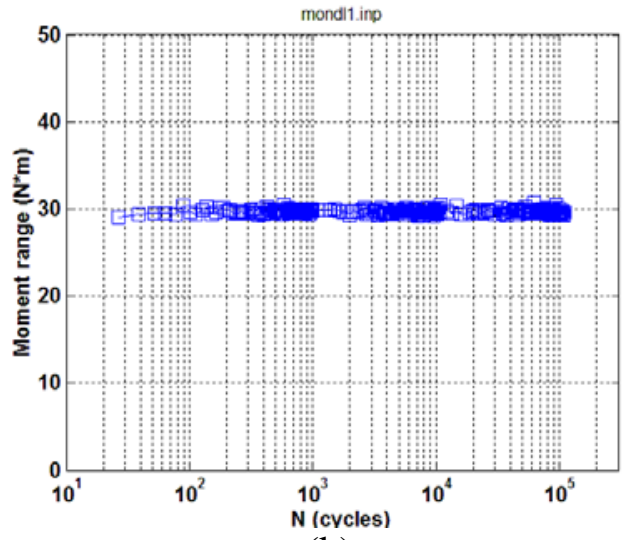

(b)

Figure 38 Variations of (a) curvature range, (b) applied moment range, (c) flexural rigidity as a function of number of cycles for DL1 (607C4B); $\mathrm{N}_{\mathrm{f}}=1.1 \times 10^{5}$ cycles under $\pm 15.24 \mathrm{Nm} 5 \mathrm{~Hz}$. Fuel particles collected $<1.0$ gram.

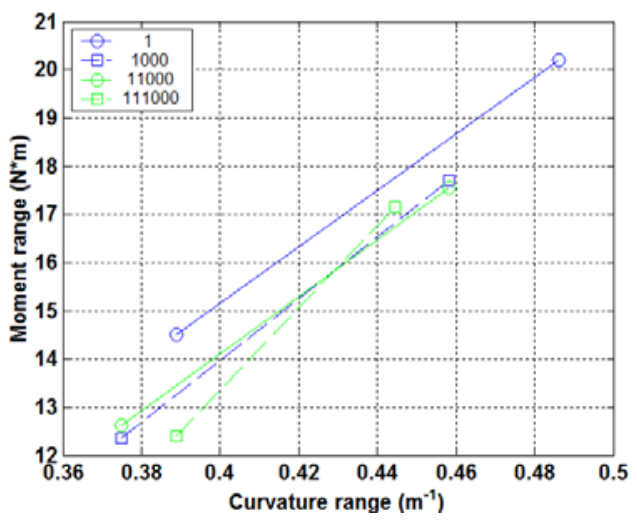

(a)

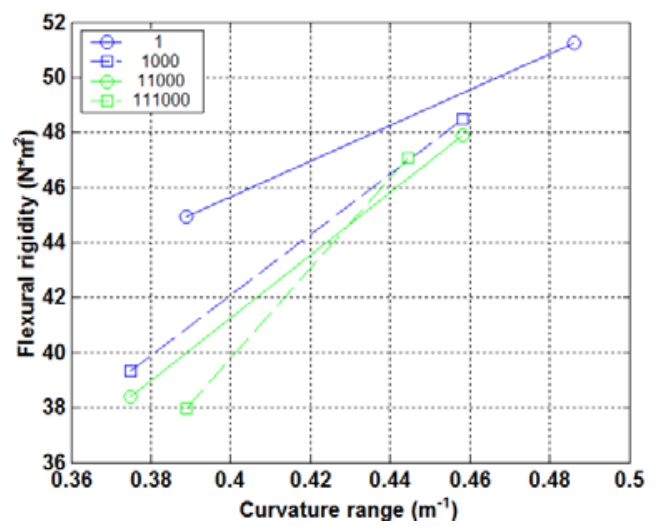

(b) 
Figure 39 (a) Moment-curvature relation, and (b) moment-flexural rigidity relation at various numbers of cycles for DL1 (607C4B); $\mathrm{N}_{\mathrm{f}}=1.1 \times 10^{5}$ cycles under $\pm 15.24 \mathrm{Nm} 5 \mathrm{~Hz}$. Fuel particles collected $<1.0$ gram.

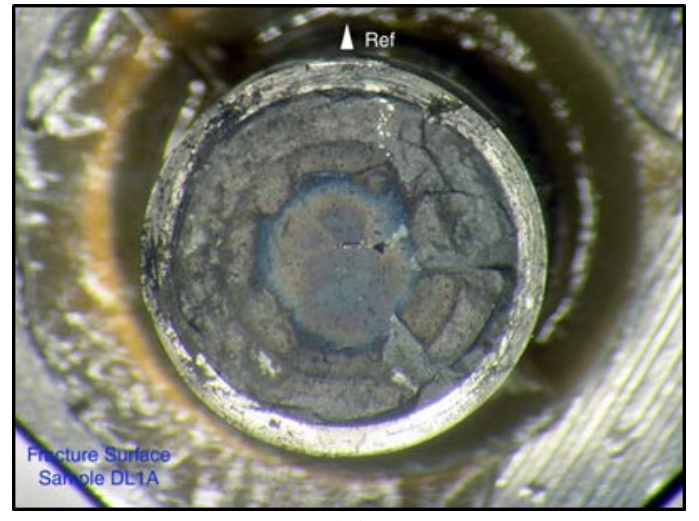

(a)

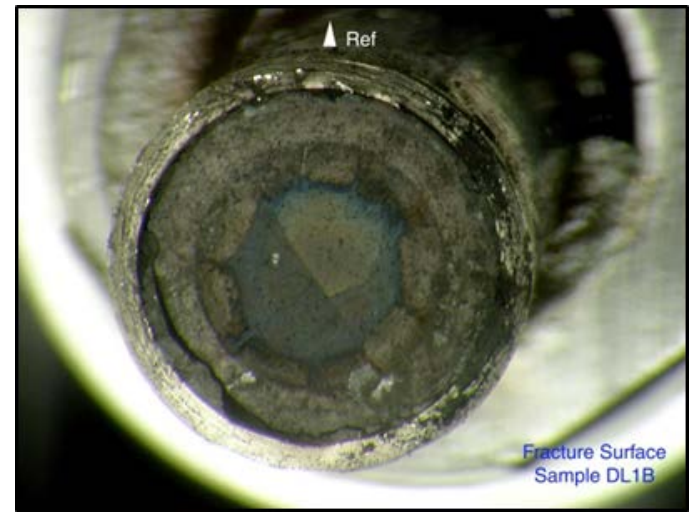

(b)
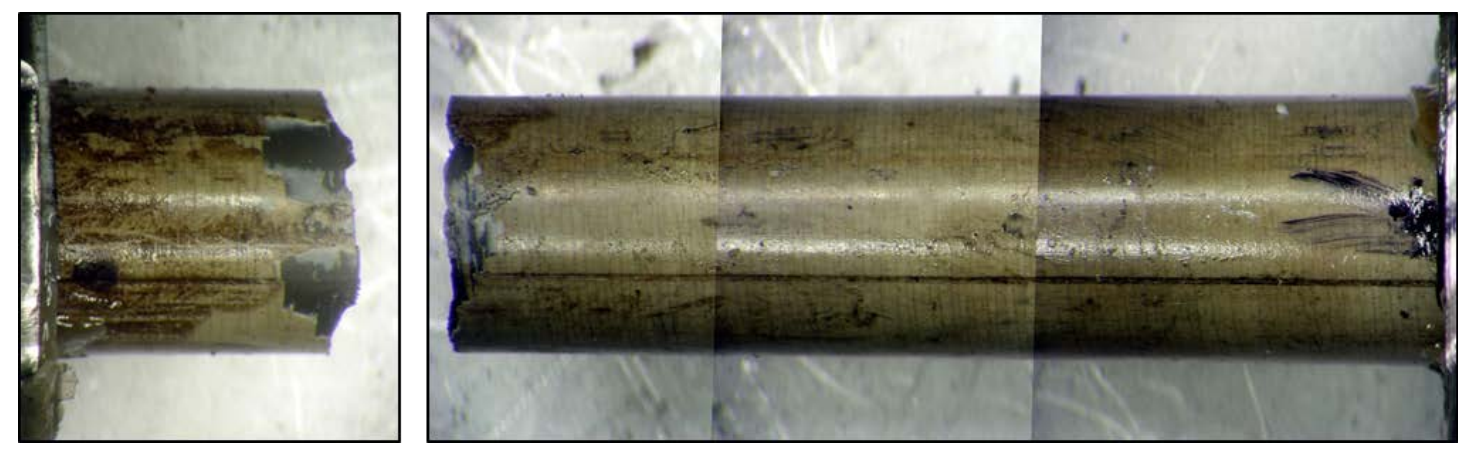

(c)
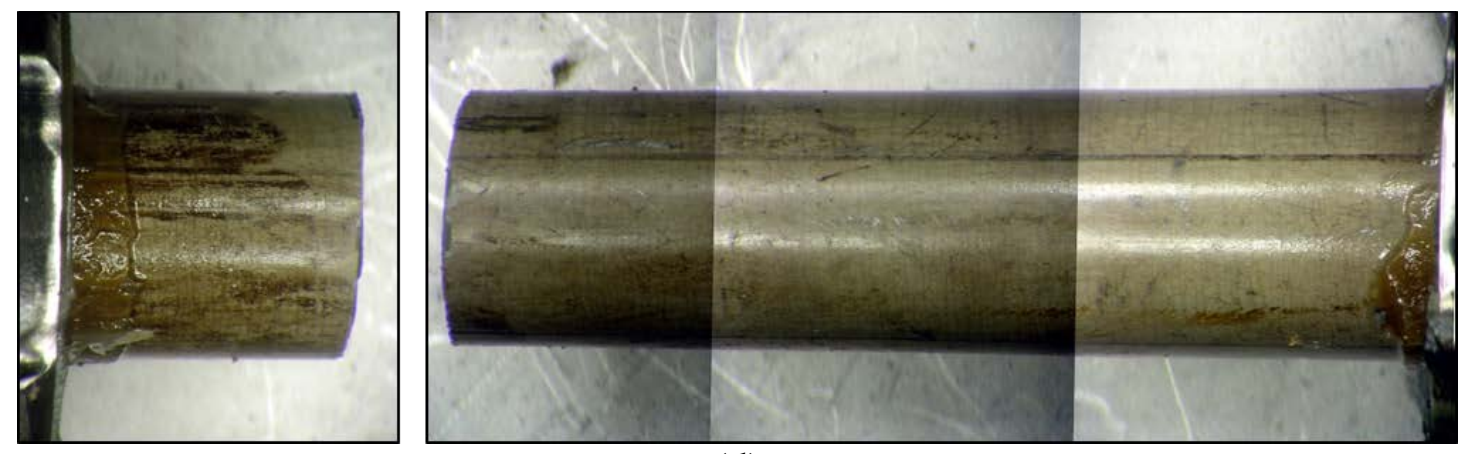

(d)

Figure 40 (a) and (b) Mating fracture surfaces, (c) frontal and (d) back sides for DL1 (607C4B), $\mathrm{N}_{\mathrm{f}}=1.1 \times 10^{5}$ cycles under $\pm 15.24 \mathrm{Nm} 5 \mathrm{~Hz}$. Fuel particles collected $<1.0$ gram. 


\subsubsection{DL2/ 608C4B ( $\pm 5.08 \mathrm{Nm} 5 \mathrm{~Hz})$}

DL2 (608C4B, $63.8 \mathrm{GWd} / \mathrm{MTU}$ burnup, 70-100 $\mu$ m oxide layer, $700 \mathrm{ppm} \mathrm{H}$ content) was tested under $\pm 5.08 \mathrm{Nm} 5 \mathrm{~Hz}$. The rod sustained more than $6.4 \times 10^{6}$ cycles of loading without showing any changes in terms of flexural rigidity from both the on-line monitoring and measurements using $0.4 \mathrm{~mm}$ relative displacement as shown in Figure 41 and Figure 42. The dynamic test on DL2 was then stopped.

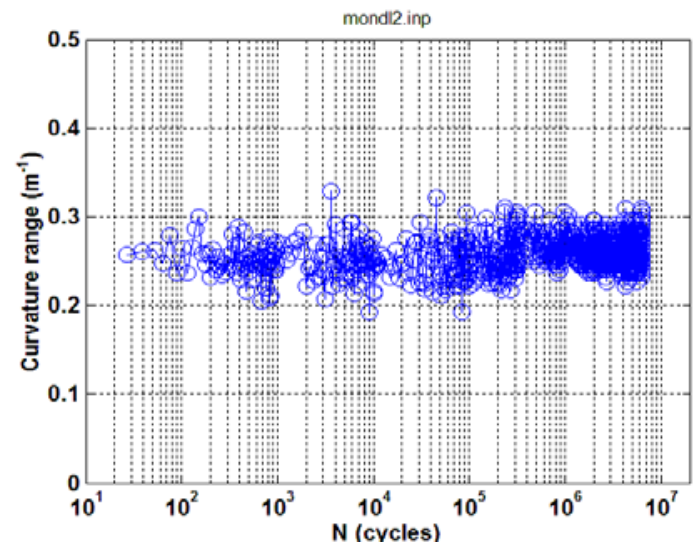

(a)

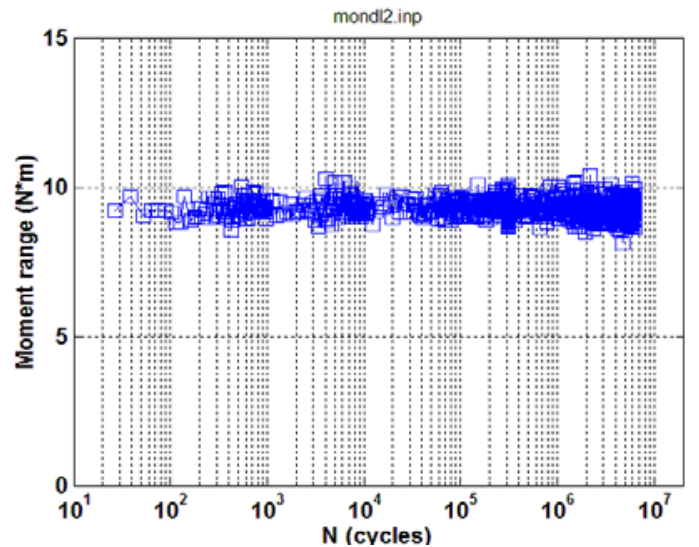

(b)

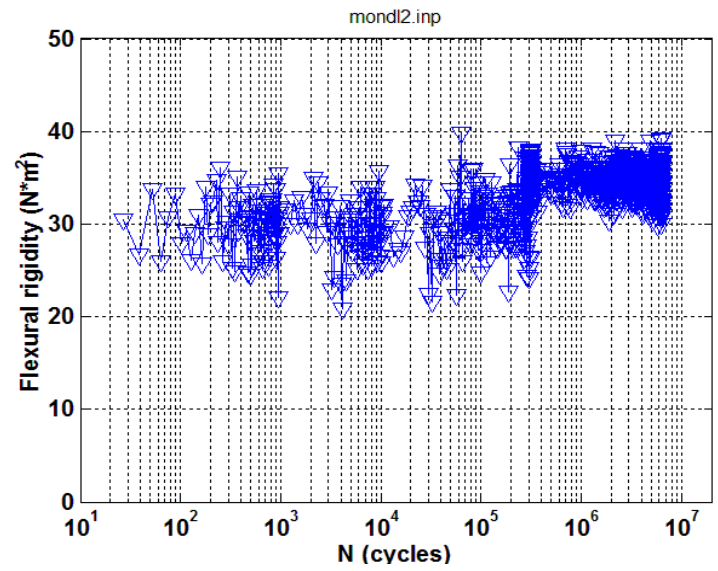

(c)

Figure 41 Variations of (a) curvature range, (b) applied moment range, (c) flexural rigidity as a function of number of cycles for DL2 (608C4B); $6.4 \times 10^{4}$ cycles finished under $\pm 5.08 \mathrm{Nm} 5 \mathrm{~Hz}$, without failure. 


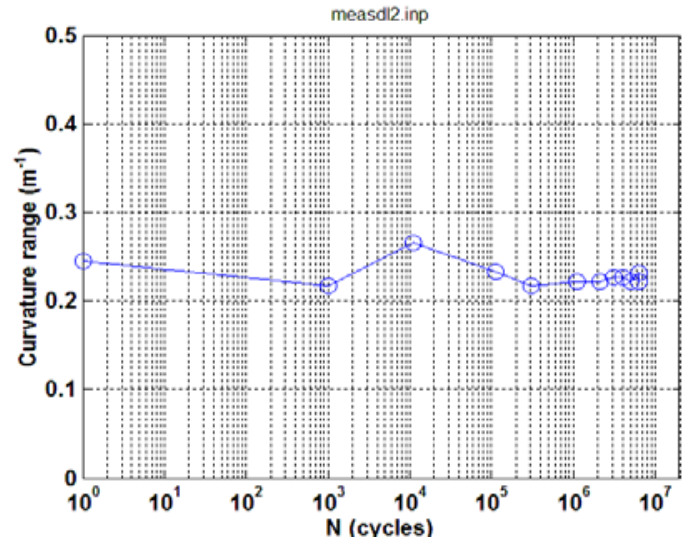

(a)

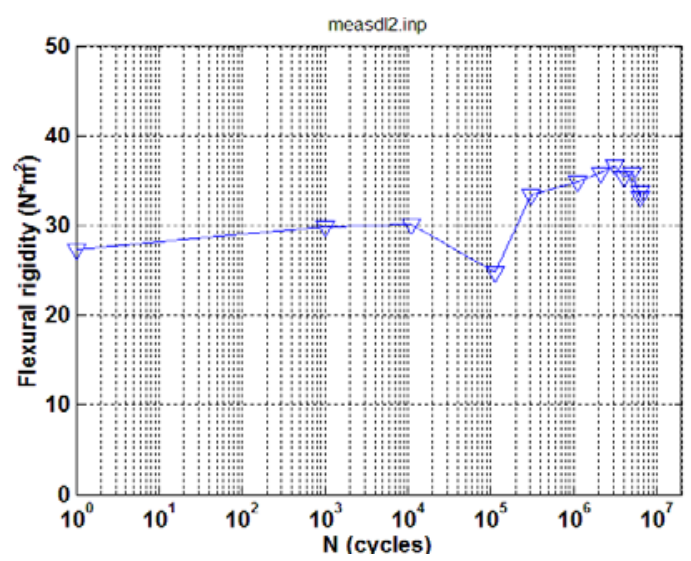

(c)

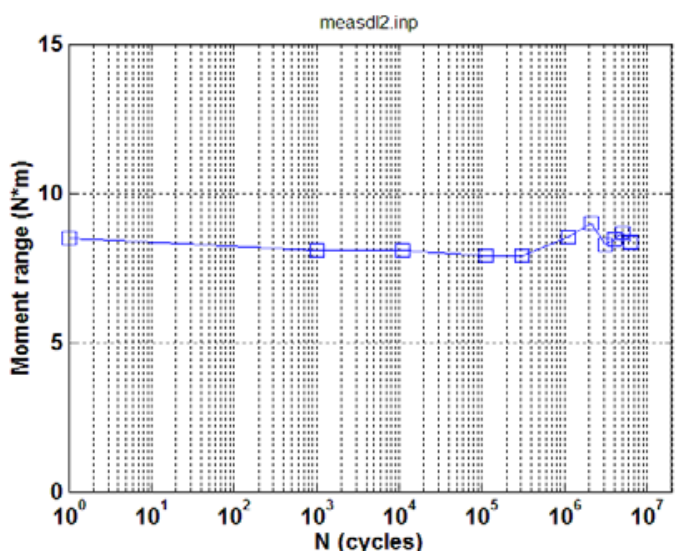

(b)

Figure 42 Variations of (a) curvature range, (b) applied moment range, (c) flexural rigidity as a function of number of cycles for DL2 (608C4B) based on measurements with maximum relative displacement $0.4 \mathrm{~mm} ; 6.4 \times 10^{6}$ cycles finished under $\pm 5.08 \mathrm{Nm} 5 \mathrm{~Hz}$, without failure.

\subsubsection{DL3 / 605C10A ( $\pm 10.60 \mathrm{Nm} 5 \mathrm{~Hz})$}

DL3 (605C10A, 66.5 GWd/MTU burnup, 70-100 $\mu$ m oxide layer, 550 ppm H content) was tested with $\pm 10.60 \mathrm{Nm} 5 \mathrm{~Hz}$. The monitoring data revealed a steady hardening prior to the failure near $1.0 \times 10^{6}$ cycles as seen in Figure 43. The measurements using 0.4 and $0.8 \mathrm{~mm}$ demonstrated a fall and rise trend as given in Figure 44. The abrupt drop of flexural rigidity indicates the rod is indeed fractured. 


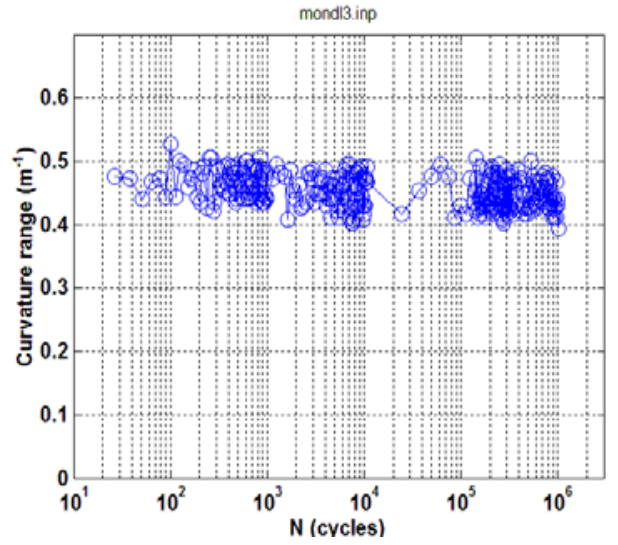

(a)

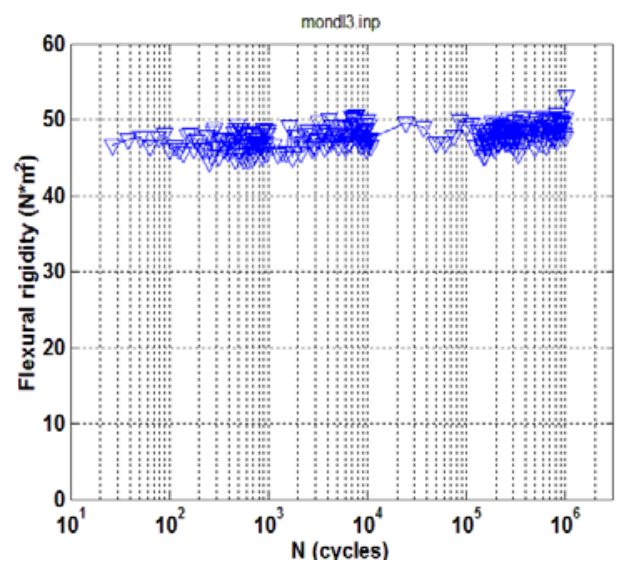

(c)

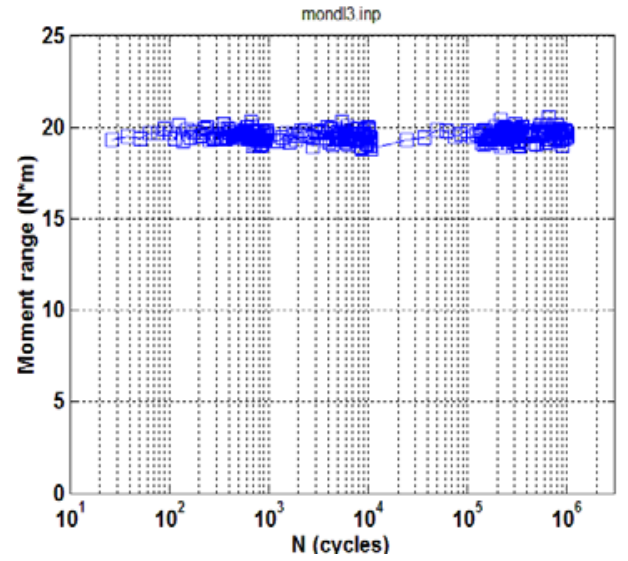

(b)

Figure 43 Variations of (a) curvature range, (b) applied moment range, (c) flexural rigidity as a function of number of cycles for DL3 $(60510 \mathrm{~A}) ; \mathrm{N}_{\mathrm{f}}=1.0 \times 10^{6}$ cycles under $\pm 10.60 \mathrm{Nm} 5 \mathrm{~Hz}$.

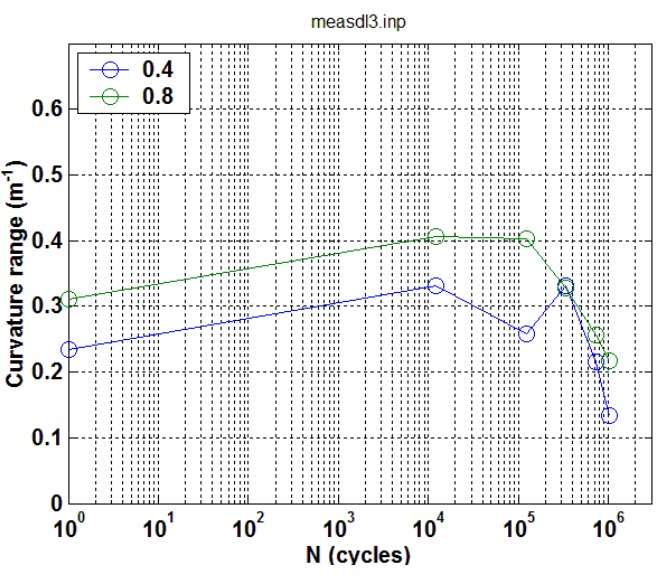

(a)

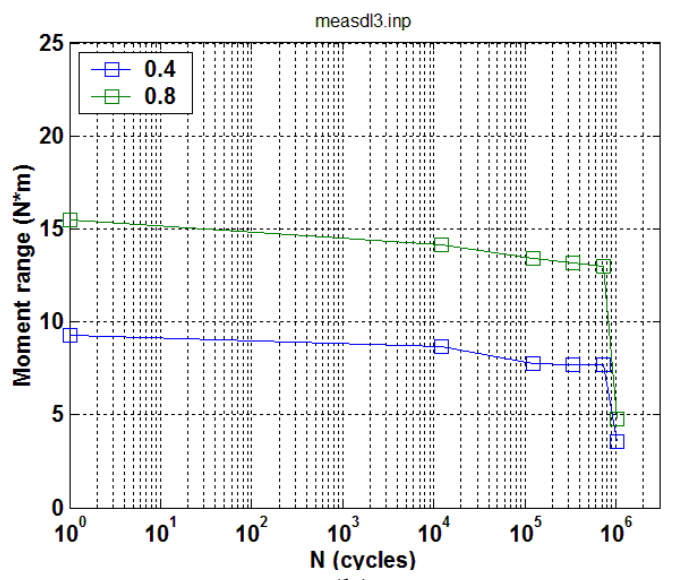

(b) 


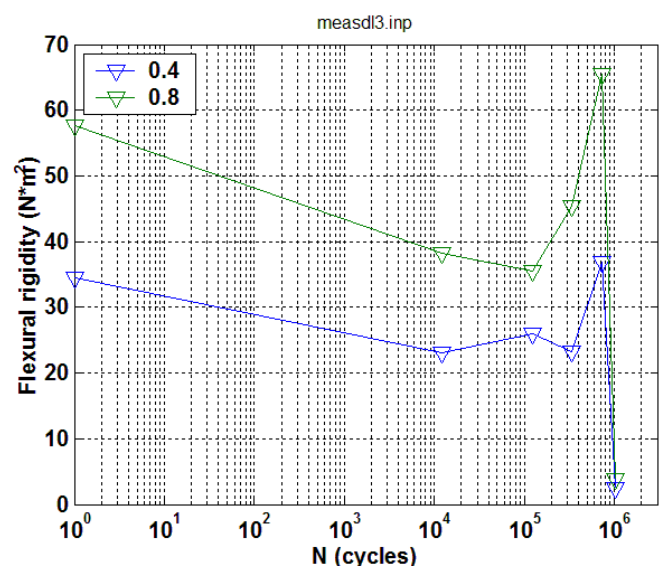

(c)

Figure 44 Variations of (a) curvature range, (b) applied moment range, (c) flexural rigidity as a function of number of cycles for DL3 (60510A) based on measurements with maximum relative displacement at 0.4 and $0.8 \mathrm{~mm} ; \mathrm{N}_{\mathrm{f}}=1.0 \times 10^{6}$ cycles under $\pm 10.60 \mathrm{Nm} 5 \mathrm{~Hz}$.

\subsubsection{DM1 / 605D1C $( \pm 7.62 \mathrm{Nm} 5 \mathrm{~Hz})$}

DM1 (605D1C, 66.5 GWd/MTU burnup, 40-70 $\mu$ m oxide layer, 500 ppm H content) is ongoing under $\pm 7.62 \mathrm{Nm} 5 \mathrm{~Hz}$ with about $4.2 \times 10^{6}$ cycles finished. 


\section{Conclusion}

The high burn-up (HBU) (>45 GWd/ MTU) of nuclear fuel is associated with an increased amount of corrosion and hydride precipitation, and high levels of irradiation-induced damage to cladding and fuel pellets. Each of these HBU phenomena has the potential to impact the mechanical behavior of spent nuclear fuel (SNF).

As a result, vibration is included in 10 CFR $\S 71.71$ for the structural evaluation of packages used by the U.S. Nuclear Regulatory Commission (NRC) to transport SNF. Currently, no testing system is available to test the vibration fatigue life of SNF. It is the aim of this research project to develop a system that can appropriately test the responses of HBU SNF rods in a simulated loading condition, and at the same time, test and evaluate the mechanical behavior of HBU SNF under the defined loading condition.

In 2011, Oak Ridge National Laboratory (ORNL) proposed a bending fatigue system for testing HBU SNF rods. Pure bending was adopted as the bending mode of the testing system. By August 2013, ORNL had completed all the modifications needed for the testing system and the associated vise mold. On August 19, 2013, the completed testing system was installed in the Building 3525 hot cell and formally named the Cyclic Integrated Reversible-bending Fatigue Tester (CIRFT). CIRFT consists of a U-frame testing setup and a real-time curvature measurement tool: (1) the U-frame setup consists of two rigid arms, connecting plates, and links to the universal testing machine; (2) a three-point deflection measurement method determines the curvature of the fuel rod being tested. Three linear variable differential transformers (LVDTs) are clamped into the side connecting plates of the U-frame to capture the fuel rod deformation. At this time, ORNL also completed the cutting of H. B. Robinson (HBR) HBU SNF rods according to the cutting plan proposed by NRC, and finished the diameter measurements of the rod test segments. Testing of CIRFT after installation in the hot-cell using surrogate rods indicated that the response of the rods was the same as that obtained in the out-of-cell study. The loading and unloading of rod specimens using manipulators was demonstrated using surrogate rods. Connecting rigid sleeves into the CIRFT, the SNF rod using epoxy was also demonstrated in the hot cell.

In September 2013, ORNL completed tuning the test system using a HBU SNF specimen and benchmark testing using three HBU SNF specimens. At the end of October 2013, ORNL had completed four static tests under displacement control at the rate of $0.1 \mathrm{~mm} / \mathrm{s}$ to a maximum displacement of $12.0 \mathrm{~mm}$. The maximum equivalent strain obtained was $1.9 \%$. The benchmark and static testing results were critically reviewed at the NRC-ORNL review meeting in early November 2013. The cyclic testing was then initiated. Currently, 16 cyclic tests have been conducted in the hot cell. Load ranges varied from \pm 5.08 to $\pm 35.56 \mathrm{~N} \cdot \mathrm{m}$; there were 12 tests with failure and 4 tests without failure. One of the cyclic tests reached $1.3 \times 107$ cycles and was stopped. 
The following observations were noted:

- The HBU HBR rods survived static unidirectional bending to a maximum curvature of 3.1 to $3.5 \mathrm{~m}^{-1}$, or a maximum moment of 86 to $87 \mathrm{~N} \cdot \mathrm{m}$. The maximum equivalent strain was 1.7 to 1.9 $\%$, corresponding to equivalent stress 733 to $748 \mathrm{MPa}$.

- The HBU HBR rods exhibited a multiple-stage constitutive response, with the two linear stages followed by a nonlinear stage. The flexural rigidity at the initial stage was 52 to $63 \mathrm{~N} \cdot \mathrm{m} 2$, corresponding to an elastic modulus of 83 to $101 \mathrm{GPa}$. The flexural rigidity at the second stage was 37 to $41 \mathrm{~N} \cdot \mathrm{m}^{2}$, and the corresponding elastic modulus was 59 to $66 \mathrm{GPa}$.

- The equivalent $0.2 \%$ yield strength of the HBU irradiated clad was estimated to be 687 to 727 MPa based on the equivalent stress-strain curves.

- Most of the failures of HBU HBR rods under static unidirectional loading were coincident with the pellet-to-pellet interface, as validated by the outcrop of pellet end faces in most of the fracture surfaces. Fragmentation of the pellets also occurred to a limited degree along with clad failure.

- The fatigue life of HBU HBR rods in the cyclic test depended on the level of loading. Under loading with moments of \pm 8.89 to $\pm 35.56 \mathrm{~N} \cdot \mathrm{m}$, namely \pm 0.07 to $\pm 0.49 \%$ at $5 \mathrm{~Hz}$, the fatigue life ranged from $5.5 \times 10^{3}$ to $2.3 \times 10^{6}$ cycles.

- The failure of HBU HBR rods under cyclic reverse loading often occurred near pellet-to-pellet interfaces, as validated by the outcrop of clean pellet end faces. 


\section{References}

${ }^{1}$ NRC, “General Standards for all packages,” §43(f) in Title 10, Code of Federal Regulations, Part 71, Packaging and transportation for radioactive material, US Nuclear Regulatory Commission, Washington, DC, Dec. 6, 2010.

${ }^{2}$ F. E. Ostrem and W. D. Godshall, An Assessment of the Common Carrier Shipping Environment, General Technical Report FPL 22, Forest Products Laboratory Forest Service, US Department of Agriculture, Madison, Wis., 1979.

${ }^{3}$ B. Hanson, H. Alsaed, C. Stockman, D. Enos, R. Meyer, and K. Sorenson, Gap Analysis to Support Extended Storage of Used Nuclear Fuel, US DOE Used Fuel Disposition Campaign, FCRD-2011-000136 Rev. 0, January 2012.

${ }^{4}$ W. Weibull, Fatigue and Analysis of Results, Pergamon Press, New York, 1961, pp. 31- 65.

${ }^{5}$ A. E. Carden, "Fatigue at elevated temperatures: a review of test methods," in Fatigue at Elevated Temperatures, ASTM STP 520, Eds. A. E. Carden, A. J. McEvily, and C. H. Wells, ASTM, Philadelphia, 1973, pp. 195-223.

${ }^{6}$ ASTM, Manual on Low Cycle Fatigue Testing, ASTM STP 465, ASTM, Philadelphia, 1969, pp. 149-162.

${ }^{7}$ ASTM E-9 Committee on Fatigue, Handbook of Fatigue Testing, ASMT STP 566, Ed. S. R. Swanson, ASTM, Philadelphia, 1974, pp. 19-84.

${ }^{8}$ ASTM B 593-96, Standard Test Method for Bending Fatigue Testing for Copper-Alloy Spring Materials, ASTM International, West Conshohocken, PA.

${ }^{9}$ M. A. Abojaradeh, M. W. Witczak, M. S. Mamlouk, and K. E. Kaloush, "Validation of initial and fatigue stiffness definition in flexure fatigue test for hot mix asphalt,” J. Test. Eval. 35, 1-8 (2007).

10 T. K. O’Brien, A. D. Chawan, R. Krueger, and I. L. Paris, “Transverse tension fatigue life characterization through flexure testing of composite materials,” Int. J. Fatigue 24, 127-145 (2002).

${ }^{11}$ W. D. Bowman, "End constraint and alignment effects in three and four point tensioncompression bending tests," in Factors That Affect the Precision of Mechanical Tests, ASTM STP 1025, Eds. R. Papirno and H. C. Weiss, ASTM, Philadelphia, 1989, pp. 174-184.

${ }^{12}$ L. Bertele, A. Papack, and K.-H. Wichmann, Testing Device for Performing Four Point Fatigue Strength Tests under Alternating Bending Stresses, US Patent 5231882, Aug. 3, 1993. 
${ }^{13}$ T. B. Zineb, A. Sedrakian, and J. L. Billoet, "An original pure bending device with large displacements and rotations for static and fatigue tests of composite structures," Composites Part B: Engineering 34, 447-458 (2003).

${ }^{14}$ T. Zhai, Y. G. Xu, J. W. Martin, A. J. Wilkinson, and G.A.D. Briggs, "A self-aligning fourpoint bend testing rig and sample geometry effect in four-point bend fatigue," Int. J. Fatigue 21, 889-894 (1999).

${ }^{15} \mathrm{H}$. R. Jhansale and T. H. Topper, "Equipment for cyclic deformation and fatigue studies in pure bending,” paper 1726, SESA Fall Meeting, Society for Experimental Stress Analysis, Boston, MA, Oct. 18-22, 1970.

${ }^{16}$ R. Lagneborg and R. Attermo, "The effect of combined low-cycle fatigue and creep on the life of austenitic stainless steel,” Metall. Trans. 2, 1821-1827 (1971).

${ }^{17}$ N. Gao, M. W. Brown, K. J. Miller, and P. A. S. Reed, "An effective method to investigating short crack growth behavior by reverse bending testing,” Int. J. Fatigue 29, 565-574 (2007).

${ }^{18}$ P. G. Forrest and A. B. Penfold, "New approach to thermal fatigue testing," Engineering (London) 192, 522-523 (1961).

${ }^{19} \mathrm{D}$. J. White, "The effect of environment and hold time on the high strain fatigue endurance of 0.5\% Mo steel," Proc. Inst. Mech. Eng. 184, 223-240 (1969).

${ }^{20}$ A. D. Batte, R. A. T. Dawson, E. B. Evans, and G. Thomas, "Reverse-bend testing to obtain long-term endurance data," in Techniques for High Temperature Fatigue Testing, Eds. G. Sumner and V. B. Livesey, Elsevier Appl. Sci. Pub., London, 1985, pp. 97-115.

${ }^{21}$ A. A. Tayebali, J. A. Deacon, and C. L. Monismith, "Development of dynamic flexural beam fatigue test system," National Research Council, Transportation Research Board, Transportation Research Record 1545, 89-97 (1996).

${ }^{22}$ J.-A. J. Wang, H. Wang, Y. Yan, R. Howard, and B. Bevard, High Burn-up Spent Fuel Vibration Integrity Study Progress Letter Report (Out-of-Cell Fatigue Testing DevelopmentTask 2.1), ORNL/TM-2010/288, Oak Ridge National Laboratory, Oak Ridge, Tenn. (January 2011).

${ }^{23}$ J.-A. J. Wang, H. Wang, T. Tan, H. Jiang, T. Cox, and Y. Yan, Progress Letter Report on Uframe Test Setup and Bending Fatigue Test for Vibration Integrity Study (Out-of-Cell Fatigue Testing Development - Task 2.2), ORNL/TM-2011/531, Oak Ridge National Laboratory, Oak Ridge, Tenn. (January 2012). 
${ }^{24}$ H. Wang, J.-A. J. Wang, T. Tan, H. Jiang, T. S. Cox, R. L. Howard, B. B. Bevard, and M. E. Flanagan, Development of U-frame bending system for studying the vibration integrity of spent nuclear fuel, J. of Nuclear Materials, 440, 2013, 201-213.

${ }^{25}$ R. L. Norton, Machine Design, Prentice-Hall, London, 1996.

${ }^{26}$ http://www.engineersedge.com/plastic/materials_common_plastic.htm

${ }^{27}$ http://www.eplastics.com/Plastic/Lexan_Polycarbonate_Sheet

${ }^{28}$ K. J. Geelhood et al., PNNL Stress/Strain Correlation for Zircaloy, PNNL-17700, Pacific Northwest National Laboratory, Richland, Wash. (July 2008).

${ }^{29}$ BARC Highlights, Nuclear Fuel Cycle, Chapter 4, Bhabha Atomic Research Center, Trombay, Mumbai, India, 2007, pp. 35-39.

http:/www.barc.ernet.in/publications/eb/golden/nfc/toc/Chapter\%204/4.6.pdf

${ }^{30}$ H. Jiang, J.-A. J. Wang, H. Wang, Reversible bending fatigue testing system design concepts for spent fuel vibration integrity study, submitted for publishing.

${ }^{31}$ D. Papaioannou, R. Nasyrow and V.V. Rondinella, W. Goll, H.-P. Winkler, R. Liedtke, D. Hoffmann, Fuel release experiments on irradiated fuel rodlets under transient impact conditions, European Commission, Joint Research Centre, Annual Meeting on Nuclear Technology, 12-14 May 2009, Dresden, Germany

32 J.-A. J. Wang, H. Wang, T. Cox, Y. Yan, Progress letter report on U-frame test setup and bending fatigue test for vibration integrity study (out-of-cell fatigue testing development - Task 2.3), ORNL/TM- 2012/417, August, 2012.

${ }^{33}$ G. Bjorkman, "High burnup spent fuel testing program objectives,” NRC Program Review Meeting, ORNL, Aug. 8, 2011.

34 J.-A. J. Wang, H. Wang, T. Cox, C. Baldwin, Progress letter report on bending fatigue test system development for spent nuclear fuel vibration integrity study (out-of-cell fatigue testing development - Task 2.4), ORNL/TM- 2013/225, July 2013.

${ }^{35}$ RDP Electronics Ltd., D5 \& D6 LVDT Displacement Transducer; RDP Transducers for high radiation environments, PR. No. RDP273, RDP Group 10/11/2008, www.rdpe.com

${ }^{36}$ RDP Electrosense, Inc., Technical Manual Transducer Amplifier Type DR7AC, Doc. Ref CD2402E, RDP Group, www.rdpe.com

${ }^{37}$ ElectroForce Systems Group, ElectroForce ${ }^{\circledR}$ LM2 TestBench Test Instrument Reference Manual, Bose Corporation, 2012. 
${ }^{38}$ Measurement Specialties ${ }^{\text {TM }}$, MHR Series - Miniature General Purpose AC LVDT, Feb. 2013, www.meas-spec.com

${ }^{39}$ Sensing and Control, Model 47 Fatigue Rated Ultra Precision Universal Load Cell, May 2008, Honeywell, www.honeywell.com/sensing.

40 J.-A. J. Wang, H. Wang, B. B. Bevard, R. L. Howard, and M. E. Flanagan, Spent nuclear fuel test system for bending stiffness and vibration integrity, Proc. 2013 International High-Level Radioactive Waste Management Conference, ANS, Albuquerque, New Mexico, USA, Arp 28May 2, 2013.

${ }^{41}$ M. Flanagan, U.S. Nuclear Regulatory Commission, Oct. 7, 2013.

${ }^{42}$ C. Baldwin, Oak Ridge National Laboratory, Mar. 6, 2013.

${ }^{43}$ C. Baldwin, Oak Ridge National Laboratory, Nov. 13, 2013. 